Florida International University FIU Digital Commons

6-30-2015

\title{
Characterization of an Epoxide Hydrolase from the Florida Red Tide Dinoflagellate, Karenia brevis
}

pengfei sun

FIU, psun001@fiu.edu

DOI: $10.25148 /$ etd.FIDC000133

Follow this and additional works at: https://digitalcommons.fiu.edu/etd

Part of the Biochemistry Commons, and the Molecular Biology Commons

\section{Recommended Citation}

sun, pengfei, "Characterization of an Epoxide Hydrolase from the Florida Red Tide Dinoflagellate, Karenia brevis" (2015). FIU Electronic Theses and Dissertations. 2066.

https://digitalcommons.fiu.edu/etd/2066 


\title{
FLORIDA INTERNATIONAL UNIVERSITY
}

Miami, Florida

\section{CHARACTERIZATION OF AN EPOXIDE HYDROLASE FROM THE FLORIDA RED TIDE DINOFLAGELLATE, KARENIA BREVIS}

A dissertation submitted in partial fulfillment of the requirements for the degree of DOCTOR OF PHILOSOPHY

\author{
in \\ CHEMISTRY \\ by \\ Pengfei Sun
}


To: Dean Michael R. Heithaus

College of Arts and Sciences

This dissertation, written by Pengfei Sun, and entitled Characterization of an Epoxide Hydrolase from the Florida Red Tide Dinoflagellate, Karenia, brevis, having been approved in respect to style and intellectual content, is referred to you for judgment.

We have read this dissertation and recommend that it be approved.

$\begin{array}{r}\hline \text { Lidia Kos } \\ \hline \text { David Becker } \\ \hline \text { Watson J. Less } \\ \hline \text { Xiaotang Wang } \\ \hline \text { Kathleen S. Rein, Major Professor }\end{array}$

Date of Defense: June 302015

The dissertation of Pengfei Sun is approved.

\begin{tabular}{r}
\hline $\begin{array}{r}\text { Dean Michael R. Heithaus } \\
\text { College of Arts and Sciences }\end{array}$ \\
\hline Dean Lakshmi N. Reddi \\
University Graduate School
\end{tabular}

Florida International University, 2015 


\section{DEDICATION}

I dedicate this work to my parents, my grandma, my brother and sister for their love and support. Without their understanding and encouragement, the completion of this work would not have been possible. 


\section{ACKNOWLEDGMENTS}

The accomplishment of this dissertation would not have been possible without the guidance and the help of several individuals contributed the countless time and valuable assistance. It is my great pleasure to express my gratitude to all of them in my humble acknowledgment.

First and foremost, I would like to thank my major professor Dr. Kathleen Rein for the opportunity to study and work in her group to pursue a doctoral degree. I would like to express my utmost gratitude to her endless support, supervision, guidance and patience. I do appreciate everything she has done for me!

I would also like to thank Dr. Lidia Kos, Dr. David Becker, Dr. Xiaotang Wang, and Dr. Watson Less for their valuable time, advice and constant support.

Many thanks go to all the faculty and staff members of the chemistry department, stock room, NMR facility and GC-MS facility for the support, help and coordination.

I would like to thank my lab mates for their support and friendship. Special thanks to Li Liu, Ryan Cassell and Wei Chen for their help in my study, work and life.

Finally, I wish to express my appreciation to those who have helped me in any respect during my six years study at FIU. 


\section{ABSTACT OF THE DISSERTATION \\ CHARACTERIZATION OF AN EPOXIDE HYDROLASE FROM THE FLORIDA \\ RED TIDE DINOFLAGELLATE, KARENIA BREVIS}

by
Pengfei Sun

Florida International University, 2015

Miami, Florida

\section{Professor Kathleen S. Rein, Major Professor}

Polyether compounds are a subgroup of natural products with regular occurrence of multiple $\mathrm{C}-\mathrm{O}-\mathrm{C}$ motifs. The biosynthetic origin of polycylic polethers has been studied and the majority of them are derived from polyketide or terpene pathways. Normally, the polycyclic polyethers can be divided into two groups based on their structural features: the first group features multiple rings that are interconnected by carbon-carbon single bond, which are produced by a biosynthetic cascade of exo epoxide-opening reactions; the other group has multiple fused cyclic ethers and are formed by an cascade of endo epoxide-opening reactions.

Karenia brevis (K. brevis) is known as principle harmful bloom (HAB) organism of the Gulf of Mexico which can cause red tides. Brevetoxins (PbTx) are a suit of cyclic polyether ladder compounds produced by K. brevis. Brevetoxins are neurotoxins that can bind to voltage-gated sodium channels in nerve and muscle cells, resulting in disruption of normal neurological processes causing the human illness which is clinically described as neurotoxic shellfish poisoning (NSP). 
Inspired by Cane-Celmer-Wesley's proposal regarding monensin biosynthesis, Nakanishi and Shimizu proposed a biosynthetic pathway for brevetoxin which suggests that PKS-mediated synthesis of the polyene is followed by epoxidation to afford a polyepoxide which then undergoes an epoxide-opening cascade, catalyzed by an epoxide hydrolase (EH).

To find evidence to support the hypothesis that an epoxide hydrolase from polyether ladder producing dinoflagellates will catalyze the construction of the polyether ladder framework from polyepoxide substrates, and to study the role of epoxide hydrolase in the biosynthesis of polyether ladder compounds, it is necessary to identify and produce one or more epoxide hydrolase from dinoflagellates. The methods to detect epoxide hydrolase activity in $K$. brevis and different techniques to obtain epoxide hydrolases from K. brevis are discussed. A microsomal EH identified from a K. brevis EST library was cloned and expressed. The characterization of this EH, including substrate selectivity and enantioselectivity as well as its potential to catalyze the critical ento-tet cyclization epoxy alcohol, is discussed. 


\section{CONTENTS}

CHAPTER

PAGE

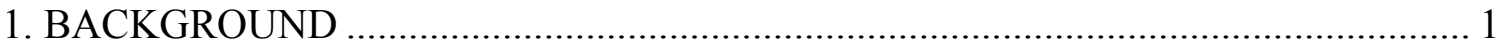

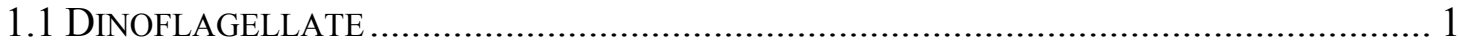

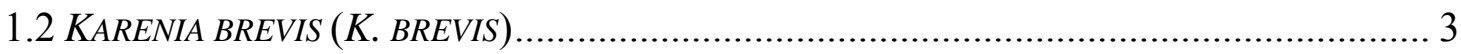

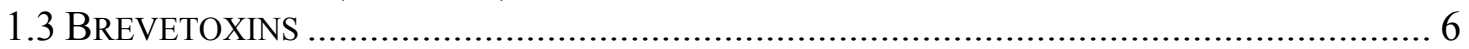

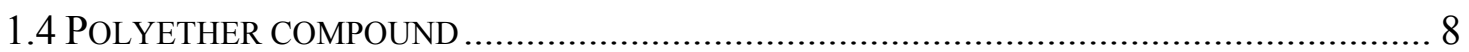

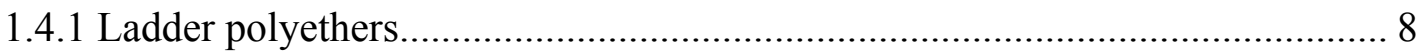

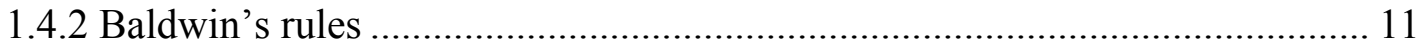

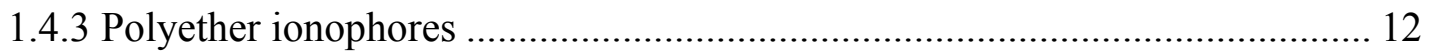

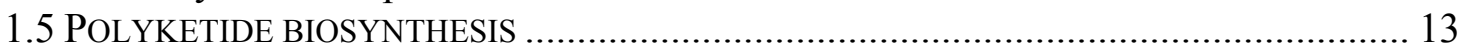

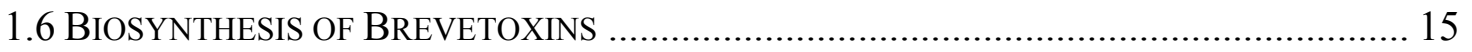

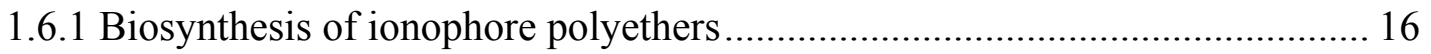

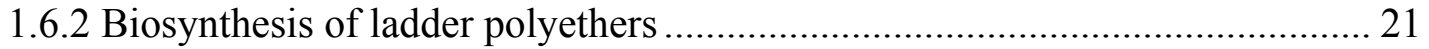

1.7 EPOXIDE HYDROLASE (EH, E.C.3.3.2.3) ......................................................... 24

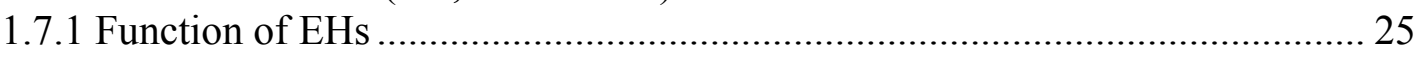

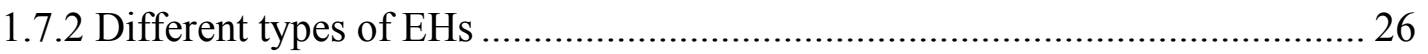

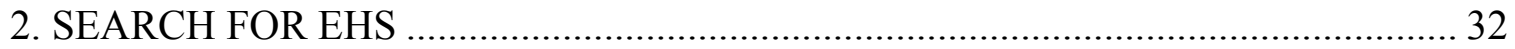

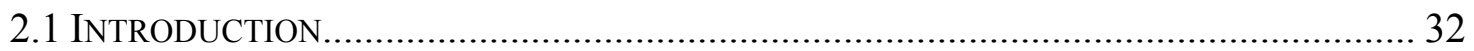

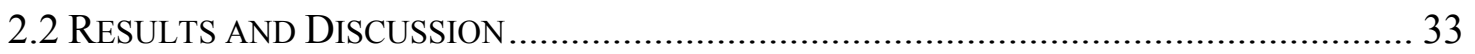

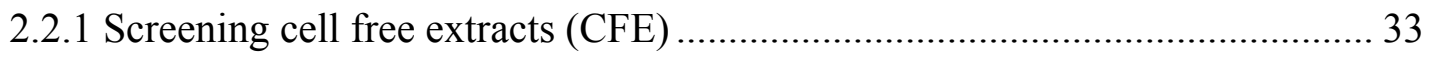

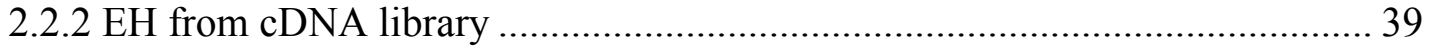

2.2.3 Searching Expressed Sequence Tag (EST) library ...................................... 44

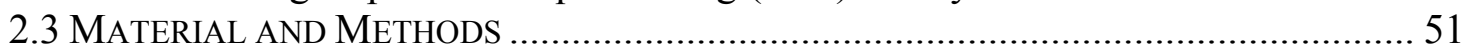

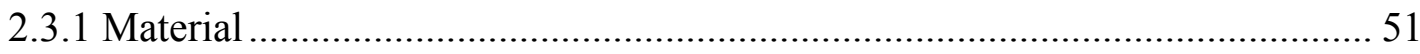

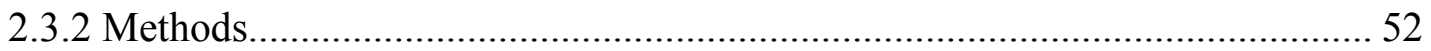

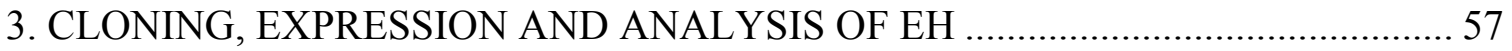

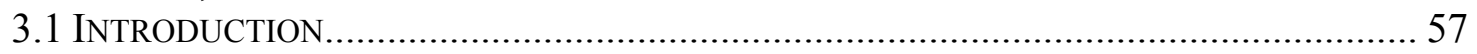

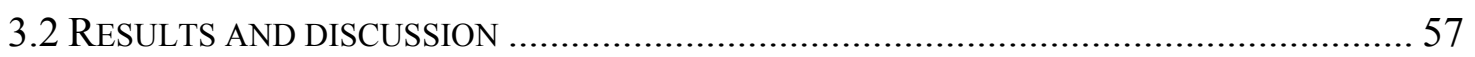

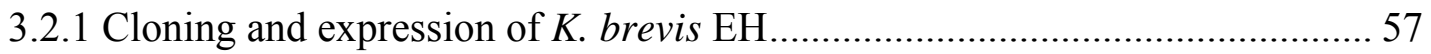

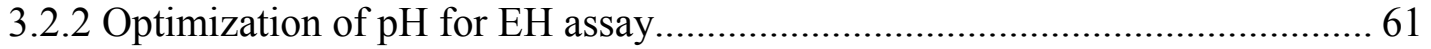

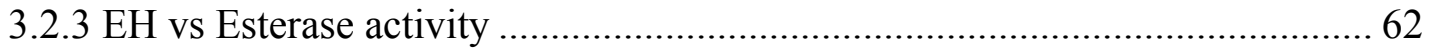

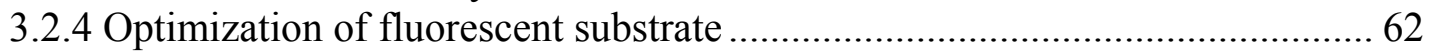

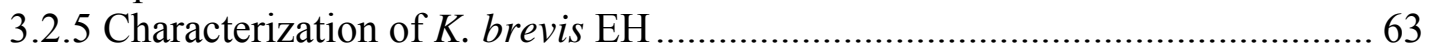

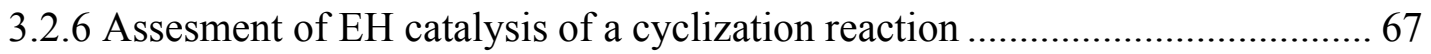

3.2.7 EH activity/expression and toxin content over the life of a culture................. 68

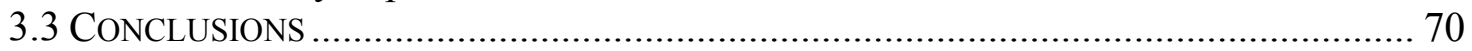

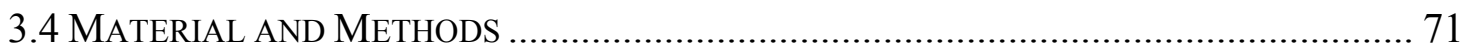

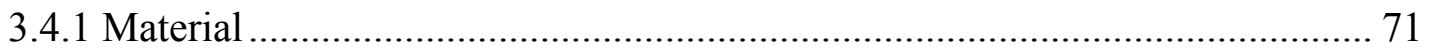

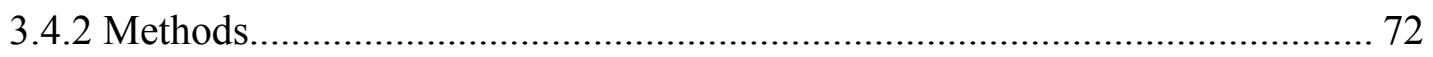




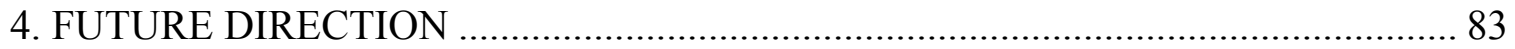

4.1 SYNTHESIZE OF MORE APPROPRIATE ENZYME SUBSTRATES................................... 83

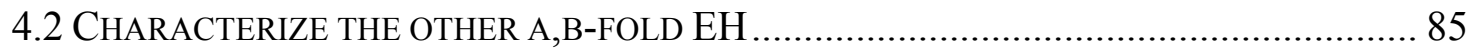

4.3 CONTINUE TO SEARCH FOR LIMONENE EH ....................................................... 85

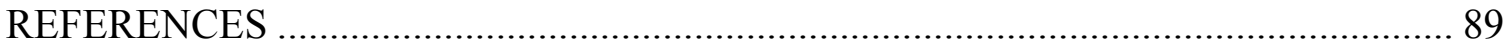

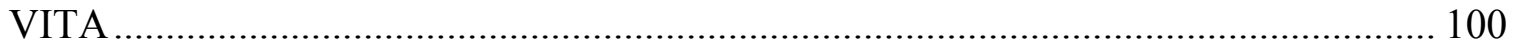




\section{LIST OF TABLES}

TABLE

PAGE

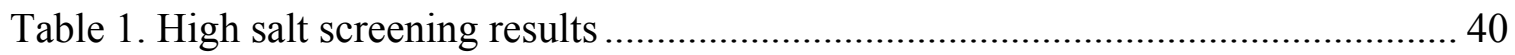

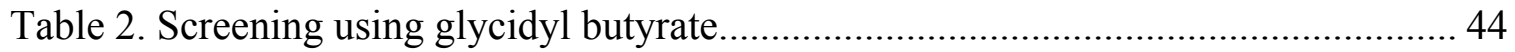

Table 3. Alignment of putative K. brevis EH with Aspergillus niger EH ..................... 45

Table 4. Alignment of some known limonene EH involved in biosynthesis of polyether46

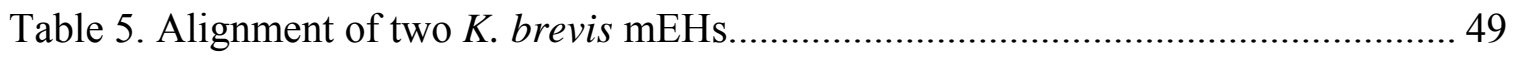

Table 6. Comparison of optimized (for E. coli) and native K. brevis EH sequence......... 58

Table 7. Kinetic parameters of the K. brevis EH with various substrates ....................... 65

Table $8 . \mathrm{IC}_{50}$ for non-terminal epoxides using fluorescent probe $\mathbf{2 b}$ as substrate........... 66 


\section{LIST OF FIGURES}

FIGURE

PAGE

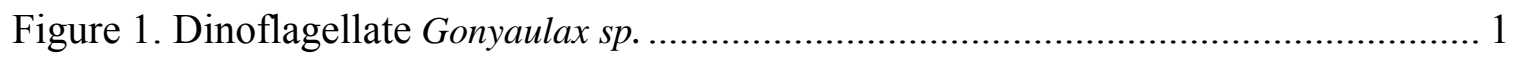

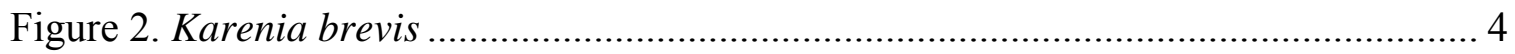

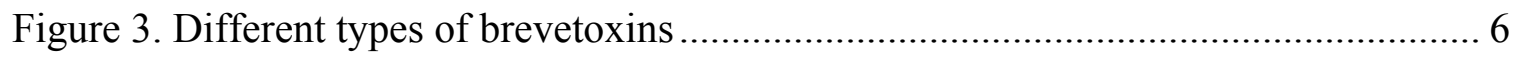

Figure 4. Terpene derived polyethers (left: terurilene; right: ent-Abudinol B) ................ 8

Figure 5. Ladder polyethers (top: brevenal; bottom: yessotoxin) ............................... 9

Figure 6. a)cyclization modes and directing strategies b)Jamison's polyepoxide cascade 11

Figure 7. Baldwin'rules (top: ring closure reactions; bottom: dis/favored ring closure) .. 12

Figure 8. Ionophore polyethers (left: tetronomycin; right: cationomycin) .................... 13

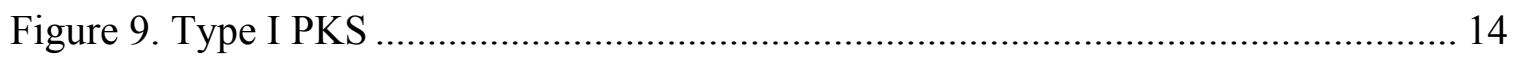

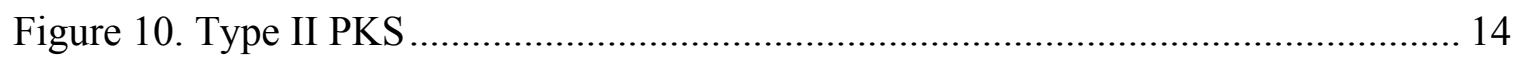

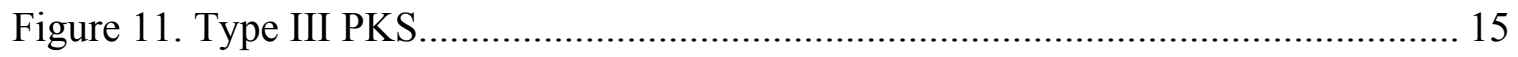

Figure 12. proposed pathway of biosynthesis of monensin .................................... 17

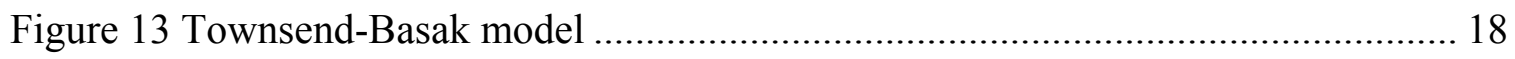

Figure 14. Comparison of with or without Lsd19 (left: lasalocid; right: isolasalocid).... 20

Figure 15. Proposed biosynthetic pathway of brevetoxin........................................ 22

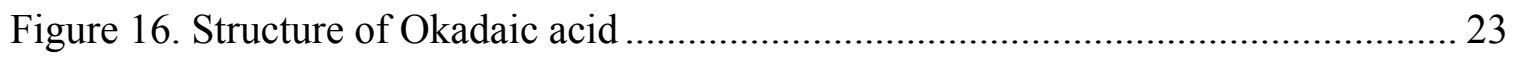

Figure 17. Biosynthesis of ladder polyethers in epoxy ester pathway .......................... 23

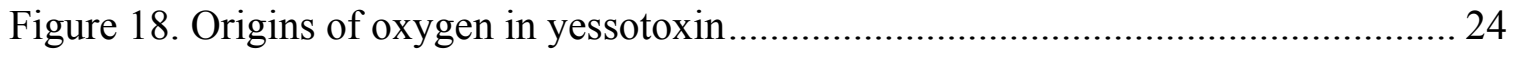

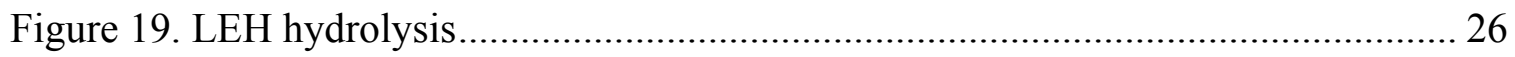

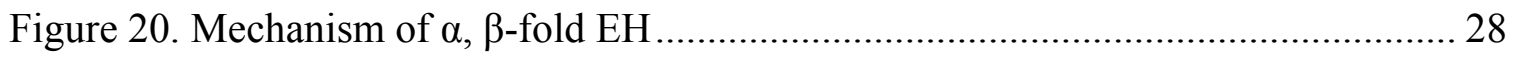

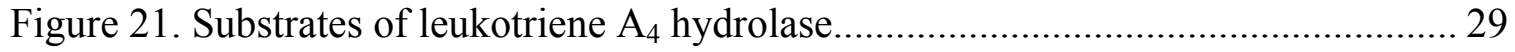


Figure 22. Mechanism of leukotriene $\mathrm{A}_{4}$ hydrolase ............................................... 30

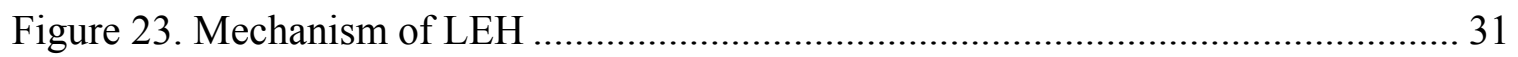

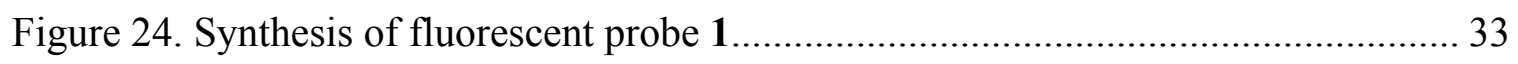

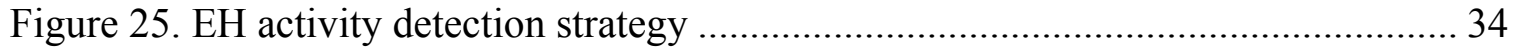

Figure 26. EH activity in K. brevis CFE.............................................................. 34

Figure 27. Esterase catalyzed hydrolysis yields the same fluorescent reporter as EH ..... 35

Figure 28. EH and esterase activity in K. brevis CFE .......................................... 36

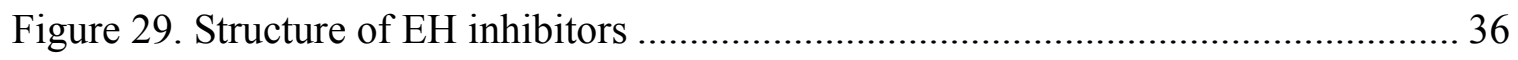

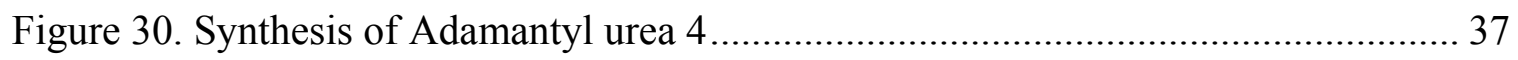

Figure $31 . \mathrm{EH}$ activity in K. brevis cultures and sensitivity to inhibitors ....................... 38

Figure 32. Esterase activity in K. brevis cultures and sensitivity to inhibitors ................ 38

Figure 33. Structure of antibacterial compound, glycidyl butyrate ............................. 43

Figure 34. Standard curve for protein assay ......................................................... 53

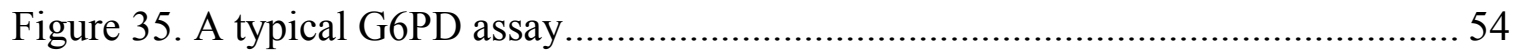

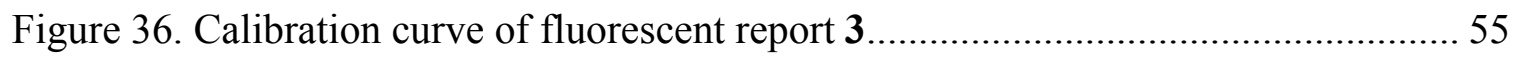

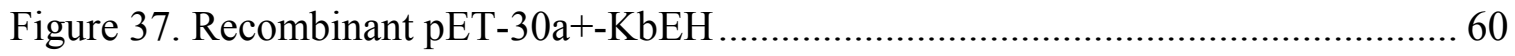

Figure 38. SDS PAGE of expressed EH after purification and dialysis....................... 61

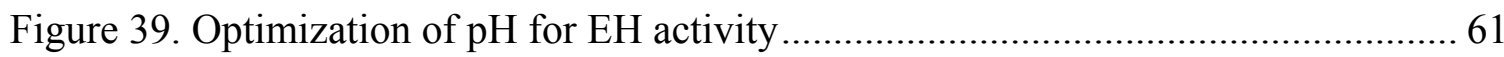

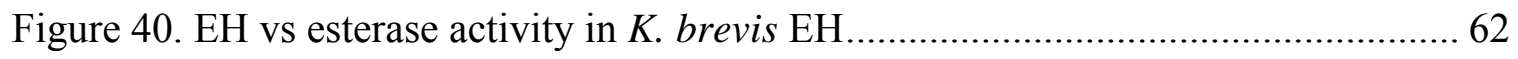

Figure 41. Preparation of an aliphatic substituted fluorescent probe............................ 63

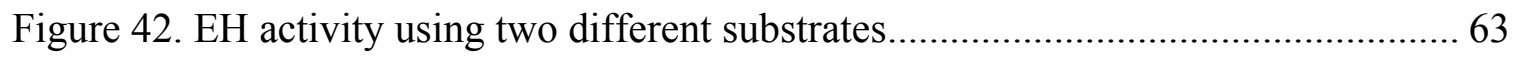

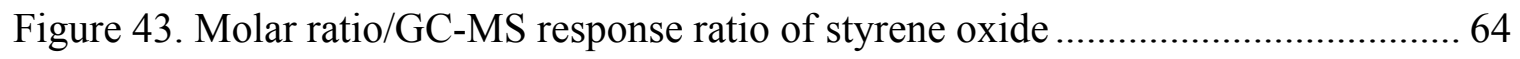

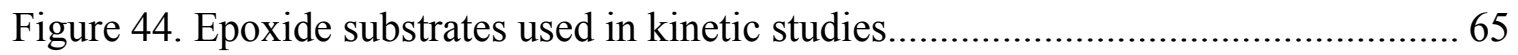




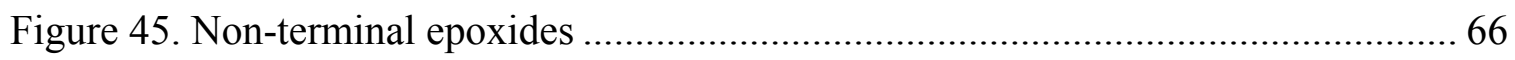

Figure 46. Alternate cyclization reactions or hydrolysis .................................................. 68

Figure 47. Left: EH activity of two strains of $K$. brevis over a 21 day period; right: average EH activity of two strains of $K$. brevis over 21 day period (normalized to protein concentration)

Figure 48. EH activity of two strains of $K$. brevis over a 21 day period; right: average EH activity of two strains of $K$. brevis over 21 day period (normalized to thousand cells)

Figure 49. Left: Ratio of $\mathrm{C}_{\mathrm{t}}$ for $\mathrm{EH} / \mathrm{RuBisCO}$ for low and high toxin K. brevis; right:

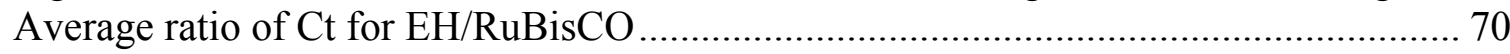

Figure 50. Substrates analog studied in monensin EHs .................................................. 84

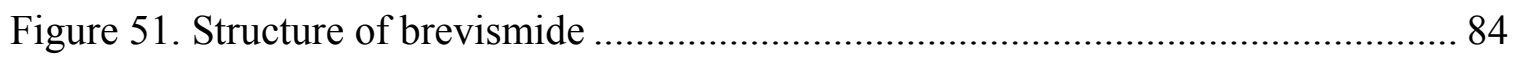

Figure 52. Scheme for syntheizing K. brevis EH substrates using nerolidol.................... 85

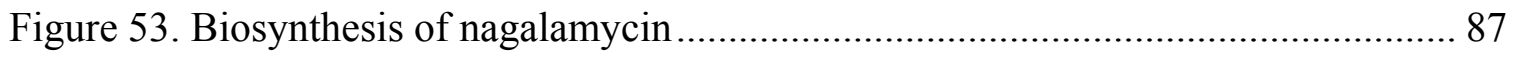

Figure 54. conserved domains of new found polyketide cyclase ..................................... 88

Figure 55. Conserved domains of second found polyketide cyclase ................................ 88 


\section{BACKGROUND}

\subsection{DINOFLAGELLATE}

Dinoflagellates are members of the class Dinophyceae, which is a diverse group of unicellular, flagellate algae that fossil records suggested have been in existence for at least 400 million years ${ }^{1}$. Dinoflagellates are one of the three main phyla of the protozoan taxon Alveolata. The other two are the parasitic apicomplexans and the mostly free-living ciliates. Motile dinoflagellate cells have two flagella, one longitudinal and one transverse which encircles the cell, and this design causes a corkscrew-like swimming motion from which the name dinoflagellate is derived (Greek dinos $=$ whirling). Their unique propulsion system has been studied over the last several decades ${ }^{2}$. In terms of number of species, dinoflagellates are one of the largest groups of marine eukaryotes ${ }^{3}$. However, the dinoflagellate nuclei are not characteristically eukaryotic, as they lack histones, nucleosomes and maintain continually condensed chromosomes during mitosis. However, they do contain typically eukaryotic organelles, such as mitochondria, chloroplasts, and Golgi bodies ${ }^{4}$. Figure 1 shows one dinoflagellate Gonyaulax sp. (http://www.sms.si.edu/irlspec/Phyl_Dinofl.htm).

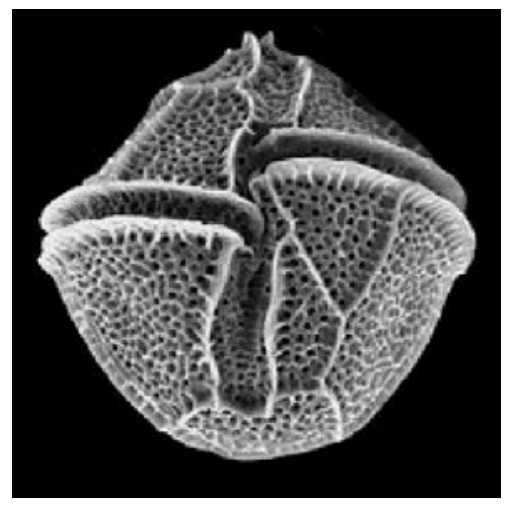

Figure 1. Dinoflagellate Gonyaulax sp. 
Most dinoflagellates are marine plankton, but more than 200 species are found in fresh water ${ }^{5}$. Their growth is affected by temperature, salinity or depth. Although many dinoflagellates are photosynthetic, a large fraction of these are in fact mixotrophic, combining photosynthesis with ingestion of prey ${ }^{6}$. Some species are endosymbionts of marine animals and play an important role in the biology of coral reefs, for instance Symbiodinium, the coral symbiont ${ }^{7}$. Other dinoflagellates are predators on other protozoa, and some forms are parasitic. They are also known to produce novel secondary metabolites including heterocycles, macrolides, highly oxygenated alkyl compounds among others ${ }^{8}$. The chloroplasts of photosynthetic dinoflagellates have been studied for the evolution of organelle genomes. The most common type of dinoflagellate chloroplast is bound by 3-membranes and contain chlorophylls a and c2, the carotenoid beta-carotene and xanthophylls that seems to be unique to dinoflagellates, mainly peridinin, dinoxanthin and diadinoxanthin. Many dinoflagellates show goldenbrown color because of these pigments. However, Karenia brevis, Karenia mikimotoi and Karlodinium micrum, have other pigments through endosymbiosis, including fucoxanthin ${ }^{9}$. Most dinoflagellates have a haplontic life cycle. The reproduction type is binary fission, either desmoschisis or eleuteroschisis ${ }^{10}$. In a small percentage of dinoflagellates, sexual reproduction also occurs ${ }^{11}$.

Dinoflagellates can bloom in a very high concentration resulting in red tides. The toxins, known as dinotoxins produced by dinoflagellates can kill fish and accumulate in filter feeders such as shellfish, which may be passed on to people who eat them. However, some dinoflagellate blooms are not hazardous. Bioluminescent dinoflagellate 
can emit short flashes of light when disturbed. There are more than 28 dinoflagellates

which are bioluminescent and most of them emit a blue-green light ${ }^{12}$. These species contain dinoflagellate luciferase, the main enzyme in dinoflagellate bioluminescence and luciferin, a chlorophyll derived tetrapyrrole ring which acts as the substrate in the luminescent reaction ${ }^{13}$.

The large amount of DNA of dinoflagellate is one of their most striking features. Dinoflagellate DNA can range from $3 \sim 250 \mathrm{pg} / \mathrm{cell}$, whereas most other eukaryotic algae contain on average $0.54 \mathrm{pg} / \mathrm{cell}^{14}$. In addition, dinoflagellate nuclei are unique in their morphology, composition and regulation.

\subsection{KARENIA BREVIS (K. BREVIS)}

Karenia, formerly included in the genus Gymnodinium, is a genus of 12 species of dinoflagellates ${ }^{15}$. Several species can cause red tides, including K. brevis, and Karenia mikimotoi, which was first described in Japan, but is now found in the Atlantic ocean ${ }^{16}$. These species are similar in their pigmentation and possession of a linear apical groove, but can be distinguished by morphological characteristics and large subunit (LSU) rRNA gene sequences ${ }^{17}$.

Karenia brevis (genus Karenia species brevis, formerly known as Gymnodinium breve and Ptychodiscus brevis) is an unarmored, photosynthetic marine dinoflagellate. It is a microscopic, single-celled organism that is responsible for frequent blooms along Florida and Texas coastal waters. K. brevis uses its two flagella to move through the water in a spinning motion. Karenia brevis cell is about $20-40 \mu \mathrm{m}$ in size, the cell color is

yellow-green because of the presence of chloroplasts ${ }^{18}$. Karenia brevis has a $10^{11} \mathrm{bp}$ 
genome, which is approximately 30 times the human genome. It has permanently condensed chromatin lacking nucleosomes. The condensed chromosomes have a characteristic banding pattern with stacked disks which form a continuous left-handed twist along the longitudinal axis. Due to its huge size, the genome has not yet been sequenced ${ }^{19}$. Karenia brevis was shown in Figure 2 (https://upload.wikimedia.org/wikipedia/commons/a/a0/Karenia_brevis.jpg).

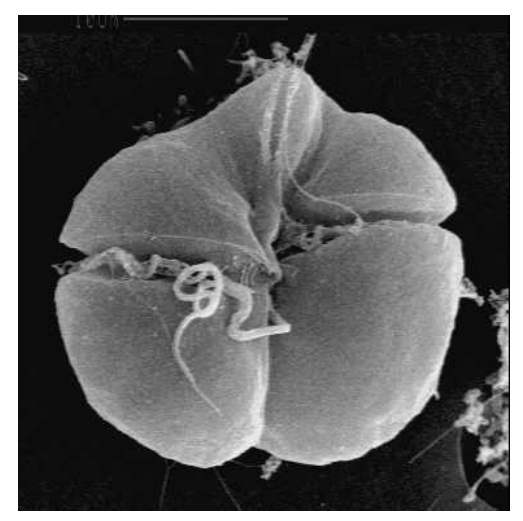

Figure 2. Karenia brevis

Karenia brevis can be found in the Gulf of Mexico, along the coasts of Texas, Louisiana, Florida, and North Carolina. It is photosynthetic and performs much of the area's primary production, which is the synthesis of organic compounds from atmospheric or aqueous carbon dioxide ${ }^{18}$. Normally, K. brevis moves towards greater light ${ }^{20}$ and against gravity ${ }^{21}$, which results in keeping the cells at the surface of water. Because of dependence on light, they cannot live at a depth below 200 feet. The optimal temperature for their growth is between $22-28^{\circ} \mathrm{C}$, although they can survive in a temperature range between 4 and $33^{\circ} \mathrm{C}$. In addition, $K$. brevis requires salinity between $25-45$ ppt. They can provide oxygen to the environment contributing around $20 \%$ of the primary production in the West Florida Shelf during blooms or red tides ${ }^{22}$. 
Multiple reasons may lead to a chemical change in water. The most common is when chemicals are dumped into the water from local run-off zones. These chemicals can come from certain fertilizers which are used to promote agricultural growth. The algae will reproduce rapidly if nutrient levels such as nitrogen increase beyond normal levels, resulting in an algal bloom. These blooms can deplete oxygen in the water and create a shade from the sun, inhibiting the growth of other autotrophs ${ }^{23}$. Karenia brevis can produce harmful algal blooms (HABs) or red tides, during which toxins are released in the ocean and may kill marine animals, and cause human illness that can arise from eating seafood that have retained toxins. Blooms of $K$. brevis may also provide a significant source of fixed carbon thorough photosynthesis ${ }^{24}$. With nutrient regimes and light conditions, $K$. brevis can bloom from 100,000 to 250,000 cells/liter within 2 months 25. Monospecific blooms can cover a surface area of up to $1.4-3.0 \times 10^{4} \mathrm{~km}^{2}{ }^{24}$. An historical assessment of $K$. brevis in the western Gulf of Mexico found documented reports of massive fish kills together with human respiratory irritation and dry cough from Veracruz, Mexico in the late 1800s, and earlier evidence of red tides on the Mexican coastline dating back to the $1500 \mathrm{~s}^{26}$. Throughout most of the Gulf of Mexico and US south Atlantic Bight, K. brevis is found in background concentration levels of 11000 cells/liter ${ }^{25}$. Blooms are most frequent along the west coast of Florida, especially from Clearwater to Sanibel Island. Most commonly, blooms can last more than two months in regions of the Gulf of Mexico including: the west Florida shelf, the Campeche Bay between Rio Ciatzacoalcos and Rio Grijalva, and the Texas coast between Port Arthur and Galveston Bay ${ }^{25}$. 
Karenia brevis has attracted great interest among scientists. Microscopy or pigment analysis are among the traditional methods for the detection of $K$. brevis. However, those methods are time-consuming and require an experienced microscopist for identification ${ }^{27}$. Molecular and PCR based methods for detection of $K$. brevis cells have been developed ${ }^{28}$. Another technique, which uses a model-based examination of UV-vis spectra, multiwavelength spectroscopy has also been used for detection of K. brevis ${ }^{29}$.

\subsection{BREVETOXINS}

Brevetoxins $(\mathrm{PbTx})$ are a suit of cyclic polyether ladder compounds. Brevetoxins are neurotoxins that can bind to voltage-gated sodium channels in nerve and muscle cells, resulting in disruption of normal neurological processes causing the human illness which is clinically described as neurotoxic shellfish poisoning (NSP) ${ }^{30}$. Brevetoxins have two main skeletal types, brevetoxin A and brevetoxin B, which differ in the carbon backbone. Each type of brevetoxin has several subtypes, which differ in the side-chain substituents 31.
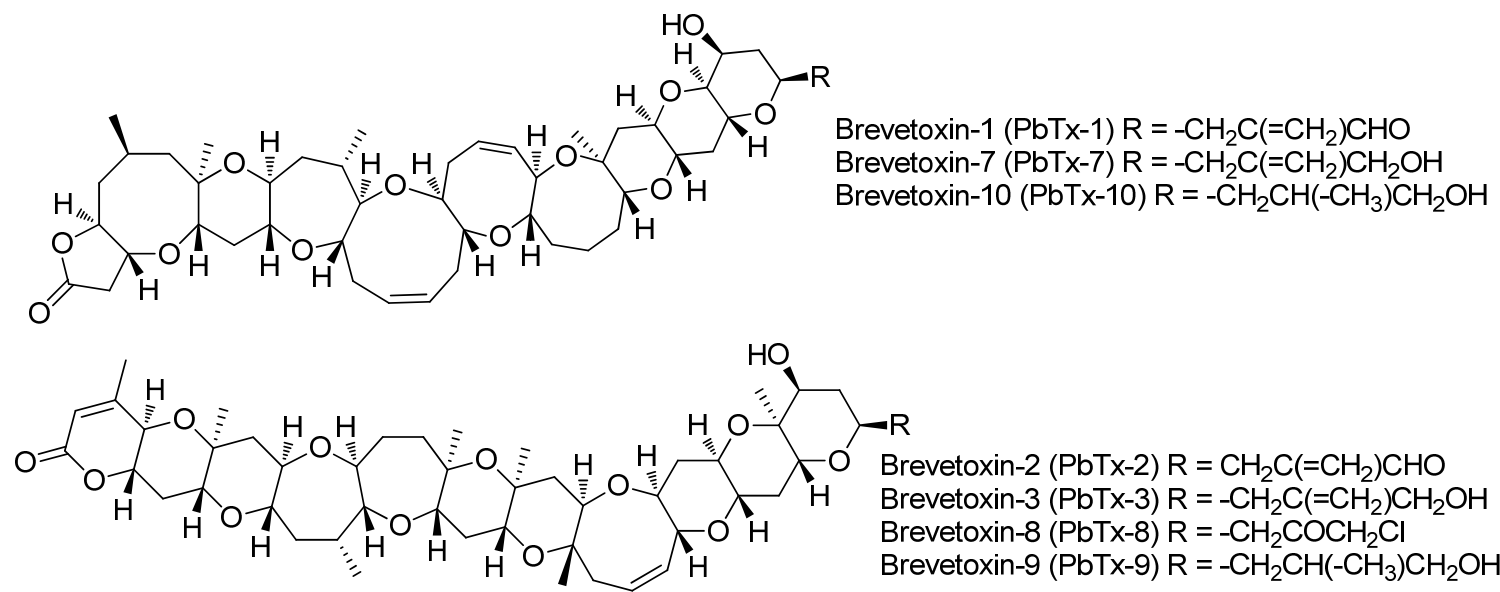

Figure 3. Different types of brevetoxins 
Brevetoxins are lipid soluble and adversely affect human health as well as ecosystems. Brevetoxins are most studied in K. brevis, but they are also found in other species of Karenia ${ }^{30}$. The toxins activate voltage-gated sodium channels in vertebrates directly damaging the nervous system of an organism even at very small concentrations. This results in neurological symptoms in the affected organism, including humans. The most common way for humans to be exposed to these toxins is through the consumption of contaminated shellfish. Ecological health effects include massive mortality of invertebrates, fish, birds, and some marine mammals. This could be due to either direct exposure to the toxins or from the brevetoxins in the food web ${ }^{32}$. Due to its extensive adverse impacts on coastal environments and communities, the growth physiology and toxicity of K. brevis have been studied for over 60 years. Research on the underlying molecular biology has not been initiated until the last decade, which is enabled by the availability of rapidly evolving molecular technologies from the biomedical field ${ }^{19}$. The processes contributing to the development of $K$. brevis blooms span spatial and temporal scales from the molecular mechanisms within the cell that respond the environmental cues to the oceanographic and even atmospheric processes that drive the local environmental conditions in which $K$. brevis lives. How a bloom is initiated and terminated remains poorly understood, but is crucial for the prediction and management of bloom impacts. However, the integration of the cellular responses with these physical forcings is needed to refine these models. A lack of information on these processes severely limits predictive models as they require a more thorough understanding of the cellular level decisions through which $K$. brevis interacts with its environment ${ }^{19}$. 


\subsection{POLYETHER COMPOUNDS}

Polyether compounds are a subgroup of natural products with regular occurrence of multiple C-O-C motifs. Polyethers are commonly divided into two categories, linear and polycylic. The latter group is especially interesting because of the structural diversity and biological activities, which include antibiotic, antifungal, and anticancer. The origin of polycylic polethers has been studied and the majority of them are derived from polyketide, such as brevetoxins (Figure 3, above), or terpene pathways such as entAbudinol $\mathrm{B}^{33}$ and terurilene ${ }^{34}$. Normally, the polycyclic polyethers can be divided into two groups based on their structural features: the first group features multiple rings that are interconnected by carbon-carbon single bond, and it's produced by an biosynthetic cascade of exo epoxide-opening reactions; the other group has multiple fused cyclic ethers and are formed by an cascade of endo epoxide opening ${ }^{35}$.
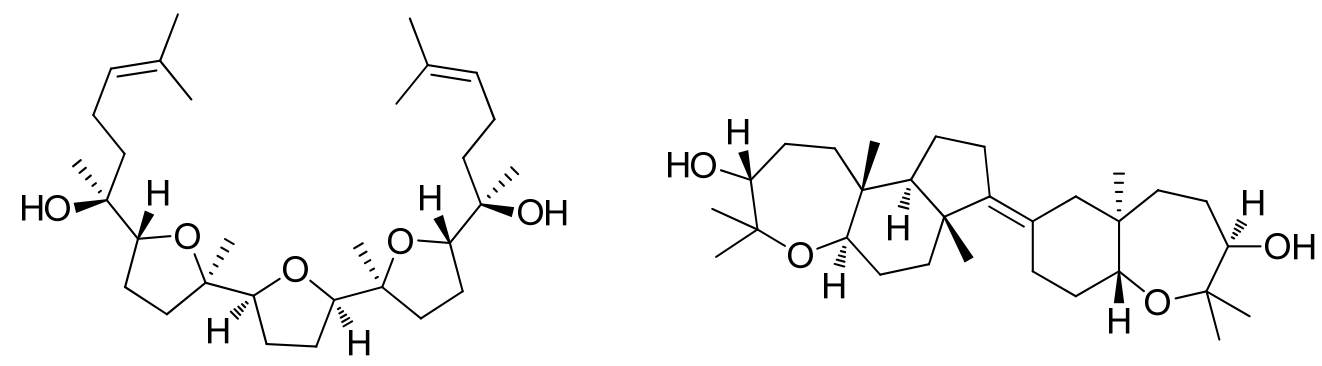

Figure 4. Terpene derived polyethers (left: terurilene; right: ent-Abudinol B)

\subsubsection{Ladder polyethers}

Ladder polyethers are one type of polyether with ladder-like configuration. The ladder polyethers contain 4 to 32 five- to nine- member fused rings. The first isolated polyether ladder compound is brevetoxin B. Numerous others have been found including maitotoxin, the largest nonpolymer isolated from natural source ${ }^{36}$. Ladder polyethers are 
known to be associated with harmful algal blooms, commonly referred to as red tide. Due to the uniform structures, ladder polyethers show various biological activities ranging from extreme toxicity to beneficial anticancer and antifungal character ${ }^{37}$. Many ladder polyethers and their analogs were found to have the potential to improve human health. For example, brevenal, which is also a secondary metabolite of $K$. brevis, has the potential of treatment of the debilitating lung disorder cystic fibrosis (CF) by effective clearance of mucus from the lungs ${ }^{38}$. Cystic fibrosis afflicts 30,000 people in the United States. It has been demonstrated that brevenal is one million times more effective than amiloride in enhancing mucus clearance from lungs. However, the supply of this dinoflagellate-derived substance is very limited, which has prevented full exploration of its therapeutic value. Figure 5 shows two ladder polyethers: brevenal and yessotoxin.

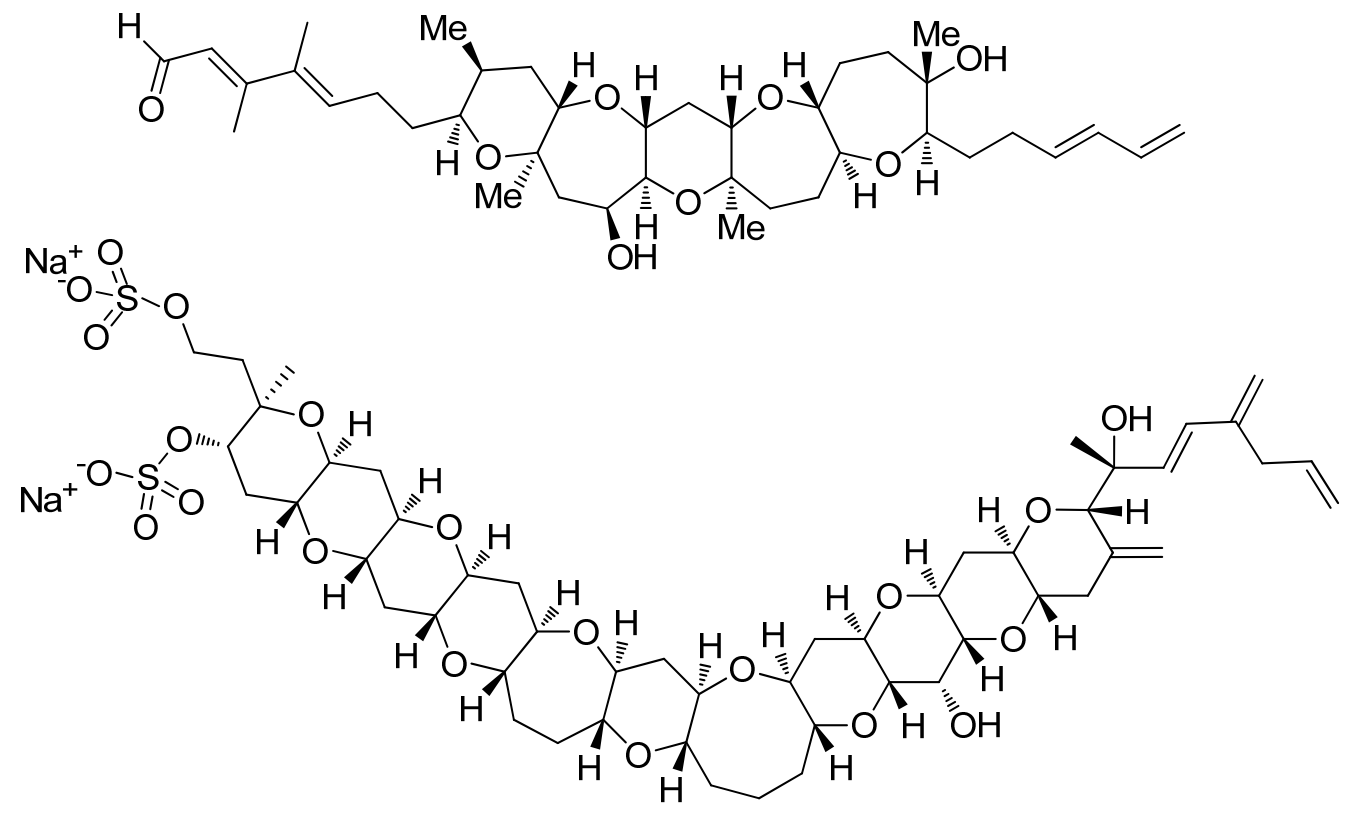

Figure 5. Ladder polyethers (top: brevenal; bottom: yessotoxin) 
Normally, there are three ways to obtain the natural products: extraction and purification from the producing organism, total synthesis or genetically engineering biosynthetic pathways in a heterologous host. The first source for obtaining the PE ladder is also not practical due to its low yield. Several milligram of brevetoxins may be obtained from several hundred liters of $K$. brevis culture. The total synthesis of many natural products, the other source, is quite challenging and time-consuming. The chemical synthesis of the PE ladder motif is still extremely challenging, though total syntheses of these complex molecules has been accomplished. In 1995, after 12 years of effort, the Nicoloau group completed the first total synthesis of a PE ladder, brevetoxin B 39. Brevetoxin A was first synthesized in 1998 also by Nicoloau group, in 34 steps ${ }^{40}$. Another synthesis of brevenal, a relatively simple polyether ladder, was described as highly efficient, but still the longest linear sequence required no less than 32 synthetic steps ${ }^{41}$. These compounds were synthesized several times subsequent to the first synthesis ${ }^{41 b, 42}$. However, due to the structural complexity, all syntheses required over 30 steps and total yields were less than $5 \%$ even when the average yield in each individual step reached up to $90 \%$.

Several biomimetic syntheses of PE ladders via epoxides have been reported. The epoxide ring opening can proceed via both favored, but undesired exo-tet cyclization and the disfavored, but desired endo-tet cyclization. Therefore, strategies to direct the cyclization have been introduced into the syntheses by incorporating directing groups to favor the endo-tet cyclization or to disfavor the exo-tet ${ }^{43}$. More recently, the Jamison group utilized a polyxpoxide cascade to construct more than three rings in only one step; water was used to overcome the inherent exo-tet selectivity. But this method needs 
templating of the substrate with a pyran ring. Furthermore, the reaction is slow, the yields are poor, and side products were produced.

a)

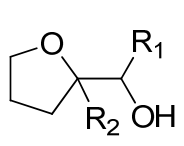

path 1

favored exo-tet

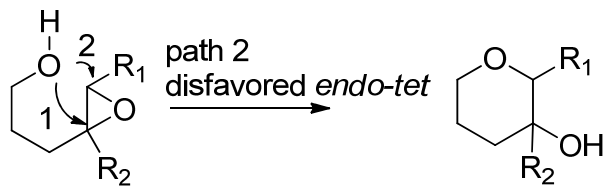

b)

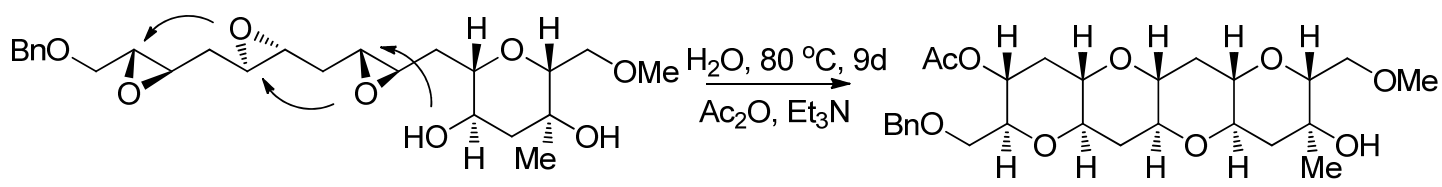

Figure 6. a) cyclization modes and directing strategies b) Jamison's polyepoxide cascade

\subsubsection{Baldwin's rules}

As mentioned above, one of the biggest challenges challenging for the synthesis of PE ladder compounds through the biomimetic routes is that the endo-tet cyclization is disfavored. Baldwin's rule, first proposed by Jack Baldwin in 1976, provides a set of guidelines ranking the relative favorability of ring closure in alicyclic compounds ${ }^{44}$. Relative rates of ring closure of these types of compounds were discussed. These rules are not meant to describe the absolute probability that a reaction will or will not take place; rather they are used in a relative sense. A disfavored reaction does not have a rate that can compete effectively with the other reaction that is favored. However, the disfavored product may still be observed ${ }^{44}$. Figure 7 (below) showed a ring closure reaction in the top, and favor or disfavor of the ring closure in the bottom. 


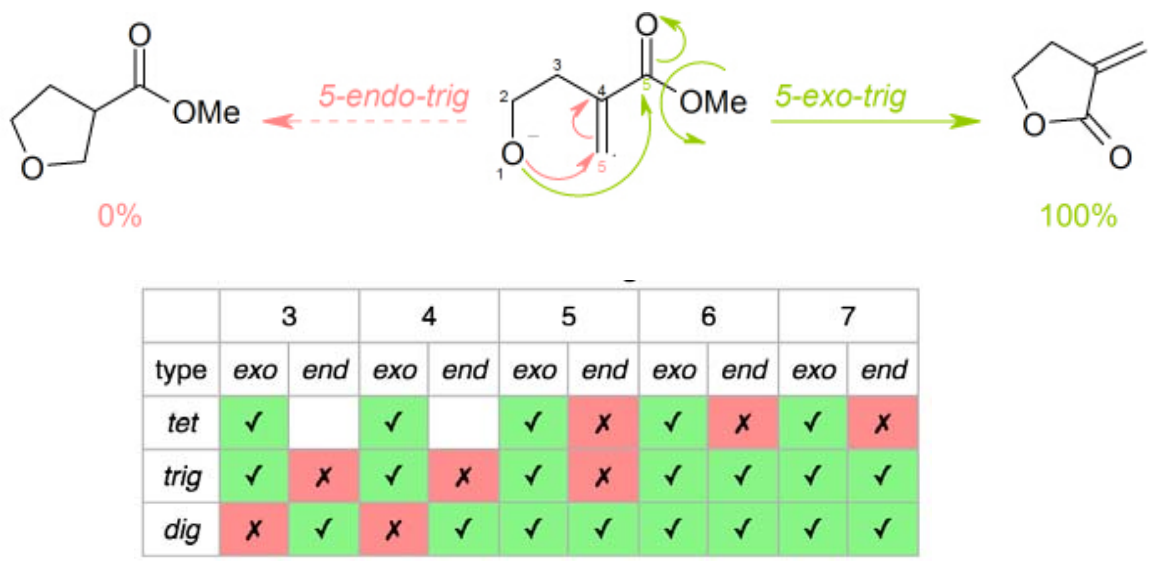

Figure 7. Baldwin'rules (top: ring closure reactions; bottom: dis/favored ring closure)

\subsubsection{Polyether ionophores}

Besides ladder polyethers, polyether ionophores are another large group of polyethers. They are lipophilic carboxylic acids containing multiple five- and sixmembered cyclic ethers, either as spiroketals or as linked bicyclic ethers. Nigericin and lasalocid are the first members isolated in this family ${ }^{45}$. Not until an X-ray structure of monesin A was disclosed ${ }^{46}$ and cation binding abilities of these molecules were first examined ${ }^{47}$, did this family of polyethers start drawing great attention. Over one hundred members in this family have been isolated and characterized, most of which are produced by bacteria of the the genus Streptomyces. Their ability to control coccodiosis, a devastating poultry disease, and promote growth of ruminant, inspired numbers of scientists to isolate novel ionophore polyethers, make efforts on their total synthesis and study their biosynthesis. Polyether ionophores can exhibit numerous biological effects including antibiotic, anti-obesity and insecticide activity, by disturbing the delicate dynamic equilibrium of cations across the cell membrane ${ }^{48}$. Figure 8 shows two ionophore polyethers tetronomycin and cationmycin. 

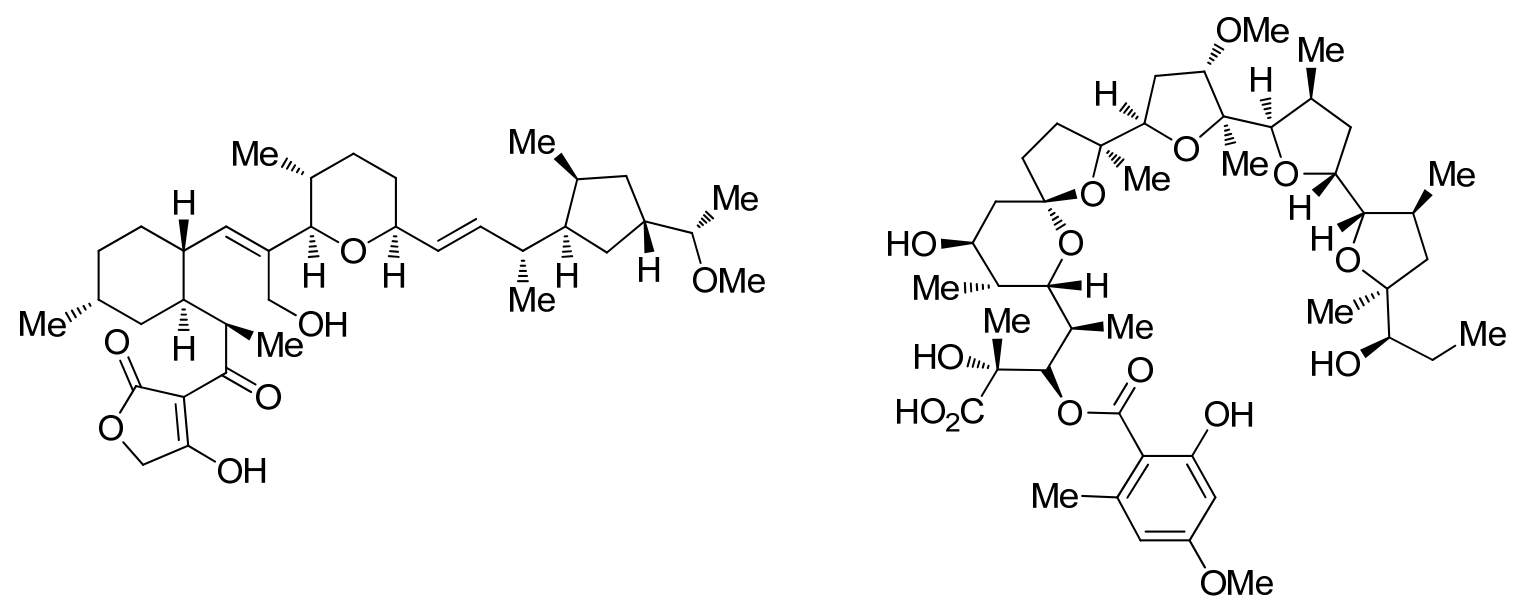

Figure 8. Ionophore polyethers (left: tetronomycin; right: cationomycin)

\subsection{POLYKETIDE BIOSYNTHESIS}

Brevetoxins are members of the polyketide family of natural products. Polyketides are mostly produced by bacterial, filamentous fungi, plants and algae. Polyketides exhibit high structural diversity and vary widely in pharmacological effects, but they share a common biosynthetic origin ${ }^{49}$. All polyketides carbon backbone construction is catalyzed by polyketide synthase (PKS) through a pathway which is highly similar to fatty acid biosynthesis. In the polyketide biosynthetic pathway, small units derived from acetate, propionate or butyrate, are condensed into a carbon chain by a PKS. PKSs have been identified as type I (non-iterative), type II (iterative), and type III (chalcone synthase).

Type I PKSs are large multifunctional enzymes that are organized into modules, each of which directs one cycle of chain extension and condensation. Typically, one PKS module should contain the ketosynthase domain (KS) that elongates the chain, the acyl carrier protein $(\mathrm{ACP})$ that provides a thiol binding site where intermediates are added, and the acyl transferase domain (AT) that transfers units from acyl-CoA precursors to the 
ACP. Additional domains may exist to modify a $\beta$-keto including the keto-reductase (KR), dehydratase (DH), and enoyl reductase (ER). More recent studies have shown that in some type I PKS modules which lack AT domains, the corresponding function is carried out by an iterative AT enzyme ${ }^{50}$.

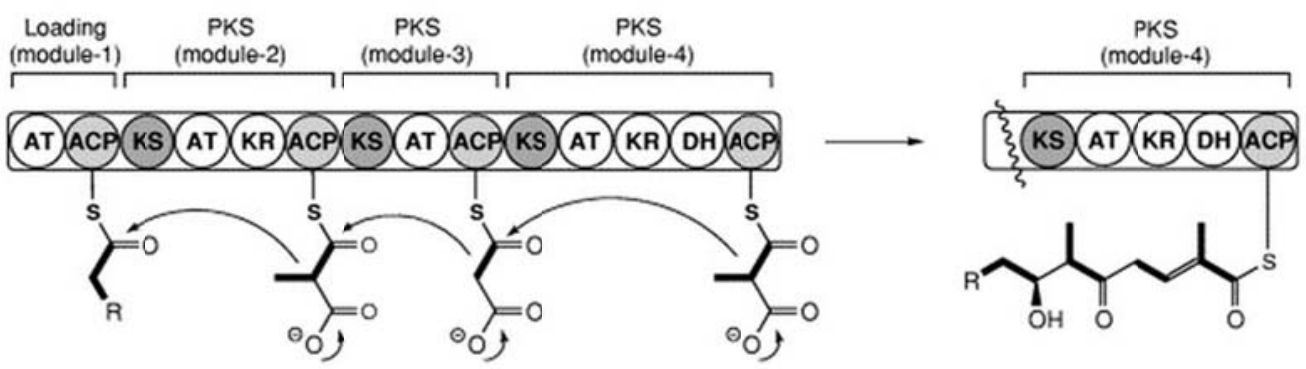

Figure 9. Type I PKS (Shen, 2003)

Type II PKS, carrying a single set of iteratively acting activities, are multienzyme complexes. Four of the domains in type II PKS, KS, AT, KR and DH, are characteristic of known type I PKSs, however, the fifth domain, residing at the C-terminus (terminal domain, TD), is unique to type I PKSs. Type II PKS which lack ACP, utilize acyl CoA directly and catalyze both $\mathrm{C}-\mathrm{C}$ and $\mathrm{C}-\mathrm{O}$ bond formation in the biosynthesis.

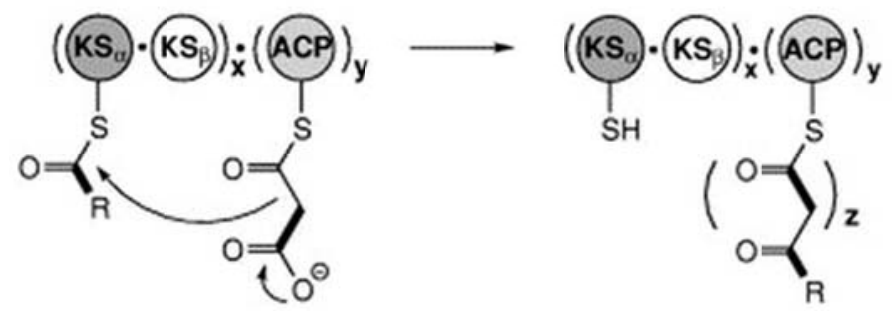

Figure 10. Type II PKS (Shen, 2003)

Type III PKSs, known as chalcone synthase-like PKSs, are homodimeric enzymes that are iteratively acting condensing enzymes. Their structure are distinct from Type I 
and Type II PKSs. Type III PKSs, which are ACP independent, act directly on the acyl CoA substrate, whereas Type I and II PKSs use acyl carrier protein (ACP) to activate the acyl CoA substrates and to channel the growing polyketide intermediates.

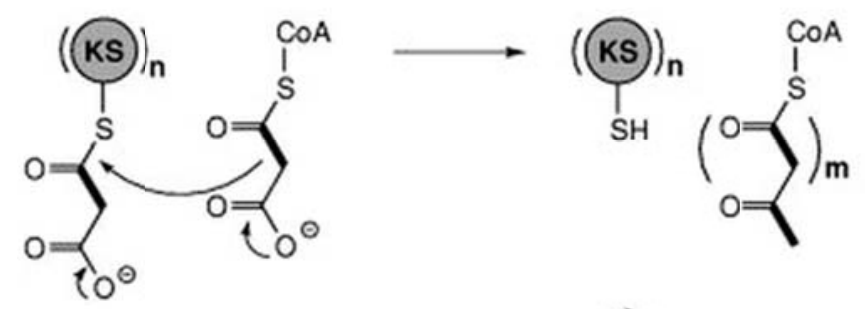

Figure 11. Type III PKS (Shen, 2003)

\subsection{BIOSYNTHESIS OF BREVETOXINS}

While the origins of the carbon atoms in the brevetoxins have been determined, the remainder of the polyether ladder pathway has yet to be revealed. The prevailing hypothesis, put forth nearly 30 years ago by Nakanishi, suggests that PKS-mediated synthesis of the polyene is followed by epoxidation to afford a polyepoxide which then undergoes an epoxide-opening cascade, catalyzed by an epoxide hydrolase (EH), to provide the polyether ${ }^{51}$. This hypothesis, which remains unconfirmed, accounts for the oxygen-carbon-carbon $(\mathrm{O}-\mathrm{C}-\mathrm{C})$ connectivity pattern and trans-syn topography in the natural products and is supported by the recent identification of molecular oxygen $\left(\mathrm{O}_{2}\right)$ as the source of the ether oxygen atoms in the structurally similar PE ladder yessotoxin, produced by the dinoflagellate Protoceratium reticulatum ${ }^{52}$. 


\subsubsection{Biosynthesis of ionophore polyethers}

\subsubsection{Cane-Celmer-Wesley model (1983)}

The fact that the universal building blocks of the polyether carbon skeleton are acetate, propionate and butyrate was well recognized by the early 1980s. Studies on the orgins of the oxygens in monensin were then carried by Cane and Wesley. They fed Streptomyces cinnamonensis, monensin-producing bacterium, with ${ }^{18} \mathrm{O}$ either in carboxylic acid precursors ${ }^{53}$ or in molecular oxygen ${ }^{54}$. Their studies revealed that that not all oxygens are derived from the corresponding subunits like acetate, propionate, and butyrate, but also from molecular oxygen. The groups of Cane, Celmer and Wesley then proposed a unified stereochemical model of polyether structure and biogenesis in $1983{ }^{55}$. According to their model for the biosynthesis of monensin A, an all-E polyene precursor is first produced from five acetates, seven propionates and one butyrate in a type I PKS manner. Then the polyene is oxidized to the corresponding polyepoxide by oxygen. One hydroxyl group attacks the ketone forming a hemiketal, triggering a cascade of epoxide-

opening and ring closure leading to the formation of monensin ${ }^{55}$. This model was then extended to the biosynthesis of all known polyether ionophores. 


\section{ACETATE/ PROPIONATE/ BUTYRATE}

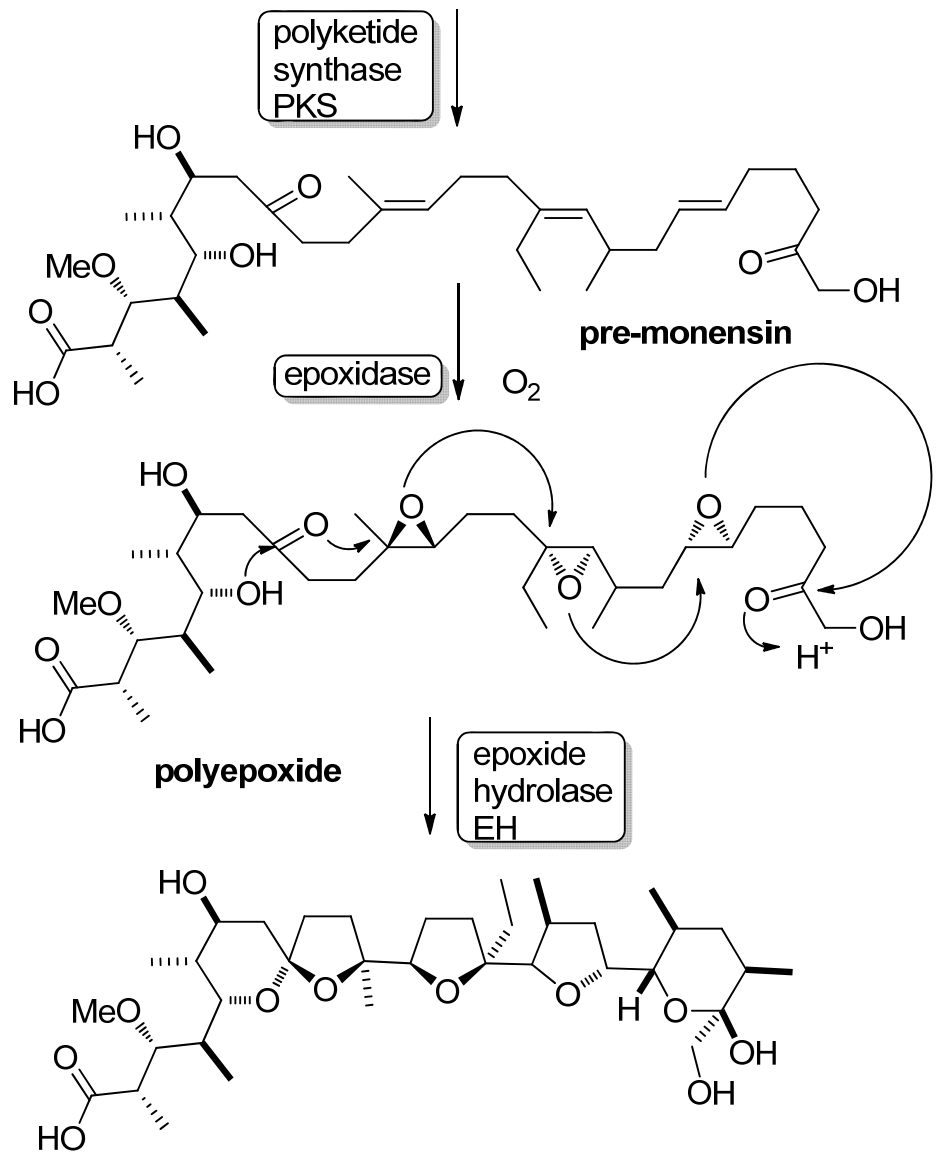

Figure 12. proposed pathway of biosynthesis of monensin

\subsubsection{Townsend-Basak model (1991)}

Numerous polyether molecules followed Cane-Celmer-Wesley proposal. However, despite significant efforts to do so, the all-E premonensin, the proposed precursor of monensin was never found. Townsend and Basak then proposed an alternate biosynthetic pathway ${ }^{56}$. In this model, instead of an all-E precursor, it was proposed that monensin may be produced from an all- $Z$ polyene precursor through several oxidative cyclizations involving the action of an iron-containing monooxygenase. This proposal 
was supported by synthetic studies ${ }^{57}$ and the work on model systems related to all-Z premonensin by McDonald ${ }^{58}$.

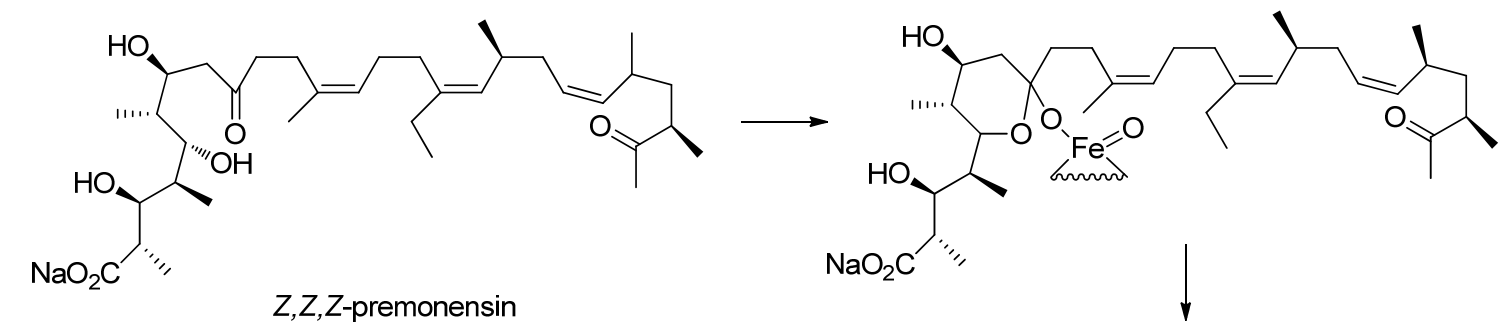

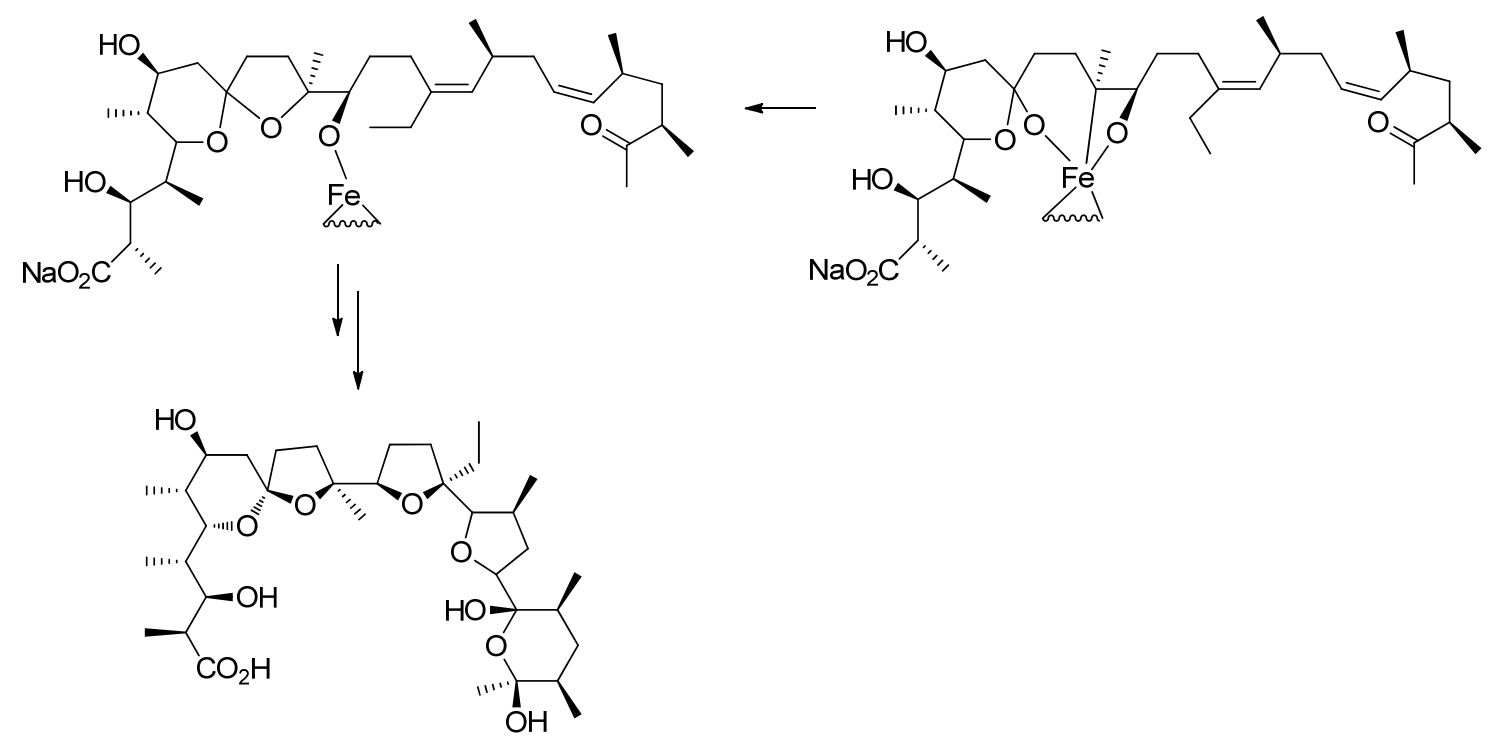

Figure 13. Townsend-Basak model

\subsubsection{Leadlay model (2001)}

Another precursor of monensin was proposed by Leadlay in $2001^{59}$. In his proposal, a Z,Z,E-polyene is required en route to monensin ${ }^{59}$. The biosynthetic gene cluster was sequenced in their group. This is the first polyether gene cluster identified. They found that this polyketide gene cluster contains twelve modules, which are responsible for the incorporation of twelve acyl units of monensin. From the gene cluster, the genes monBI, monBII and monCI were identified ${ }^{60}$. The products of both monBI and 
monBII were thought to act as isomerases, supporting their modification of the CaneCelmer-Wesley model. Deletion of monCI may lead to accumulation of all-E premonensin polyene ${ }^{61}$, indicating that the product of monCI, a single oxidase enzyme, is required in the production of polyepoxide. MonCII showed significant sequence and structural similarity to the EH. However, latter they found that the active site nucleophile in MonCII enzyme is a serine, different from the conserved aspartate residue. They then reassigned monCII as a thioesterase responsible for releasing the product in monensin biosynthesis. Disruption of monBI and monBII genes, which were latter proved to be EHs, resulted in the production of partially cyclized intermediates ${ }^{62}$, suggesting the epoxide opening and ring closure are catalyzed by the MonB enzymes, rather than by the enzyme MonCII as previous thought.

\subsubsection{Biosynthesis of lasalocid}

More direct evidence of the involvement of an enzyme-catalyzed cascade of epoxide-opening reactions in the biosynthesis of polyether was provided by Oikawa in their study of lasalocid biosynthesis ${ }^{63}$. They analyzed biosynthetic genes of lasalocid, reavealing high homology of Isd19 to the putative EH genes monBI and monBII. They obtained pure Lsd19 enzyme by cloning and expressing the Isd19 gene in E. coli. A series of enzymatic reactions were carried out by incubating the enzyme and prelasalocid diepoxides in vitro ${ }^{64}$. The efficient transformation of a proposed substrate bisepoxyprelasalocid and its synthesized analogue suggested Lsd19 is indeed an EH. Leadlay's in vivo studies on the production of lasalocid in the producing organism and a mutant lacking Isd19 clearly demonstrated that Lsd19 changes the regioselectivity of 
polyether ring formation. They found when Lsd19 is not present, the formation of the second ring proceeds the kinetically favored pathway to form isolasalocid, instead of lasalocid ${ }^{65}$. Latter studies on Lsd19 revealed it is composed two subunits, Lsd19A responsible for furan ring formation, and Lsd19B, taking roles in pyran ring formation, which are linked by a short loop and are oriented in a head-to-tail fashion.
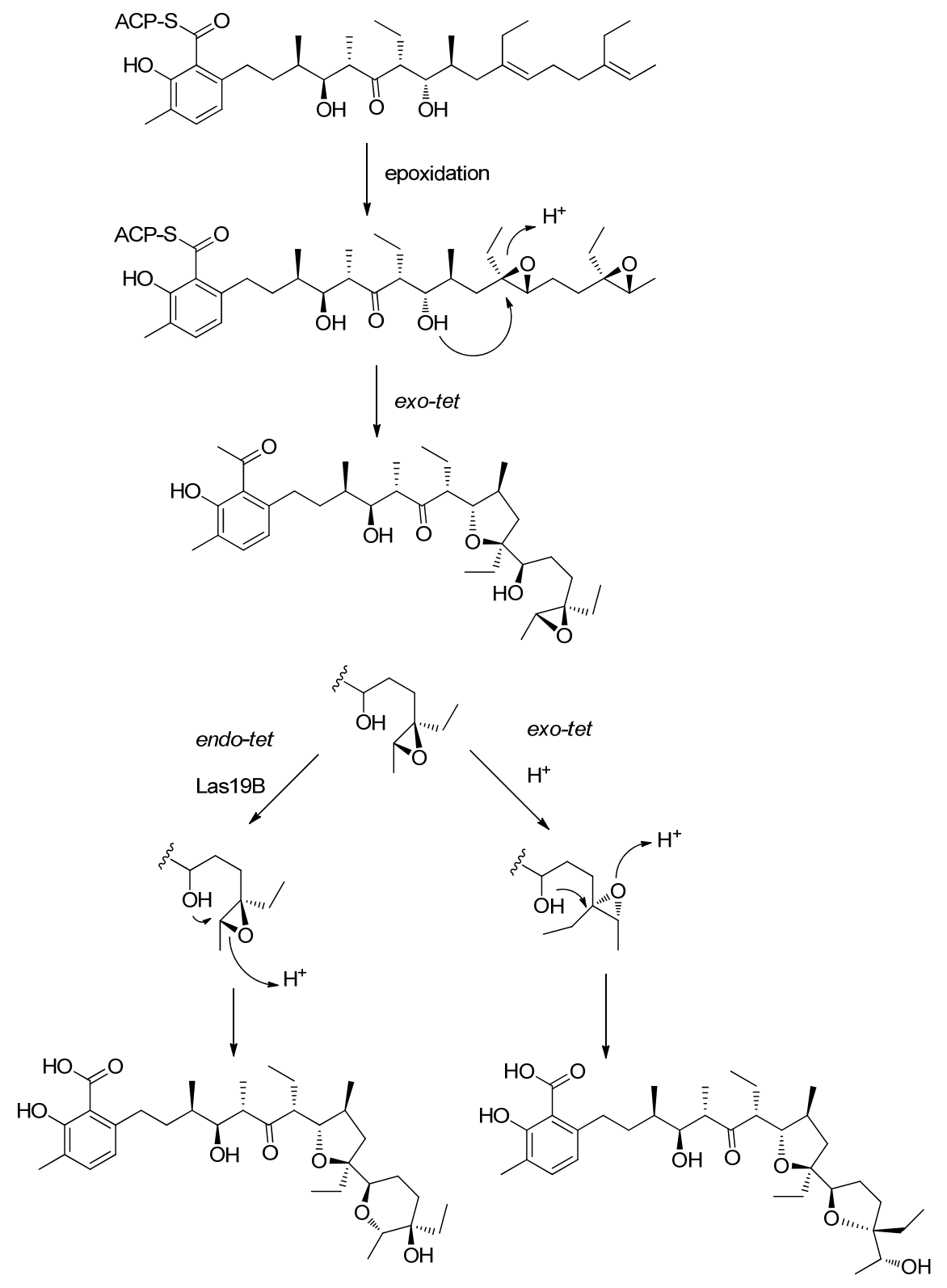

Figure 14. Comparison of with or without Lsd19 (left: lasalocid; right: isolasalocid) 


\subsubsection{Biosynthesis of ladder polyethers}

Shortly after the structure of brevetoxin B, the first ladder polyether reported, was determined in the 1980 's, efforts to understand the biosynthesis of these complex molecules began. Stable isotope incorporation experiments using ${ }^{13} \mathrm{C}$-labelled acetate revealed the polyketide origins of the brevetoxins, yet some anomalies in the labeling patterns, were also observed ${ }^{51 b, 66}$. In the feeding experiment, of the 50 carbons of brevetoxin B, 16 carbons showed enrichment from $\left[1-{ }^{13} \mathrm{C}\right]$ acetate, 30 carbons from [2$\left.{ }^{13} \mathrm{C}\right]$ acetate, and 4 carbons from methyl-methionine. The origins of the carbon atoms in the brevetoxins have been determined, the remainder of the polyether ladder pathway has yet to be revealed. Inspired by the Cane-Celmer-Wesley proposal on monensin biosynthesis, Nakanishi and Shimizu proposed a biosynthetic pathway for brevetoxin which suggests that PKS-mediated synthesis of the polyene is followed by epoxidation to afford a polyepoxide which then undergoes an epoxide-opening cascade, catalyzed by an $\mathrm{EH}$, to provide the polyether (Figure 15) ${ }^{51}$. They believed that the structural and stereochemical similarity among brevetoxins are a direct consequence of their biosynthetic origin. A single oxidase could be sufficient, as all alkenes in the hypothetical polyene precursor would require identical stereoselectivity of epoxidation to produce wither an all-S, $S$ or all- $R, R$ polyepoxide. As described above, according to Baldwin's rules ${ }^{44,62}$, epoxide ring opening reactions favors THF rather than THP, suggesting that the cascades should have to overcome ten separate disfavored epoxide opening reactions. 


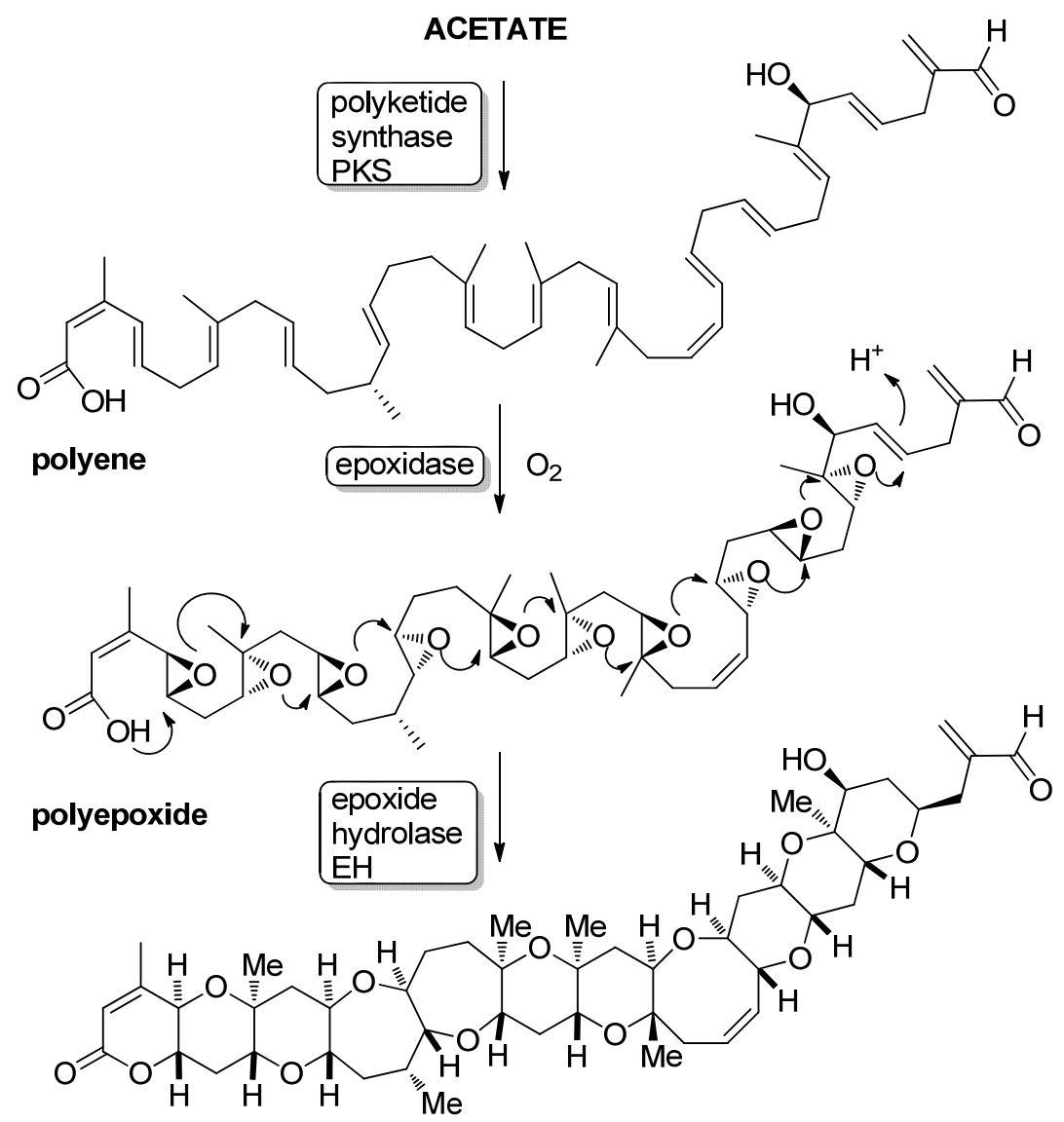

Figure 15. Proposed biosynthetic pathway of brevetoxin

Although the origins of the carbon atoms in the brevetoxins are confirmed, the subsequent epoxidation and cyclizations are still unrevealed. Labeling experiments with ${ }^{18} \mathrm{O}_{2}$ revealed that the oxygens in the fused THP diad of okadaic acid are derived from molecular oxygen ${ }^{67}$, suggesting that an epoxide intermediate is involved in the formation of this ladder polyether like motif, which provided support for the proposal. 


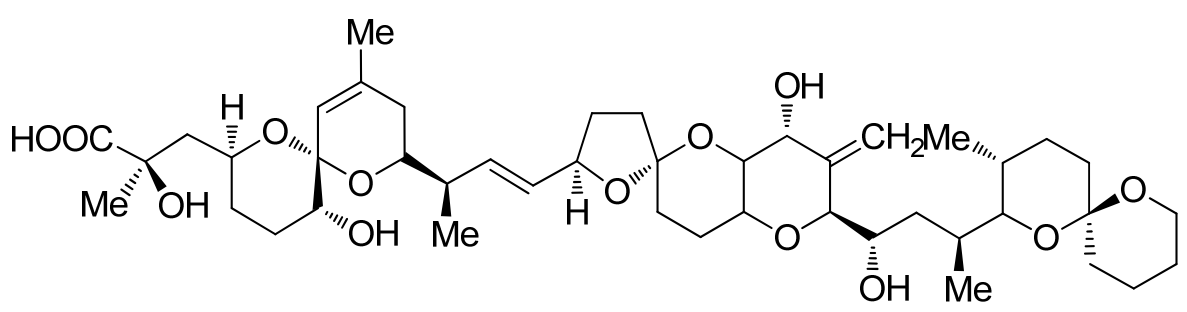

Figure 16. Structure of Okadaic acid

Giner and Mullins proposed that the ladder polyethers are derived from all-Z polyene precursor ${ }^{68}$. In their proposal, an epoxy ester intermediate undergos cyclization with the carbonyl as nucleophile, resulting in the formation of an orthoester. Upon the collapse of orthoester, the hydroxyl group attacks the previous electrophilic site of the starting cis epoxide, produces the ring in the ladder and generates an ester for next cyclization reaction. However, this proposal has not been tested.

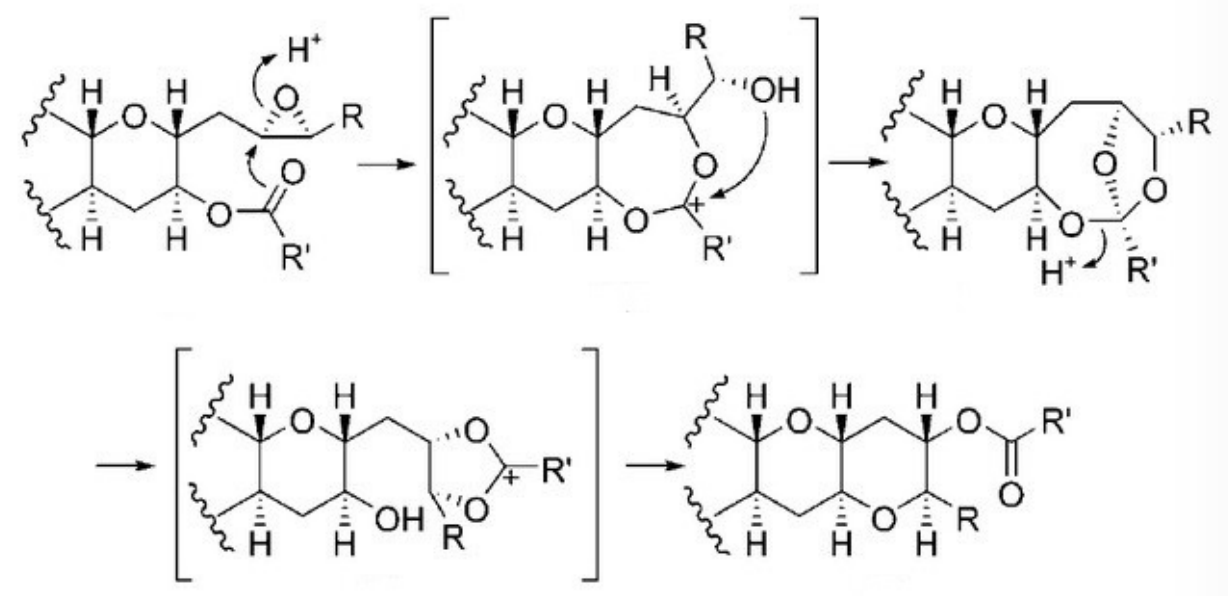

Figure 17. Biosynthesis of ladder polyethers in epoxy ester pathway

Recent identification of molecular oxygen $\left(\mathrm{O}_{2}\right)$ as the source of the ether oxygen atoms in the structurally similar PE ladder yessotoxin, produced by the dinoflagellate 
Protoceratium reticulatum ${ }^{52}$ provides significant support for Nakanishi's proposal. This study examined the results of feeding experiment using ${ }^{18} \mathrm{O}$ with either molecular oxygen or $\left[{ }^{18} \mathrm{O}_{2}\right]$ acetate. The analysis of these experiments revealed that the ether oxygens are derived from ${ }^{18} \mathrm{O}_{2}$, and the hydroxyl oxygen is from $\left[{ }^{18} \mathrm{O}_{2}\right]$ acetate. These results suggest that a polyene precursor is oxidized by a monooxygenase after acetate condensation, which supports Cane-Celmer-Wesley model, as well as Nakanishi and Shimizu's hypothesis. In addition, it was suggested the direction of epoxide ring formation was from tail to head (right to left) and a monooxygenase formed predominantly an all $(S, S)$ polyepoxide intermediate from an $E$-polyene intermediate.

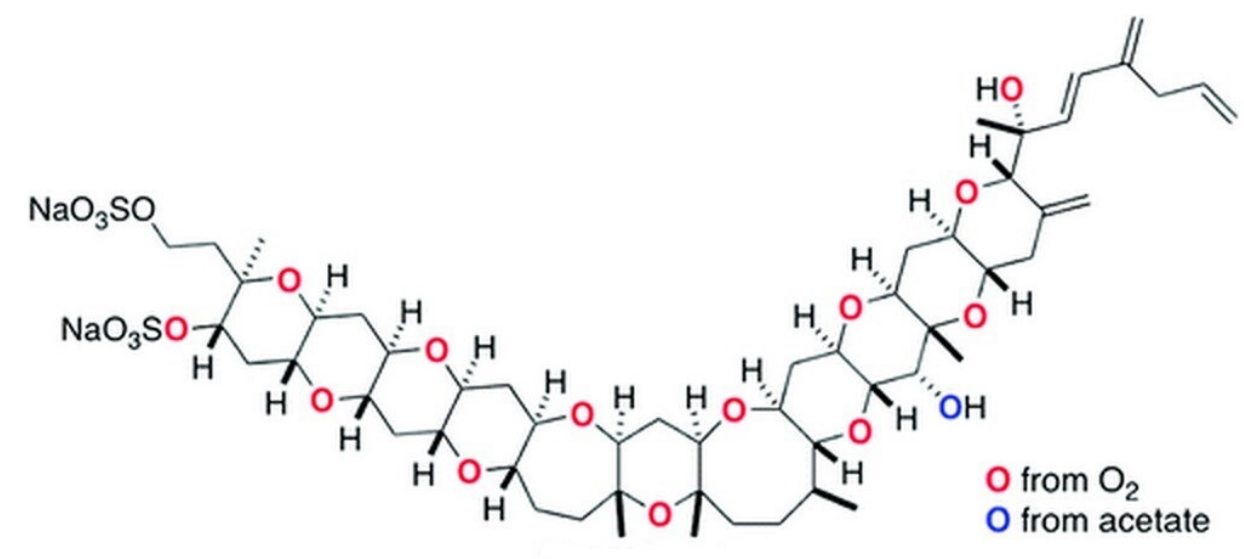

Figure 18. Origins of oxygen in yessotoxin

\subsection{EPOXIDE HYDROLASE (EH, E.C.3.3.2.3)}

Epoxide-containing compounds are very widely found in the environment, and a large variety of aromatic and alkenic compounds are also metabolized to epoxides endogenously ${ }^{69}$. An epoxide (also known as oxirane), a three-membered cyclic ether, has specific reactivity patterns owing to the highly polarized oxygen-carbon bonds in 
addition to a highly strained ring ${ }^{70}$. Most epoxides are moderately reactive, relatively stable at physiological $\mathrm{pH}$, and do not present acute dangers to cells, but they still need to be transformed in a controlled manner. EHs can catalyze epoxide hydrolysis to yield the corresponding 1,2-diol, which is only one of several ways that cells transform epoxides ${ }^{71}$.

\subsubsection{Function of EHs}

In different organisms, the role of EHs differs greatly. Generally, EHs have three functions: detoxification, catabolism, and regulation of signal molecules. In microorganisms, EHs are important in the catabolism of specific carbon sources from natural sources, like tartaric acid or limonene ${ }^{72}$. However, studies on microbial EHs are mainly for their potential use as chiral catalysts for enzymatic syntheses ${ }^{73}$. In plants, EHs seem important in cuticle formation, responses to stress, and pathogen defense ${ }^{74}$. In several insects, EHs have also been characterized, where the role of the enzyme is mediating developmental chemical, juvenile hormone, and detoxification of many plant chemical defenses. In mammals, there are also many EHs, including soluble EH (sEH), microsomal EH (mEH), and cholesterol $\mathrm{EH}(\mathrm{chEH})$, which hydrolyze the 5,6-oxide of cholesterol and other epoxy steroids. In the past 30 years, sEH and $\mathrm{mEH}$ have been mostly studied. Although these enzymes were first distinguished by their subcellular localization, they also have distinct and complementary substrate specificity ${ }^{75}$. These two enzymes are very concentrated in liver, but they are found in nearly all tissues. They are thought to complement each other in detoxifying a wide range of mutagenic, toxic and carcinogenic xenobiotic epoxides. However, recent studies found the $\mathrm{mEH}$ is involved in xenobiotic metabolism and the onset of several diseases ${ }^{76}$, and the sEH is 
involved in the regulation of blood pressure and inflammation ${ }^{77}$. What's interesting is that inhibition of the sEH seems to be a potential therapeutic treatment for several diseases, including high blood pressure, atherosclerosis, and kidney failure. Understanding of EHs mechanism of action is a prerequisite for development of potent inhibitors. Although the mechanism has been studied since the enzymes were discovered, major breakthroughs were made in the past 20 years because of the availability of recombinant EHs ${ }^{69}$.

\subsubsection{Different types of EHs}

Three types of EH, which operate through distinct catalytic mechanisms, have been identified ${ }^{69}$. The most studied of these belong to the larger family of hydrolases containing an $\alpha, \beta$-fold and are often referred to as $\alpha, \beta$-hydrolases. All sEH and $\mathrm{mEH}$ in mammals belong to this category. A second type of EH is the leukotriene- $\mathrm{A}_{4}\left(\mathrm{LTA}_{4}\right)$ hydrolase ${ }^{78}$. The $\mathrm{LTA}_{4}$ hydrolase is highly substrate specific, converting $\mathrm{LTA}_{4}$ into leukotriene- $\mathrm{B}_{4}\left(\mathrm{LTB}_{4}\right)$. Only two other substrates, the double bond isomers $\mathrm{LTA}_{3}$ and $\mathrm{LTA}_{5}$, have been identified. The third EH is the limonene-1, 2-epoxide hydrolase (LEH), which was first identified to hydrolyze limonene 1-2-epoxide to limonene-1,2-diol (Figure 19) and recognized as a new type of EH in $1998^{79}$.

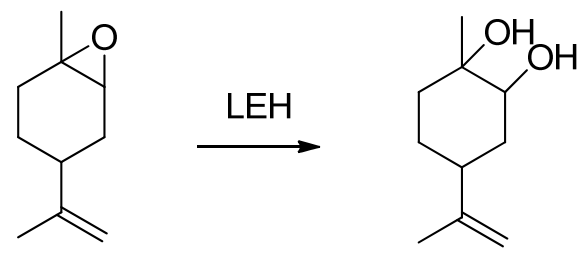

Limonene-1,2-epoxide

Limonene-1,2-diol

Figure 19. LEH hydrolysis 


\subsubsection{1 $\alpha, \beta$-fold EH}

Most EHs belong to the $\alpha, \beta$-hydrolase fold superfamily of proteins. The $\alpha, \beta$ hydrolase fold is widely found in hydrolytic enzymes of differing phylogenetic origin and catalytic function. The core of the enzyme in this family is an $\alpha, \beta$-sheet, containing $8 \beta$ sheets connected by $6 \alpha$-helices ${ }^{80}$. The enzymes have a catalytic triad, the elements of which are borne on loops, which are very conserved structural features of the fold. However, the catalytic domains of the enzymes do not share obvious sequence similarity, nor do they operate on similar substrates. Nevertheless, they are believed to evolve from a common ancestor due to their structural similarity and preservation of the arrangement of the catalytic residues ${ }^{81}$. Beside EH, this superfamily also includes proteases, lipases, peroxidases, esterases, and dehalogenases.

All known $\alpha, \beta$-fold epoxide EHs are characterized by a nucleophile-histidineacid catalytic triad. The mechanism is two-step involving the formation of a covalent intermediate ${ }^{82}$. Before the two-step mechanism was described, the generally accepted mechanism was a general-base-catalyzed direct attack of water on the epoxide ring. The triad of these enzymes can be described as nucleophile-histidine-acid. Two conserved tyrosine residues and a conserved Asp-His-Asp catalytic triad make up the active site. The tyrosines are believed to serve as general acids for activation of the epoxide by forming two hydrogen bonds with the oxygen ${ }^{83}$. The carboxylate group of one of the Asp residues is activated by the His and other Asp in the active site and is the nucleophile that attacks the epoxide, typically at the least substituted carbon. In a second step a water molecule, activated by the His-Asp charge relay, cleaves the ester that is formed, liberating the diol and regenerating the enzyme as shown in Figure 20. 

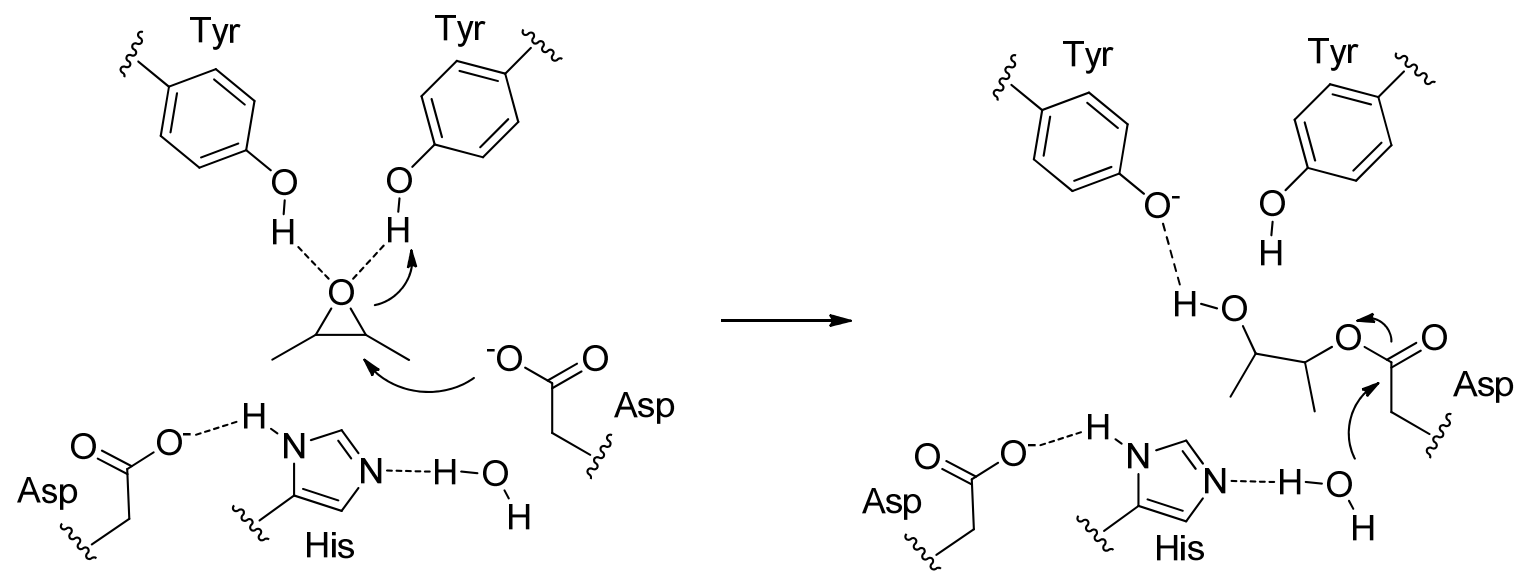

Figure 20. Mechanism of $\alpha$, $\beta$-fold EH

\subsubsection{Leukotriene-A4 $\left(\mathrm{LTA}_{4}\right)$ hydrolase}

Leukotrienes, first discovered in leukocytes, are a class of lipid mediators involved in inflammatory and allergic reactions. 5-Lipoxygenase converts arachidonic acid into epoxide intermediate $\mathrm{LTA}_{4}$, which is then hydrolyzed into the proinflammatory lipid mediator leukotriene $\mathrm{B}_{4}\left(\mathrm{LTB}_{4}\right)$ by $\mathrm{LTA}_{4}$ hydrolase. $\mathrm{LTA}_{4}$ hydrolase (EC 3.3.2.6) is a bifunctional zinc metalloenzyme, besides EH activity, it also exhibits an anion dependent aminopeptidase activity. It is commonly believed that peptidase activity is involved in the bioactive peptides related to inflammation ${ }^{78}$.

The $\mathrm{LTA}_{4}$ hydrolase is highly substrate specific, converting $\mathrm{LTA}_{4}$ into leukotriene- $\mathrm{B}_{4}\left(\mathrm{LTB}_{4}\right)$. Only two other substrates, the double bond isomers leukotriene $\mathrm{A}_{3}$ $\left(\mathrm{LTA}_{3}\right)$ and leukotriene $\mathrm{A}_{3}\left(\mathrm{LTA}_{5}\right)$, have been identified. 


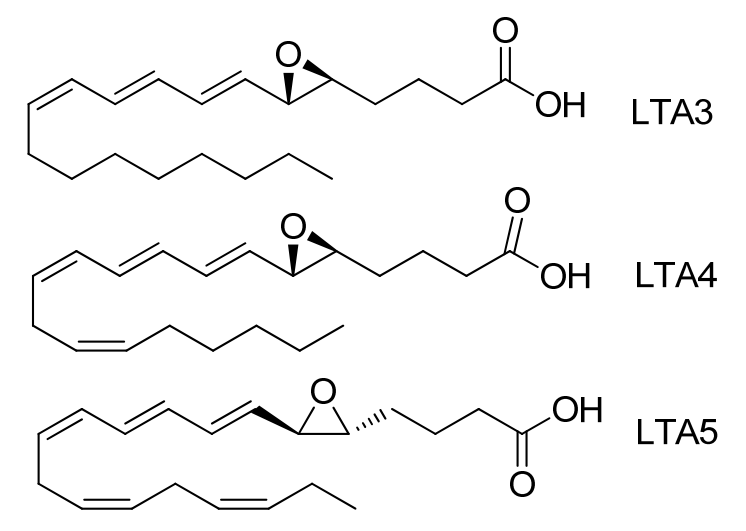

Figure 21. Substrates of leukotriene $\mathrm{A}_{4}$ hydrolase

In this enzyme's active site two histidines and a glutamate coordinate a $\mathrm{Zn}^{2+}$ ion, which in turn coordinates the epoxide oxygen. Upon activation of the 5, 6-epoxide, an intermediate carbocation, whose charge is delocalized over a conjugated triene system, is quenched at C-12 by a water molecule which is activated and delivered by a conserved Asp residue, to produce a 5, 12-diol rather than a 1, 2-diol. The active site has two domains with structures very different from those of $\alpha, \beta$-hydrolase. A covalent adduct between the enzyme and substrate is not formed in this process making it distinct from the $\alpha, \beta$ hydrolase type. 

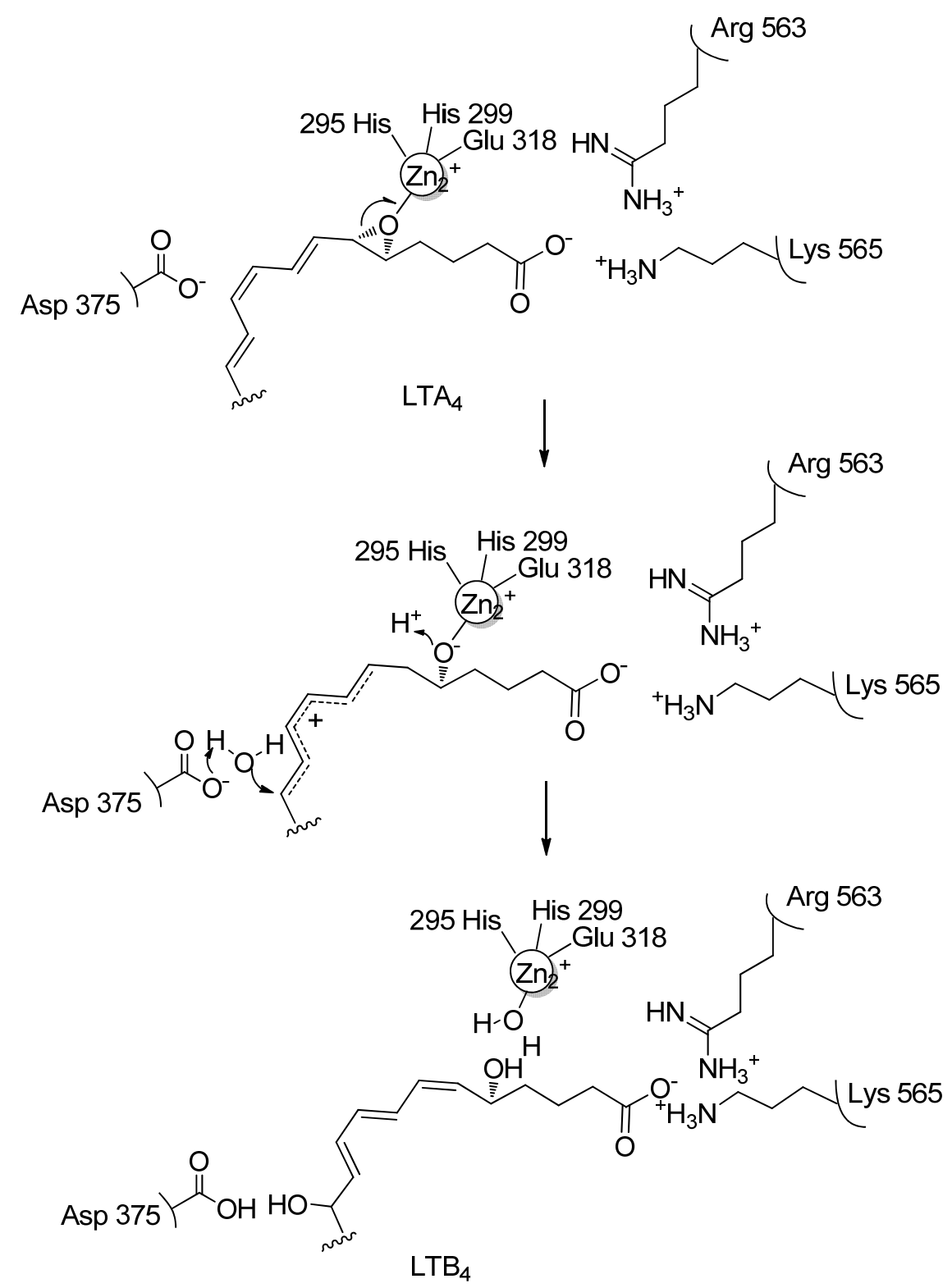

Figure 22. Mechanism of leukotriene $\mathrm{A}_{4}$ hydrolase

\subsubsection{Limonene EH}

Limonene EH (LEH) was first found to be involved in the limonene degradation pathway in Rhodococcus erythropolis, in which it allows the bacterium to grow on limonene as carbon source. LEHs do not exhibit any sequence similarity to the $\alpha, \beta$ hydrolases. LEH can hydrolyze limonene-1,2-epoxide to produce limonene-1,2-diol. In 
both structure and mechanism, LEHs are different from $\alpha, \beta$-hydrolase fold EHs. Structurally, LEH is much smaller, and does not contain any highly conserved motifs of the catalytic triads found in $\alpha, \beta$-hydrolase fold EHs and exhibits a novel active site structure in the LEH crystal structure ${ }^{84}$. LEH contains a curved $\beta$-sheet with three $\alpha$ helices on top. Five charged residues constitute the active site.

In LEH, the epoxide is activated by hydrogen bonds to an Asp residue. However, as in the case of $\mathrm{LTA}_{4}$ hydrolase, a water molecule is activated and delivered by Asn, Asp and Tyr residues in a one-step mechanism and a covalent intermediate is not formed ${ }^{84}$. Figure 23 shows the mechanism of LEH.

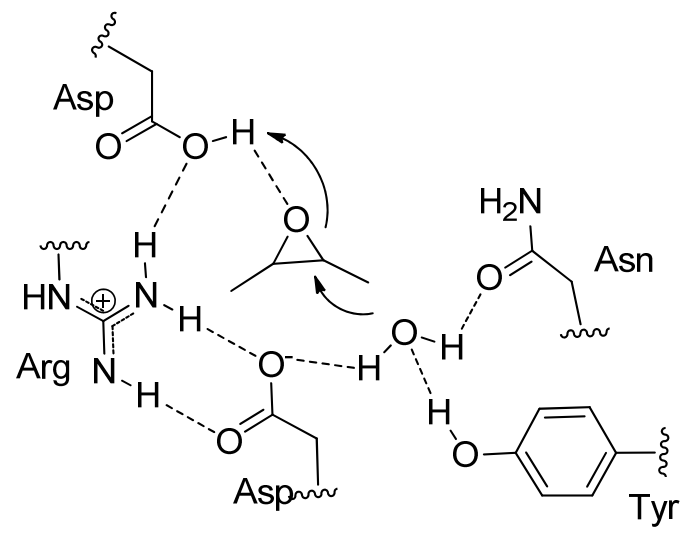

Figure 23. Mechanism of LEH

All EHs which are confirmed to be involved in the biosynthesis of non-ladder type polyethers are of the LEH type. Genes coding for LEHs have been identified in the biosynthetic gene clusters for the bacterial polyethers monenesin ${ }^{60}$, lasalocid ${ }^{65}$, nanchangmycin ${ }^{85}$, tetronomycin ${ }^{86}$ and nigericin ${ }^{87}$. In the case of monensin ${ }^{62,88}$ and lasalocid $^{63,89}$, these EHs encoding genes have been expressed and the EH activity of the enzymes confirmed. 


\section{SEARCH FOR EHS}

\subsection{INTRODUCTION}

As described previously, EHs are believed to be able to cyclize polyepoxides into polyethers ${ }^{55}$. EHs from Karenia brevis were proposed to catalyze a kinetically disfavored endo-tet cyclization to produce brevetoxins from polyene precursors. There are three types of EHs: $\alpha, \beta$-fold EHs, limonene EHs, and leukotriene-A4-hydrolase. Most known EHs belong to $\alpha, \beta$-fold class of EHs.

\section{Objectives}

- Find evidence to support the hypothesis that EH from polyether ladder producing dinoflagellates will catalyze the construction of the polyether ladder framework from polyepoxide substrates

- Study the role of EH in the biosynthesis of polyether ladder compounds, and

- Evaluate the potential of EH in semi-enzyme synthesis.

To achieve these objectives, it is necessary to identify and produce one or more EH from dinoflagellates. In this chapter, different methods were described to search for various classes of EHs in K. brevis. 


\subsection{RESULTS AND DISCUSSION}

2.2.1 Screening cell free extracts (CFE)

\subsubsection{EH detection in Karenia brevis}

Prior to attempting to obtain an $\mathrm{EH}$ from $K$. brevis, it is crucial to prove that $\mathrm{EH}(\mathrm{s})$ exist in the organism. Detection of EH activity from K. brevis utilized a sensitive fluorescent assay as shown below in Figure 24. The substrate $\mathbf{2}$ was prepared from transtyrylacetic acid and 7-methoxy-2-napthaldehyde ${ }^{90}$.<smiles>N#CC(O)[AlH2+]</smiles>

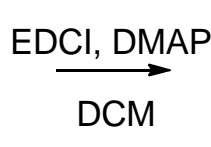

$57 \%$
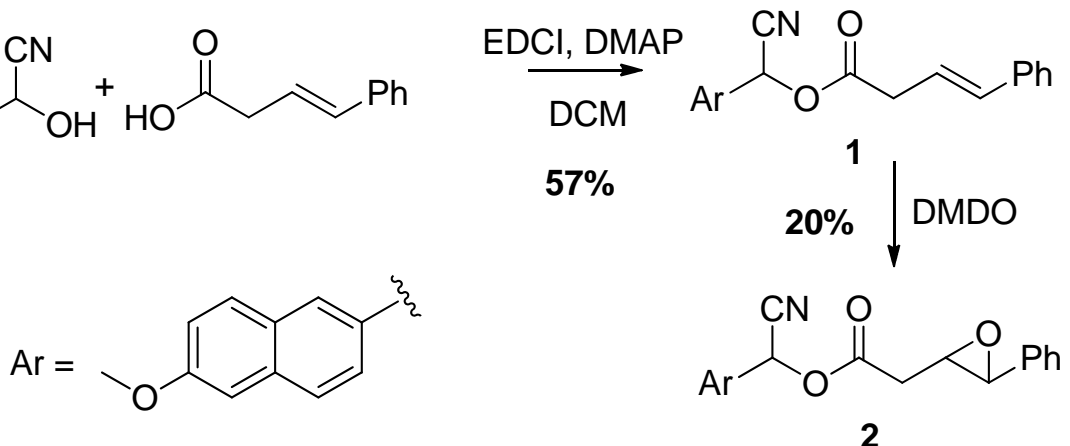

Figure 24. Synthesis of fluorescent probe 1

Typically, an EH will catalyze epoxide ring opening to yield the corresponding 1,2-diol. An EH catalyzed hydrolysis of the epoxide substrate, compound 2 produces an intermediate diol which lactonizes to release the fluorescent reporter $\mathbf{3}$ after hydrolysis of the intermediate cyanohydrin as shown in Figure 25. 


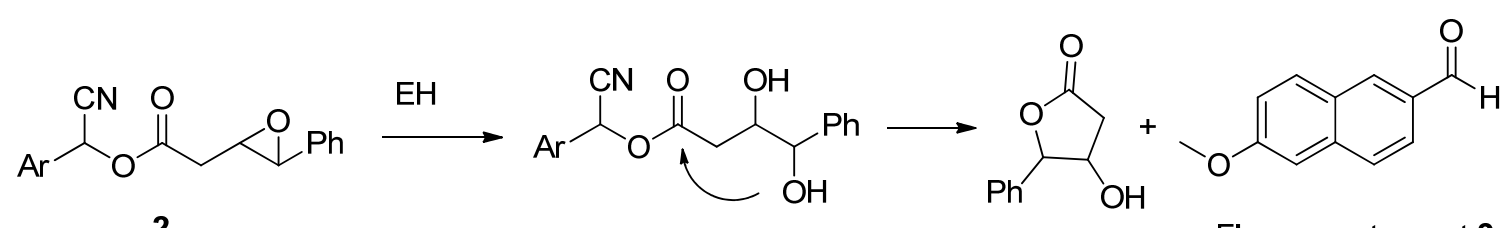

2

Fluorescent report 3<smiles>[Li]c1ccc2cc(OC#[Zn])ccc2c1</smiles>

Figure 25. EH activity detection strategy

Cell free extracts (CFE) of K. brevis were prepared and evaluated for EH activity. The protein concentration of $K$. brevis CFE was adjusted to $0.25 \sim 0.5 \mathrm{mg} / \mathrm{mL}$ based on the Bradford protein assay. Gluocose-6-phosphate dehydrogenase activity was evaluated to insure the CFE has retained sufficient enzymatic activity. The concentration of fluorescent reporter was calculated for each reading according to a standard curve of the reporter. The result (Figure 26) showed that the K. brevis cell free extracts have significant EH activity.

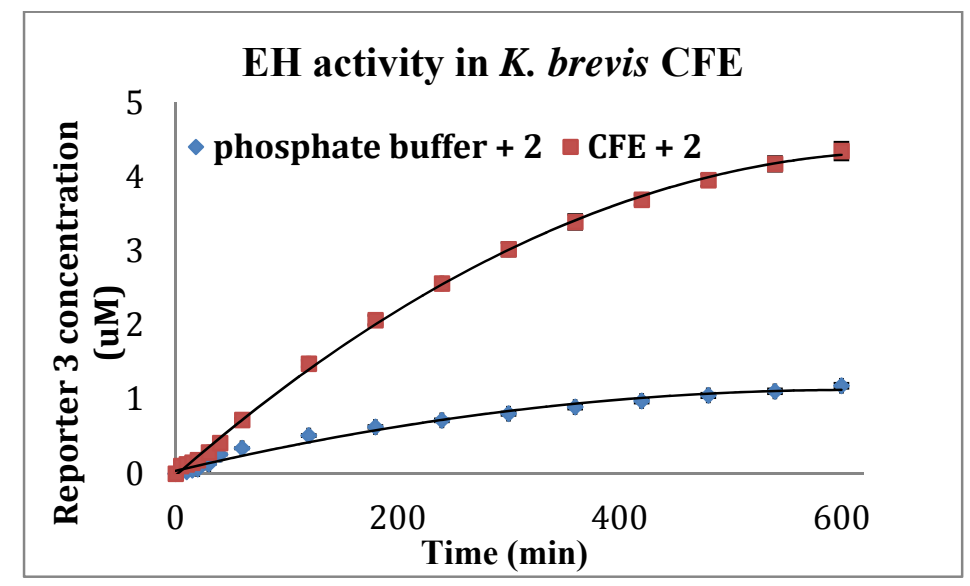

Figure 26. EH activity in K. brevis CFE 


\subsubsection{Detection of esterase activity}

Esterase, which hydrolyzes an ester into a carboxylic acid and an alcohol, can also catalyze the hydrolysis of the fluorescent probe $\mathbf{2}$ and produce the fluorescent report $\mathbf{3}$ (Figure 27).

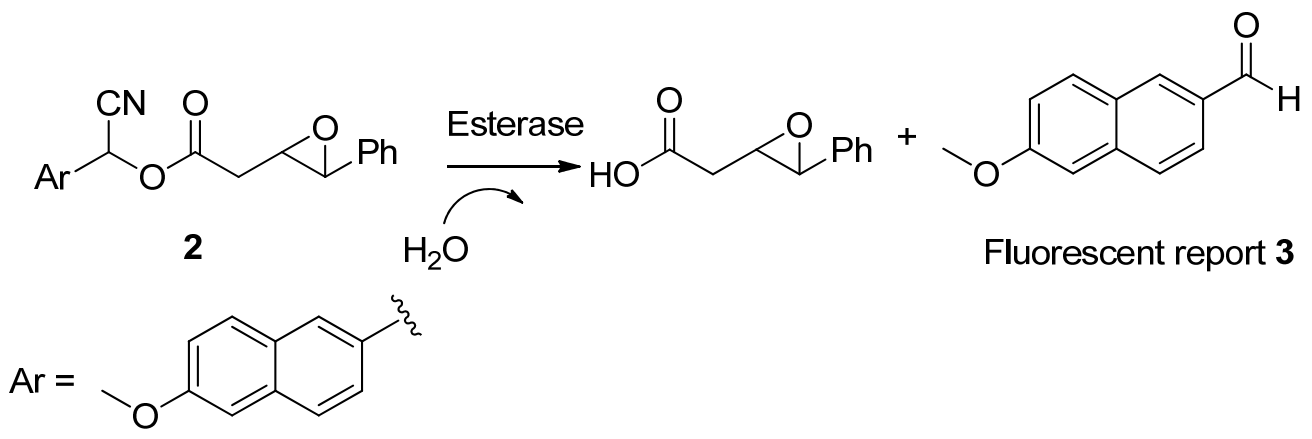

Figure 27. Esterase catalyzed hydrolysis yields the same fluorescent reporter as EH

To confirm the activity observed in the K. brevis CFE is due to EH activity not esterase activity, the precursor of the fluorescent probe $\mathbf{1}$ without the epoxide group was used as the substrate in the assay. An observation of significant difference $(\sim 2$ fold in rate of formation of fluorescent reporter 3) in EH activity vs esterase activity suggested the $K$. brevis CFE did have EH activity, and that the difference between total activity using the EH probe and esterase activity reflected EH activity alone. 


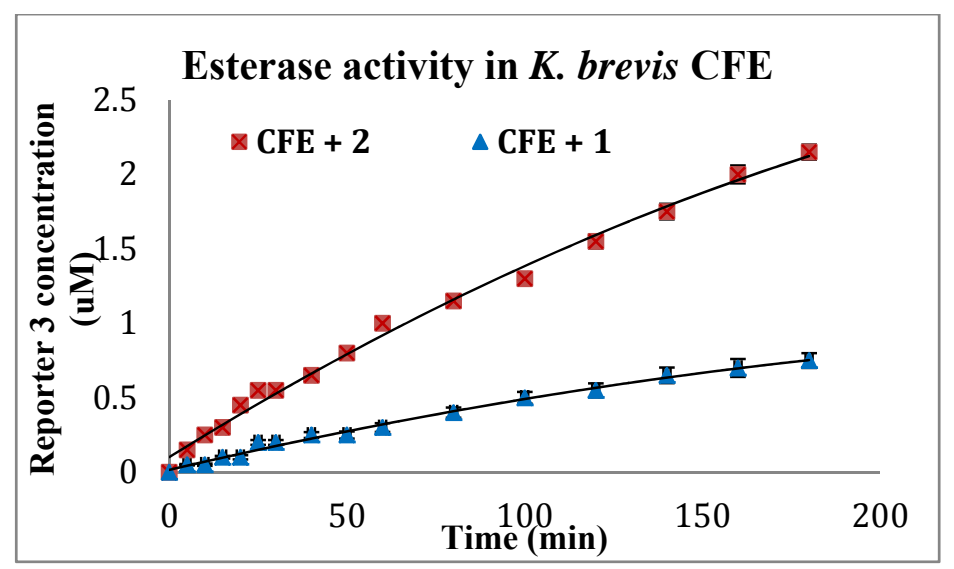

Figure 28. EH and esterase activity in K. brevis CFE

\subsubsection{Assays with EH inhibitors}

The EH activity of $K$. brevis CFE was examined in the presence of known inhibitors of two of the three classes of EH: adamantly urea 4 , inhibitor of mouse $\left(\mathrm{K}_{\mathrm{i}}\right.$ of $0.33 \mu \mathrm{M})$ and human $\left(\mathrm{K}_{\mathrm{i}}\right.$ of $\left.6.2 \mu \mathrm{M}\right) \alpha, \beta$-hydrolase type ${ }^{91}$ and two inhibitors of the Rhodococcus erythropolis LEH: hexylamine $5\left(\mathrm{~K}_{\mathrm{i}}\right.$ of $\left.35 \mu \mathrm{M}\right)$ and valpromide $6\left(\mathrm{~K}_{\mathrm{i}}\right.$ of $100 \mu \mathrm{M}$ ) as shown in Figure $29^{84}$. Due to the substrate specificity and unique mechanism of the $\mathrm{LTA}_{4}$ hydrolase, it is unlikely that our probe would detect such activity.<smiles>CCCCCCN</smiles>

Hexylamine 5

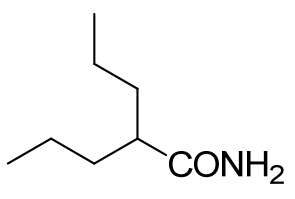

Vapromide 6

Figure 29. Structure of EH inhibitors

The inhibitor of $\alpha, \beta$-hydrolase type $\mathrm{EH}$, adamantyl urea $\mathbf{4}$ was synthesized from $N$-(1-adamantyl) urea ${ }^{90}$, as shown in Figure 30 . 

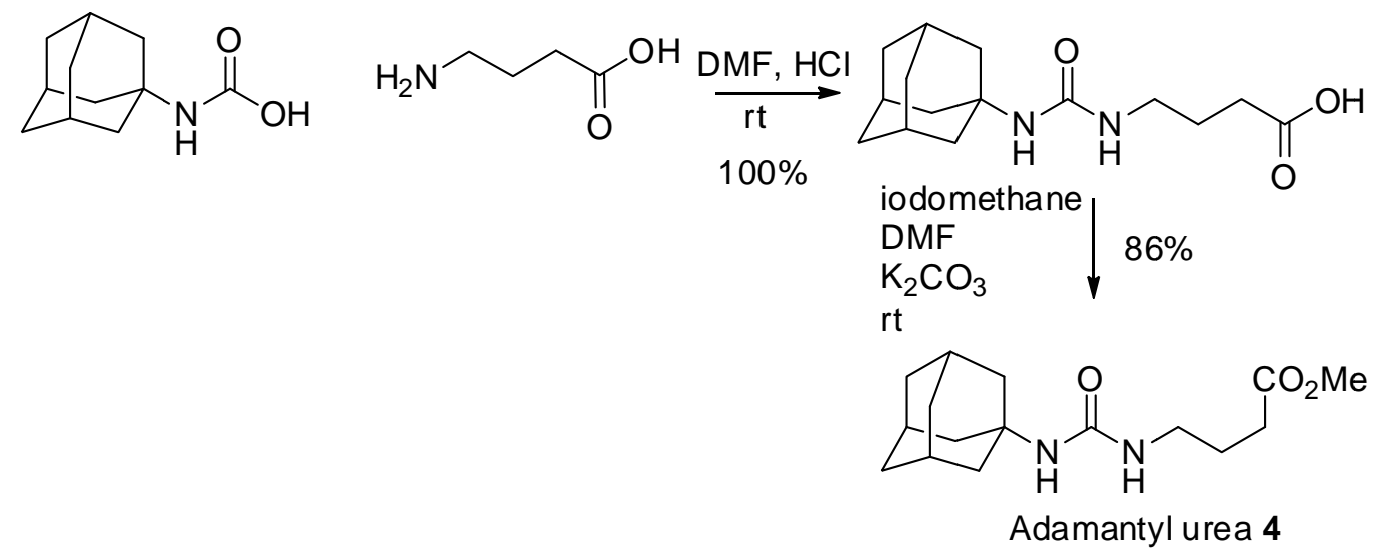

Figure 30. Synthesis of Adamantyl urea 4

The total protein concentration of $K$. brevis CFE was adjusted to $0.25 \mathrm{mg} / \mathrm{mL}$. The fluorescent probe $2(100 \mu \mathrm{M})$ with an equavalent concentration of inhibitors was incubated with K. brevis CFE.

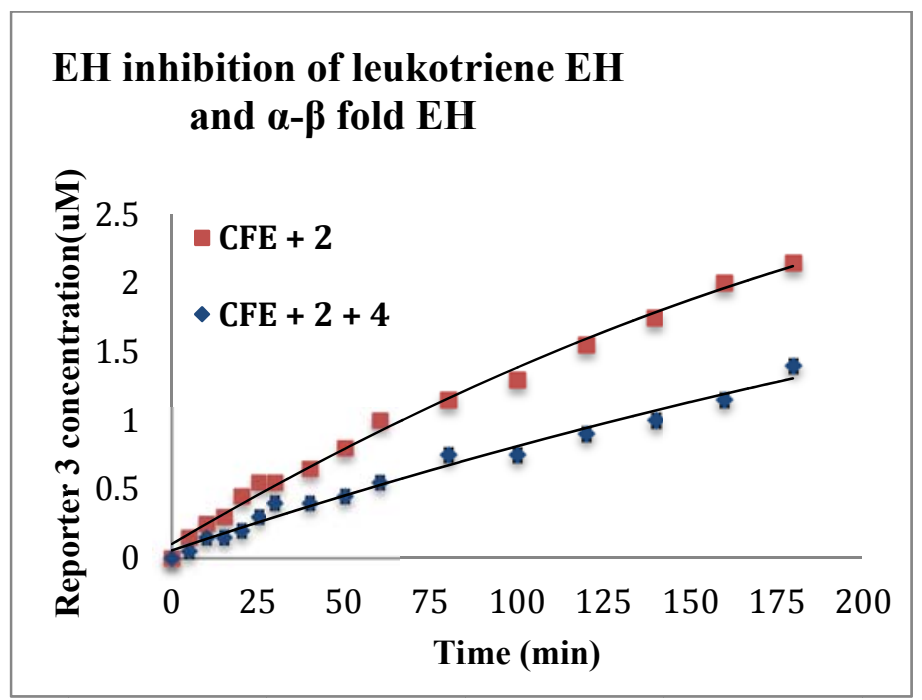




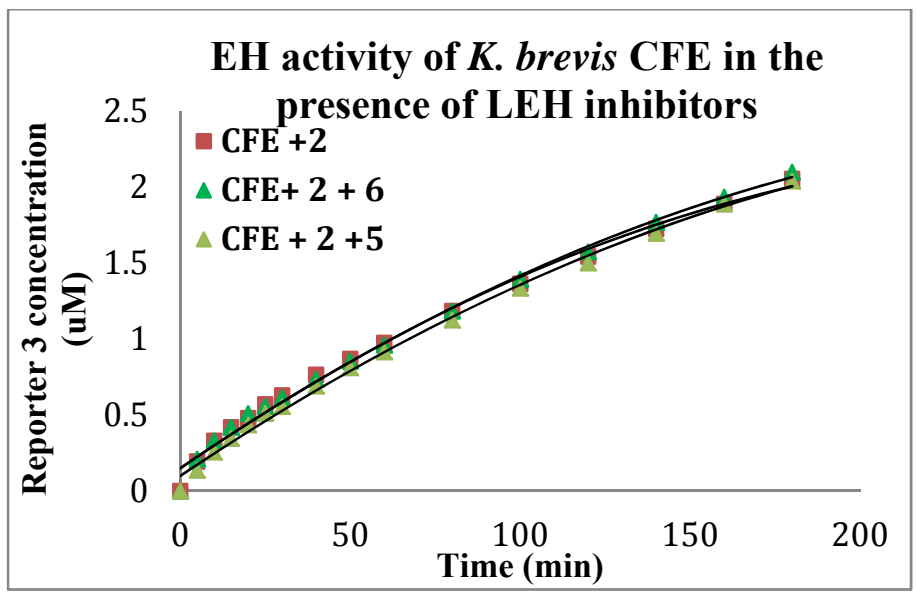

Figure 31. EH activity in K. brevis cultures and sensitivity to inhibitors (top: EH activity in $K$. brevis CFE in the presence of adamantyl urea; bottom: $\mathrm{EH}$ activity in K. brevis CFE in the presence of valpromide and hexylamine)

To insure the inhibition observed in the EH assay with adamantyl urea was a result of the inhibition of EH rather than esterase, and the sensitivity of the esterase assay to adamantly urea was examined using the alkene $\mathbf{1}$. No inhibition of esterase activity was observed under same condition (Figure 32).

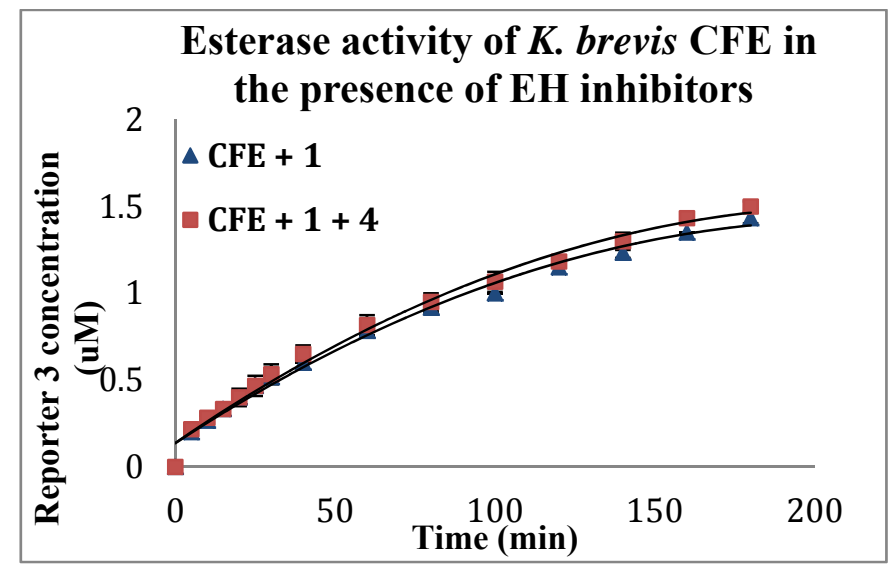

Figure 32. Esterase activity in K. brevis cultures and sensitivity to inhibitors

Among the three EH inhibitors, only adamantly urea $\mathbf{4}$ inhibited the total activity in the K. brevis CFE (Figure 31 top) when using the fluorescent probe $\mathbf{2}$ as the substrate. 
These data suggested that the observed EH activity in K. brevis CFE can be attributed, at least in part, to an EHs of the $\alpha, \beta$-hydrolase type.

\subsubsection{EH from cDNA library}

After detection of $\mathrm{EH}$ activity and inhibition with the known $\mathrm{EH}$ inhibitor adamantyl urea 4, efforts were made to identify EHs in K. brevis. A K. brevis cDNA library served as a resource to search for EHs.

\subsubsection{Screening from high salt condition}

An EH cDNA was isolated from the plant Solanum commersonii cDNA library by plating the cDNA library under high salt conditions $(0.8 \mathrm{M} \mathrm{NaCl})^{92}$. Of the $10^{6}$ bacterial cells plated, only thirteen colonies grew, yielding seven genes related to stress response including a soluble EH. The authors speculated that the EH was able to hydrolyze reactive epoxides produced during oxidative stress induced oxidative burst. The same strategy was used for searching EHs from a K. brevis cDNA library.

A cDNA library from $K$. brevis poly $(\mathrm{A})^{+}$RNA was constructed in a $\lambda$ ZAP

Express vector ${ }^{93}$. The phagemid was excised and host cells, E. coli strain, SOLR were infected. The cDNA library was plated on high salt plates $(2 \mathrm{YT}$ agar with $50 \mathrm{ug} / \mathrm{mL}$ ampicillin, 1mM isopropyl- $\beta$-D-thiogalactoside (IPTG) and $0.8 \mathrm{M} \mathrm{NaCl}$ ). One hundred sixty-six colonies $(\sim 2 / 3$ of what grew) were picked and streaked on the same media. Seventy-eight out of 166 grew and were inoculated into LB broth. The plasmids were extracted (Qiagen) and sent to Eurofins Genomics for sequencing using T3 primer. 
tBLASTx analysis was performed for all the sequences returned from Eurofins Genomics against the non-redundant protein database of NCBI. Some showed very high homology to known genes, such as that of the chloroplast light harvesting protein. However, many sequences did not share significant similarity with any known genes. Table 1 showed all the sequences with an $E$ value lower than $1 \mathrm{e}-4$ to some known sequence. Of forty-six sequence with an E value lower than 1e-4 to NCBI database, eight sequences showed homology to complete genome of some organisms, which lead to failure to identify the gene. For those assigned sequences, unfortunately, no EH-like genes were obtained. The survival strategies in high salt conditions for those recombinant cells are not known, but it's very interesting to find these genes are of high salt stress tolerance.

Table 1. High salt screening results

\begin{tabular}{|c|c|c|}
\hline Predicated protein & $\begin{array}{c}\text { Accession No. of most similar known } \\
\text { sequence }\end{array}$ & $E$-value \\
\hline Unknown & XM_002291564.1 & $9 \mathrm{e}-08$ \\
\hline Histone-like protein & AF482694.1 & $6 e-24$ \\
\hline Light harvesting protein & EF134091.1 & $3 e-88$ \\
\hline $\begin{array}{l}\text { Methionine S-adenosyl } \\
\text { transferase }\end{array}$ & AB461927.1 & $7 e-131$ \\
\hline PAP fibrillin family protein & XM_002293371.1 & $9 e-30$ \\
\hline RNA binding protein & EF134110.1 & $3 e-5$ \\
\hline n-acetylglucosamine-6- & XM_001568585.1 & $3 e-38$ \\
\hline
\end{tabular}




\begin{tabular}{|c|c|c|}
\hline phosphate deacetylase & & \\
\hline Oxidase-like protein & XM_002683903.1 & $9 e-22$ \\
\hline Unknown & СР001964.1 & $5 e-4$ \\
\hline $\begin{array}{c}\text { Carbamoyltransferase family } \\
\text { protein }\end{array}$ & XM_001315691.1 & $5 e-36$ \\
\hline TRP superfamily protein & XM_001637522.1 & $1 \mathrm{e}-10$ \\
\hline Unknown (basic nuclear protein) & EF134106.1 & $1 \mathrm{e}-15$ \\
\hline Plectin-like protein & XM_002611742.1 & $3 e-14$ \\
\hline $\begin{array}{c}\text { Calcium/calmodulin-dependent } \\
\text { protein kinase }\end{array}$ & XM_690776.2 & $1 e-3$ \\
\hline Unknown & XM_001737438.1 & $2 \mathrm{e}-22$ \\
\hline Amidase & СР000828.1 & $8 \mathrm{e}-158$ \\
\hline Unknown & GU554554.1 & $9 e-12$ \\
\hline Light harvesting protein & DQ118623.1 & $6 e-140$ \\
\hline Light harvesting protein & DQ118619.1 & $6 e-122$ \\
\hline TPR Domain containing protein & XM_001640397.1 & $2 \mathrm{e}-127$ \\
\hline Non-transporter $\mathrm{ABC}$ protein & XM_003080218.1 & $3 e-44$ \\
\hline $\begin{array}{l}\text { Phosphoadenosine- } \\
\text { phosphosulphate reductase }\end{array}$ & XM_002293751.1 & $2 e-32$ \\
\hline Kenesin & XM_002677784.1 & $4 e-23$ \\
\hline Light harvesting protein & DQ118623.1 & $4 e-129$ \\
\hline S-adenosylmethionine synthetase & DQ865292.1 & $1 e-43$ \\
\hline
\end{tabular}




\begin{tabular}{|c|c|c|}
\hline Unknown & GU554554.1 & $4 \mathrm{e}-13$ \\
\hline SET domain-containing protein & XM_002952571.1 & $5 e-13$ \\
\hline Chloride channel protein & XM_002772754.1 & $2 \mathrm{e}-6$ \\
\hline Ribosomal RNA protein & DQ779991.1 & $2 e-131$ \\
\hline phosphoglycerate mutase & XM_002677423.1 & $3 e-30$ \\
\hline CRE-GRSP-2 protein & СР000251.1 & $2 e-6$ \\
\hline Unknown & XM_002783593.1 & $1 \mathrm{e}-14$ \\
\hline $\begin{array}{l}\text { Kinesin-like calmodulin binding } \\
\text { protein }\end{array}$ & XM_002263113.1 & $8 \mathrm{e}-37$ \\
\hline WD40-repeat-containing protein & СР002013.1 & $4 e-32$ \\
\hline Ubiquitin-like protein & EU153190.1 & $5 e-85$ \\
\hline $\begin{array}{c}\text { Thioredoxin/protein disulfide } \\
\text { isomerase }\end{array}$ & GU555692.1 & $5 e-29$ \\
\hline Unknown & AC140319.3 & $5 e-5$ \\
\hline Hydroxylase & XM_002026350.1 & $5 e-7$ \\
\hline $\begin{array}{l}\text { Methyltransferase or } \\
\text { transcriptional regulatory protein }\end{array}$ & YP_003265741.1 & $3 e-33$ \\
\hline Adenosylhomocysteinase & EU742862.1 & $1 e-29$ \\
\hline $\begin{array}{c}\text { Structure specific recognition } \\
\text { protein }\end{array}$ & HP446650.1 & $1 \mathrm{e}-10$ \\
\hline Unknown & GU554259.1 & $5 e-18$ \\
\hline TPR repeat-containing protein & XM_002140365.1 & $2 \mathrm{e}-4$ \\
\hline
\end{tabular}




\begin{tabular}{ccc}
$\begin{array}{ccc}\text { SGNH-hydrolase superfamily } \\
\text { protein (lipase or esterase) }\end{array}$ & EU449488.1 & $4 \mathrm{e}-4$ \\
$\beta$-lactamase & GQ168544.1 & $1 \mathrm{e}-13$ \\
Nitrate transporter protein & HM147134.1 & $3 \mathrm{e}-35$ \\
\hline
\end{tabular}

\subsubsection{Screening from toxic chemicals}

Another strategy used to screen the K. brevis cDNA library was to grow the $E$. coli in the presence of antibacterial compounds, which can be hydrolyzed by an $\mathrm{EH}^{94}$. The same $K$. brevis cDNA library described above were plated on a M9 minimal media plate containing $0.2 \%$ glycidyl butyrate (Figure 33). After incubating overnight, only 12 colonies grew. The 12 colonies were then streaked on to LB plates to obtain single colonies. Plasmids were extracted through mini-prep and were sent to Eurofins Genomics for sequencing. After tBLASTx analysis, unfortunately, no EH-related genes were found. Table 2 showed all the sequences with an E value lower than 1e-4 to some known sequences. Four sequences were found to have an $E$ value lower than 1e-4 to the sequences in NCBI database. Only one sequence was able to identify as histone-like protein, the other three were unable to assign because they were similar either to a whole genome or cDNA of some organisms in NCBI database.

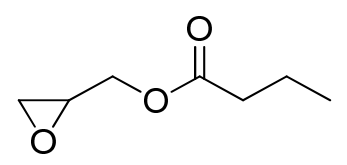

Figure 33. Structure of antibacterial compound, glycidyl butyrate 
Table 2. Screening using glycidyl butyrate

\begin{tabular}{ccc}
\hline Predicated protein & $\begin{array}{c}\text { Accession No. of most } \\
\text { similar known sequence }\end{array}$ & E-value \\
\hline Unknown & AC103411.8 & $6 \mathrm{e}-7$ \\
Unknown & GU555355.1 & $4 \mathrm{e}-7$ \\
Histone-like protein & AF482694.1 & $4 \mathrm{e}-31$ \\
Unknown & CU367609.1 & $2 \mathrm{e}-9$ \\
\hline
\end{tabular}

\subsubsection{Searching Expressed Sequence Tag (EST) library}

EST is a short sub-sequence of a cDNA sequence. EST libraries are usually used to identify gene transcripts. Sequences from a K. brevis EST library consisting of 65,000 ESTs (22,000 contigs) has been published by The Marine Genomics Project ${ }^{93}$. Data analysis was made to search for the three types of EHs within this library.

\subsubsection{Searching for $\alpha, \beta$-hydrolase $\mathrm{EH}$}

tBLASTn analysis of the K. brevis EST library against a variety of prokaryotic and eukaryotic EHs of the $\alpha, \beta$-hydrolase type revealed a transcript (MGID2034061) with significant homologies having Expect values ranging from $10^{-126}$ to $10^{-103}$. The identified EST coded for a 393 amino acid protein with a calculated molecular weight of $44.6 \mathrm{kD}$. BLASTp analysis of this protein against the NCBI non-redundant protein database returned a putative EH with Expect value of $10^{-126}$, from the polar, eukaryotic microalga Coccomyxa subellipsoidea ${ }^{95}$ as the closest match. Table 3 shows the alignment of the translated protein with the $\alpha, \beta$-hydrolase type $\mathrm{EH}$ from Aspergillus niger (NCBI 
Accession Number: CAB 49813.1 ${ }^{96}$. The two conserved catalytic tyrosine residues can be identified in the translated protein. However, the Asp-His-Asp catalytic triad is replaced with Asp-His-Glu, which suggests the newly found EH was a microsomal EH $(\mathrm{mEH})$ as all known mEHs except the EH from Aspergillus niger have a glutamic acid in their catalytic triad ${ }^{96-97}$.

Table 3. Alignment of putative K. brevis EH with Aspergillus niger EH. Catalytic residues are highlighted in red.

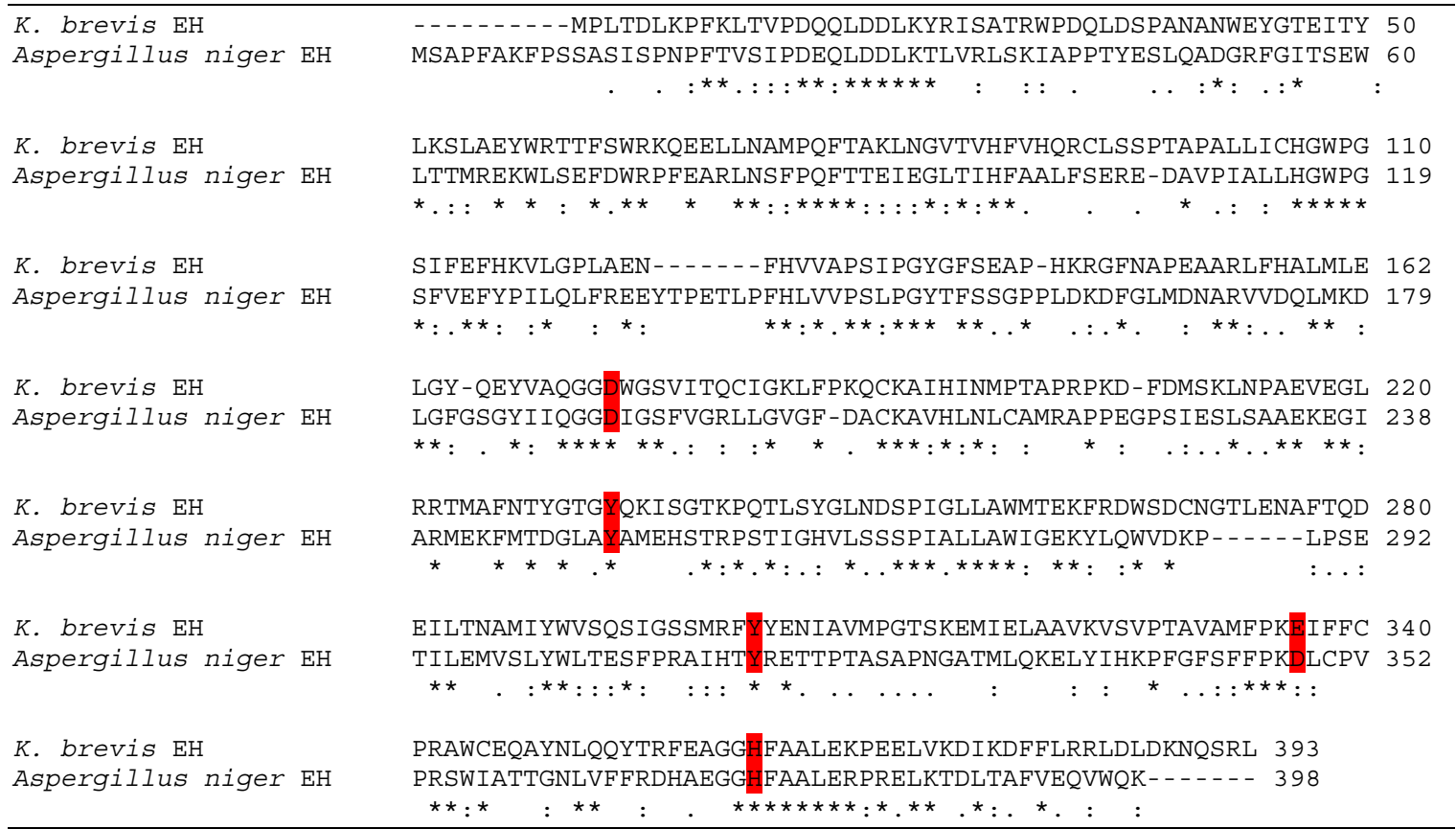

\subsubsection{Searching for limonene $\mathrm{EH}$}

tBLASTn ${ }^{98}$ analysis of a K. brevis EST library consisting of 22,000 predicted transcripts ${ }^{93}$ against Rhodococcus erythropolis LEH and nine other known or putative LEHs which are associated with biosynthetic gene clusters of bacterial polyethers: monenesin (MonB1 and MonB2), lasalocid (Lsd19A and Lsd19B), nanchangmycin (NanIA and NanIB), tetronomycin (TmnB), nigericin (NigB1 and NigB3) was 
performed. All failed to return any significant homologies with the smallest Expect values on the order of $10^{-5}$.

Even though data mining of EST library did not give any limonene EH, it still cannot exclude the possibility of limonene EH existing in K. brevis. Since many EHs have been identified, one possible way to search new EH from K. brevis based on the conserved region on the known EHs. The sequences including MonB1, MonB2, Lsd19A, Lsd19B, NanIA, NanIB, TmnB, NigB1 and NigB3 can be obtained from NCBI. Alignment of these known limonene EHs, revealed two conserved regions, 'EDPV' and 'GD(E)VD(E)'. Degenerate primers were designed based on these common residue sequences ${ }^{99}$. No conserved region was found near 3 ' end, an oligo dT primer was used as K. brevis is eukaryotic, with polyadenylated mature mRNA.

Table 4. Alignment of some known limonene EH involved in biosynthesis of polyether

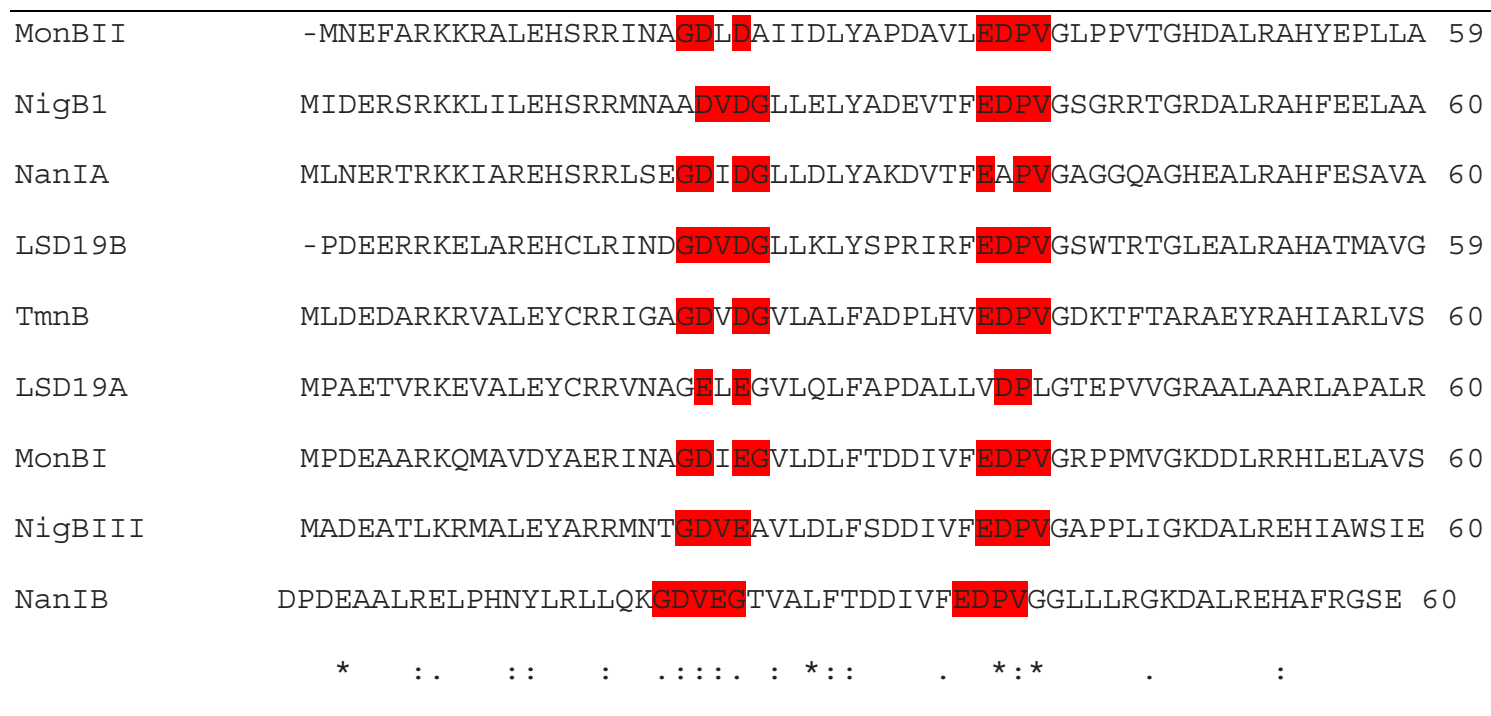

Total RNA was isolated from $K$. brevis. cDNA was obtained by using AMV reverse transcriptase (Invitrogen), K. brevis RNA as template and oligo dT as the primer 
for the first strand cDNA synthesis followed by second strands synthesis using taq DNA polymerase. Degenerate primers were designed to amplify EH by PCR using the double strandes cDNA as template. PCR conditions were varied through adjusting the annealing temperature and $\mathrm{Mg}^{2+}$ concentration. Gradient and touchdown protocols were also attempted for PCR. Unfortunately, with different conditions of PCR, products observable by gel electrophoresis were obtained infrequently, and all products were much smaller than expected size $(300 \sim 500 \mathrm{bp}$ ). The products were sent for sequencing and all the products turned out to be some unknown sequences without any homology to any other sequences.

Representatives of the limonene type of $\mathrm{EH}$ were not identified in either the library search or by PCR amplification, which, while unfortunate, is consistent with inhibition assays performed on the K. brevis CFE. The involvement of limonene EHs in the biosynthesis of bacterial polyethers has been firmly established and it has long been believed that the dinoflagellate derived polyether ladders share a common biogenic origin with bacterial polyethers including the involvement of one or more EHs.

\subsubsection{Searching for leukotriene- $\mathrm{A}_{4}\left(\mathrm{LTA}_{4}\right)$ hydrolase}

tBLASTn analysis against Emeliania huxleii LTA $_{4}$ hydrolase (NCBI Accession number: XP_005787867) returned a single transcript having an Expect value smaller than $10^{-5}\left(3 \times 10^{-6}\right)$. However, BLASTx analysis of the single transcript did not return significant homologies to any other $\mathrm{LTA}_{4}$ hydrolase. 


\subsubsection{Additional library searches}

Subsequent to these studies, three $K$. brevis reference transcriptome libraries containing 86,580 (Wilson strain), 93,668 (strain SP1) and 84,309 (strain SP3) predicted transcripts became available ${ }^{100}$. tBLASTn analysis of these transcriptome libraries against the 10 LEHs and the Emeliania huxleii $\mathrm{LTA}_{4}$ hydrolase were performed. Against the LEHs, a single transcript from the SP1 transcriptome returned an Expect value of less than $10^{-5}\left(4 \times 10^{-6}\right)$ against NanIB. However, BLASTx analysis against the NCBI nonredundant protein database did not return any significant homologies $\left(10^{-6}\right.$ or less). Against the Emeliania huxleii $\mathrm{LTA}_{4}$ hydrolase, six transcripts from each library with expect values ranging from $10^{-12}$ to $10^{-141}$ were identified. All 18 sequences are BLASTed against the database in NCBI, revealing the three transcripts with the lowest $\mathrm{E}$ value showed very high homology with known $\mathrm{LTA}_{4}$ hydrolase. These three sequences are from three libraries respectively and alignment results showed they are identical sequences. The remaining sequences were suggested to be aminopeptidase, which is not surprising because the query protein $\mathrm{LTA}_{4}$ hydrolase is a bifunctional protein, the second function of which is aminopeptidase ${ }^{101}$.

The cDNA sequence of the $\alpha, \beta$-EH which was found in Marine Genomics $K$. brevis EST library was used as a query for a nucleotide BLAST analysis of the three reference transcriptomes. Each of theses transcriptome libraries returned identical sequences (Locus 28231 from SP1; Locus 35217 from SP3; Locus 51025 from Wilson) each having Expect values ranging from $10^{-79}$ to $10^{-84}$. Additionally, a single transcript which was identical to the previously found EH was identified in the SP3 library (SP3 Locus 73930). When the newly identified sequence (Locus 28231 from SP1) was used as 
a query to search the Marine Genomics EST library, a single 50 bp sequence was returned which exactly matched the query. The alignment of these two $\alpha, \beta$-EHs is shown in Table 5.

Table 5. Alignment of two K. brevis mEHs. Catalytic residues are highlighted

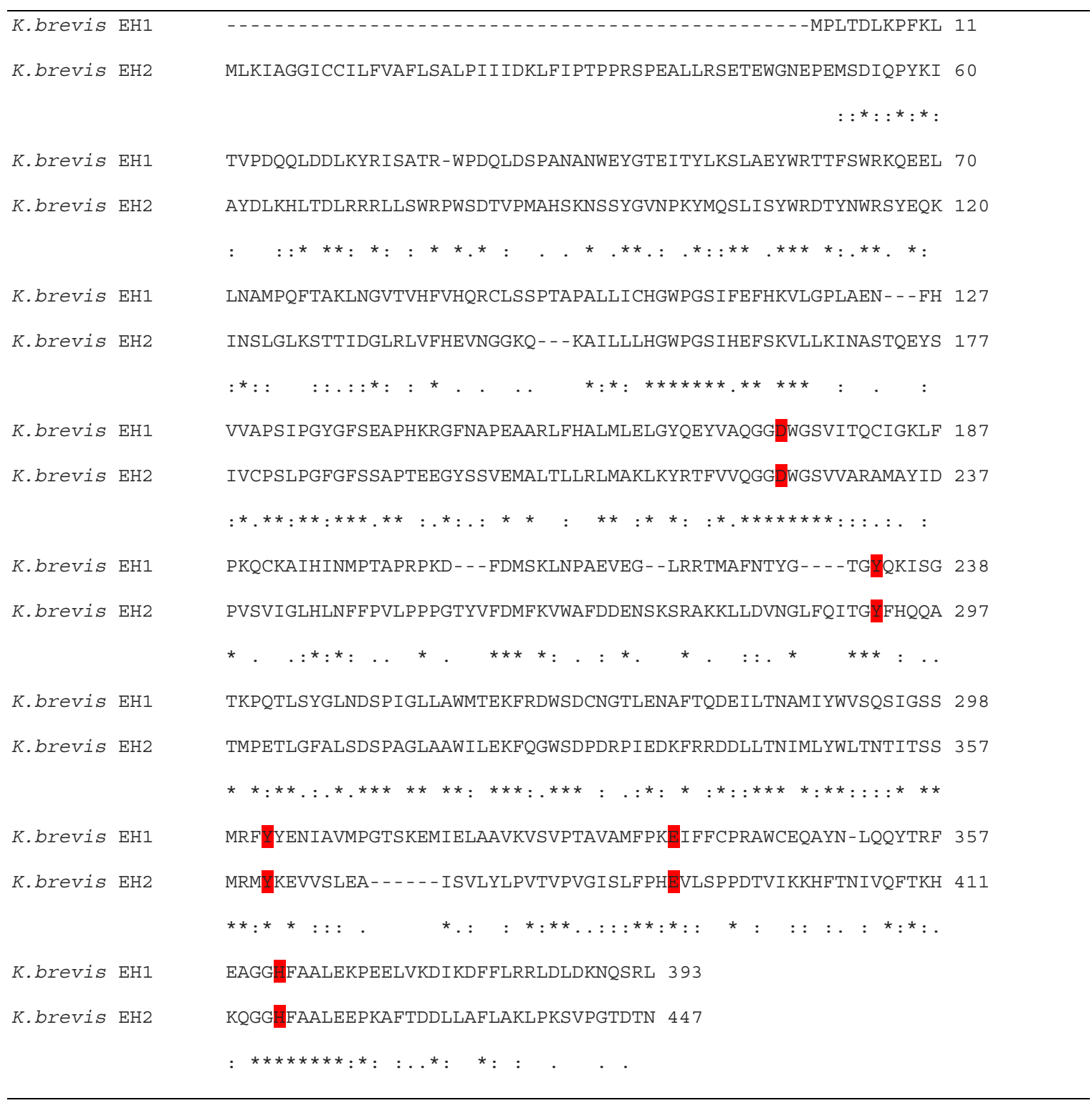




\subsubsection{Analysis of identified EHs}

As described previously, most known EHs are $\alpha, \beta$-fold EHs. In mammals, there are two types of $\alpha, \beta$-fold EHs: soluble (or cytosolic) EH (sEH) and microsomal EH $(\mathrm{mEH})$. The $\mathrm{mEHs}$ are believed to be involved in the metabolism of xenobiotics whereas the sEHs are thought to be involved in the metabolism of fatty acids ${ }^{69}$. However, only mammalian genomes encode both $\mathrm{sEH}$ and $\mathrm{mEH}$ whereas yeast, fungi, insects and plants encode only one type and the role of the absent EH type may be assumed by the other. These two types of EHs were first distinguished by their subcellular localization, but they were found to have distinct and complementary substrate specificity. Generally, sEH seems to prefer trans-di-, tri- and tetra- substituted epoxides, whereas $\mathrm{mEH}$ prefer monoand cis-di- substituted epoxides ${ }^{75}$. All the known mEH except that from Aspergillus niger have the catalytic triad Asp-His-Glu, whereas most sEH have an Asp-His-Asp instead. The mutation of glutamic acid in the rat $\mathrm{mEH}$ to aspartic acid increased the enzyme activity by more than an order or magnitude ${ }^{102}$. Mutation of aspartic acid in the Aspergillus niger EH to glutamic acid led to an activity reduction by half ${ }^{97}$. The mechanisms of these two enzymes are the identical, except difference in the aspartic acid and glutamic acid. Both of the two found EHs in K. brevis have glutamic acid rather than aspartic acid, suggesting they are $\mathrm{mEHs}$.

Besides the catalytic triad, a highly variable $\mathrm{N}$-terminal domain is another way to distinguish sEH and $\mathrm{mEH}$. Both of the $\alpha, \beta$ fold type EHs identified in K. brevis belong to the $\mathrm{mEH}$ class. The $\mathrm{N}$-terminal domains of $\mathrm{mEHs}$ are characterized by a microsomal domain which may or may not be preceded by an N-terminal membrane anchor. The membrane anchor is found in mammalian and insect $\mathrm{mEHs}$, but not in $\mathrm{EHs}$ from yeast, 
fungi or bacteria and is also absent in the two K. brevis mEHs. EHs may be further categorized according to the length of two loops: the NC-loop which links the N-terminal catalytic domain and the cap domain (the cap domain contains the two catalytic Tyr) and the cap-loop, which links two $\alpha$-helices ( $\alpha 6$ and $\alpha 7$ ) within the cap domain. The length of these loops may be determined from the pair wise alignment with the EH from A. niger (also an $\mathrm{mEH}$ ) or by inspection of a homology model constructed using the A. niger $\mathrm{EH}$ crystal structure as template ${ }^{103}$. In A. niger the NC loop is located from Leu215 to Leu249 (35 residues) whereas the cap-loop is located from Trp284 to Ser291 (8 residues). The lengths of the NC loops of the K. brevis EHs are 36 and 43 residues whereas both cap-loops are 14 residues. $\mathrm{mEHs}$ are characterized by having long to very long NCloops (33 or more residues) and short to medium cap-loops (8-36). The K. brevis NCloops and cap-loops would be considered very long and medium in length, respectively. The length of these domains is believed to govern the substrate selectivity of the EH and this combination of long/med NC-loop/cap-loop would suggest selectivity for aromatic epoxides.

\subsection{MATERIAL AND METHODS}

\subsubsection{Material}

Substrate 2 was prepared from trans-styrylacetic acid and 7-methoxy-2napthaldehyde, as previously described ${ }^{90}$. Chemicals were purchased from SigmaAldrich (St. Louis, MO). K. brevis culture (Wilson strains) were obtained from Mote Marine Laboratory (Sarasota, Florida) and maintained in L1-Si medium, with the exception that the NH 15 vitamin supplement ${ }^{104}$ replaced the L-1 supplement, in a 
growth chamber at $20^{\circ} \mathrm{C}$. Growth was monitored by counting a 1:10 dilution of culture in Z-pak reagent using a Beckman Z-series Coulter Counter with aperture size between $10 \sim 30 \mu \mathrm{m}$ according to the manufacturer's instructions. Coomassie Plus Protein Assay Reagent for Bradford assay was purchased from Pierce (Grand Island, NY). Absorbance and fluorescence were read on a Synergy ${ }^{\mathrm{TM}}$ 2, micro-plate reader from Bioteck Instrument, Inc (Winooski, VT). Reagents for the glucose-6-phosphate dehydrogenase assay were purchased from Sigma-Aldrich.

Reagents for RNA isolation were purchased from Sigma-Aldrich. 2YT agar for growing recombinant E. coli was purchased from Becton Dickinson (Franklin Lakes, NJ). Plasmid extraction kit (QIAprep Spin Miniprep Kit) was purhased from Qiagen (Valencia, CA). Sequencing was performed by Eurofins Genomics (Huntsville, AL).

\subsubsection{Methods}

Prep of K. brevis cell free extract (CFE)

K. brevis culture $(200 \mathrm{~mL})$ was concentrated by centrifugation $(5 \mathrm{~min}$ at $450 \mathrm{x}$ ) and the supernatant discarded. The cells were resuspended in phosphate buffer ( $800 \mu \mathrm{L}$, $50 \mathrm{mM} \mathrm{pH} \mathrm{7.0)}$ and vortexed for $1 \mathrm{~min}$. This suspension was centrifuged (14,000 $\mathrm{x} g$ for $10 \mathrm{~min}$ ) and the pellet was discarded. Homogenates were analyzed for protein concentration and glucose-6-phosphate dehydrogenase activity as described below. Typical protein concentrations ranged from $(0.25$ to $0.5 \mathrm{mg} / \mathrm{mL})$.

Bradford assay 
Protein concentration was determined by Bradford assay. Five concentrations of (Bovin serum albumin) BSA $(0 \mathrm{mg} / \mathrm{mL}, 0.5 \mathrm{mg} / \mathrm{mL}, 0.25 \mathrm{mg} / \mathrm{mL}, 0.0625 \mathrm{mg} / \mathrm{mL})$ in phosphate buffer (50 mM, pH 7.0) were prepared as standards. Commassie Protein Assay Reagent $(250 \mu \mathrm{L})$ was added to microplate wells and $20 \mu \mathrm{L}$ of standard or unknown sample were added. Absorbance was measured at $595 \mathrm{~nm}$ (Synergy $^{\mathrm{TM}}$ 2, Bioteck Instrument, Inc.) after incubation for $5 \mathrm{~min}$ at room temperature. Each protein solution was assayed in duplicate; error bars are smaller than data points.

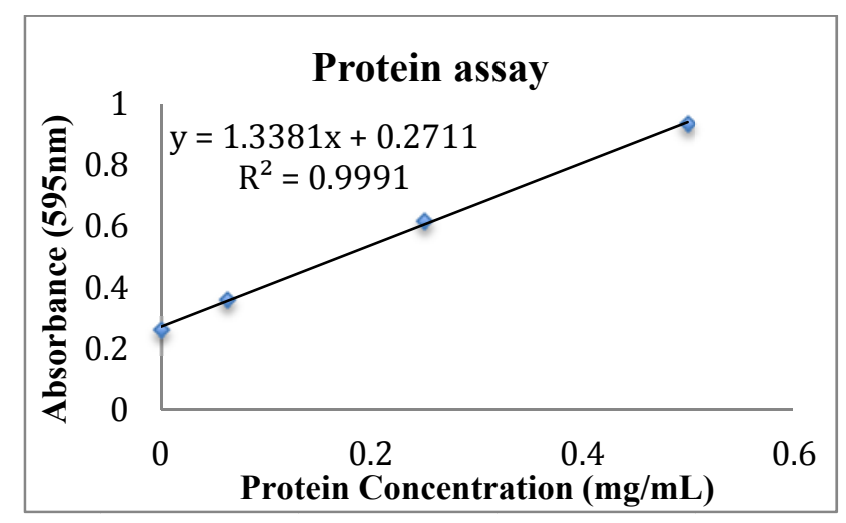

Figure 34. Standard curve for protein assay

Glucose-6-phosphate dehydrogenase (G6PD) activity

A glucose-6-phosphate dehydrogenase assay was performed as positive control prior to the EH assay. K. brevis homogenate $(150 \mu 1)$ was mixed with assay buffer $(50 \mu 1$, $31 \mathrm{mM}$ phosphate buffer, $7.5 \mathrm{mM}$ glucose-6-phophate, $2.5 \mathrm{mM}$ NADP, $38 \mathrm{mM} \mathrm{MgCl}$ ), Absorbance at $340 \mathrm{~nm}$ was determined (Synergy ${ }^{\mathrm{TM}}$ 2, Bioteck Instrument, Inc.) after incubation for 1 hour at room temperature. Boiled homogenate were also tested; typical 
activity of homogenate is more than twice that of boiled homogenate. Each sample was assayed in triplicate.

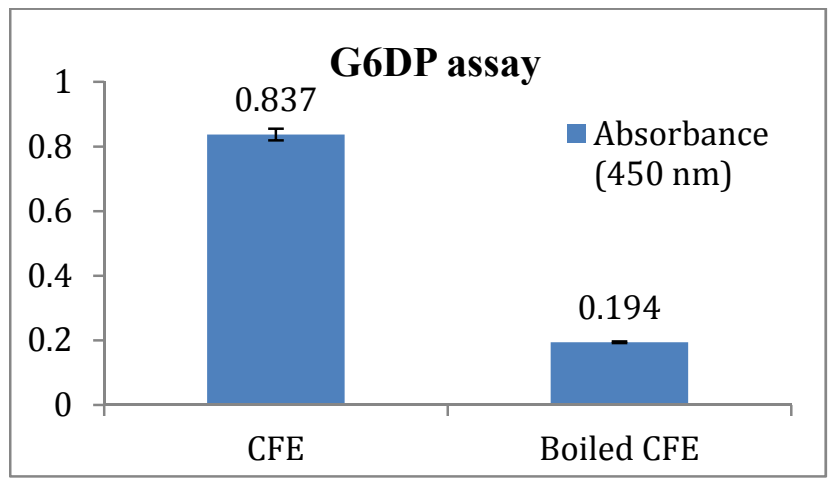

Figure 35. A typical G6PD assay

$\mathrm{EH} / \mathrm{esterase}$ assay

Fluorescent probe $\mathbf{1 / 2}(2 \mu \mathrm{L}, 10 \mathrm{mM}$ in DMSO, final concentration100 $\mu \mathrm{M})$ was added to K. brevis CFE $(198 \mu \mathrm{L})$ in duplicate. Fluorescence was monitored at $330 \mathrm{~nm}$ $\mathrm{EX} / 465 \mathrm{~nm}$ EM (Synergy ${ }^{\mathrm{TM}}$ 2, Bioteck Instrument, Inc.) every 5 minutes at $30^{\circ} \mathrm{C}$. For each data point, $\mathrm{n}=2$; the range is within the data point. The concentration of reporter 3 was calculated from a calibration curve prepared by measuring the fluorescence of 7methoxy-2-naphthaldehyde (reporter 3) $(0,3.1,12,25,50 \mu \mathrm{M}$ in phosphate buffer (50 $\mathrm{mM}$ phosphate, $\mathrm{pH}$ 7.0). Each reporter 3 solution was assayed in duplicate; error bars are smaller than data points. 


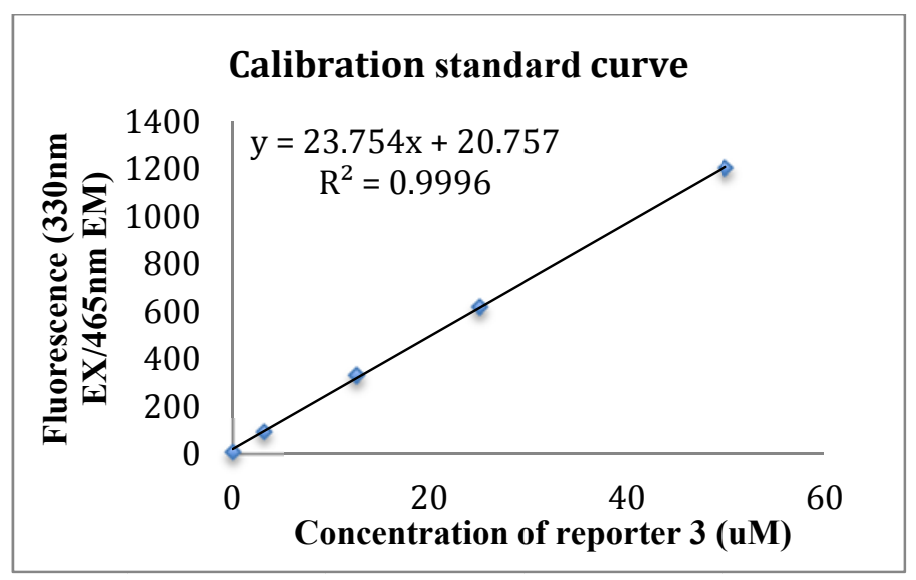

Figure 36. Calibration curve of fluorescent report 3

RNA isolation

Once EH activity is confirmed in $K$. brevis CFE, total RNA is extracted from $K$. brevis as follows: $K$. brevis culture $(100 \mathrm{~mL})$ was centrifuged $(450 \times \mathrm{g}$ for $5 \mathrm{~min})$ at $20^{\circ}$ C. The pellet was resuspended in water $(100 \mu \mathrm{L})$. Denaturing solution $(600 \mu \mathrm{L}, 5 \mathrm{M}$ guanidium thiocyanate, $50 \mathrm{mM}$ Tris $\mathrm{pH} 8,25 \mathrm{mM}$ sodium citrate, $0.5 \% \mathrm{w} / \mathrm{v}$ Sarkosyl, $2 \%$ PEG, 0.1 M DTT) was added. After standing at room temperature for 10 minutes, NaOAc (60 $\mu \mathrm{L}, 3 \mathrm{M}, \mathrm{pH} 5.2)$ was added and the mixture was vortexed. An equal volume of phenol: chloroform: isoamyl alcohol (125:24:1, $\mathrm{pH} 4.3)$, was added and the mixture centrifuged at $\left(14,000 \mathrm{x} \mathrm{g}\right.$ for 15 minutes) at $4^{\circ} \mathrm{C}$. The top (aqueous) phase was transferred to a new tube followed by the addition of equal volume chloroform: isoamyl alcohol (24:1) and the mixture was vortexed. After centrifugation at $(14,000 \times g$ for 15 minutes) at $4^{\circ} \mathrm{C}$, the top (aqueous) phase was transferred to new tube which contains equal volume of ice cold EtOH. RNA was allowed to precipitate at -20 degrees overnight. The mixture was centrifuged at $4^{\circ} \mathrm{C}$, for (30 minutes at $14,000 \times \mathrm{g}$ ) and the pellet was 
washed with cold $70 \% \mathrm{EtOH}(700 \mu \mathrm{L})$. After air-drying, the pellet was reconstituted in water $(50 \mu \mathrm{L})$. Total RNA concentration was quantitated using the Nanodrop 2000 (Thermo Scientific)

PCR reactions

Degenerate primers were designed based on the conserved region mentioned previously. Two forward primers (GTATATTGYNCARGGNGGNGAYTGG) and (TACCNWSNHTNCCNGGNTAYGGNT) were paired with oligo dT primer respectively. The PCR reaction components were mixed according to the Taq DNA polymerase manufacurer's instructions. The concentration of each component in PCR are as following: dNTP $(200 \mu \mathrm{M})$, reaction buffer $(1 \mathrm{x})$, primers $(0.05-1 \mu \mathrm{M}$ for both forward and reverse), template cDNA ( $<1,000 \mathrm{ng})$, Taq DNA polymerase (1.25 unit/50 $\mu \mathrm{L}$ PCR). Typical reactions were carried out by using the following steps: initial denaturation at 94 ${ }^{\circ} \mathrm{C}$ for 2 minutes followed by 35 cycles of $94{ }^{\circ} \mathrm{C}$ for 15 seconds (denaturation), $65{ }^{\circ} \mathrm{C}$ for 30 seconds (annealing), and $68{ }^{\circ} \mathrm{C}$ for 30 seconds (extension). Gradient annealing temperatures $\left(65,63,61,59,57,55,53,51{ }^{\circ} \mathrm{C}\right)$ were used to find optimize condition. A touchdown reaction with annealing temperature decrease from 65 to $51^{\circ} \mathrm{C}$ in first eight cycles was also tested. 


\section{CLONING, EXPRESSION AND ANALYSIS OF EH}

\subsection{INTRODUCTION}

As described in the previous chapter, one EH was found from the Marine Genomics Project K. brevis EST library. It could be heterologously expressed in bacteria. To find evidence to support the hypothesis that $\mathrm{EH}$ from polyether ladder producing dinoflagellates will catalyze the construction of polyether ladder framework from polyepoxide substrates, it is necessary to carry out a series of in vivo enzymatic reactions. Similar behavior on proposed natural substrates and on designed substrates would strongly support the role of EH in brevetoxin biosynthesis.

In this chapter, one EH from K. brevis was cloned, expressed and characterized using different substrates. The potential of this EH in semi-enzyme synthesis of cyclic ethers was evaluated using a simple substrate trans-4,5-epoxy-hexanol. The EH activity and relative EH mRNA levels were evaluated in two strains of K. brevis in an effort to identify a correlation between EH activity or mRNA expression with the brevetoxin content.

\subsection{RESULTS AND DISCUSSION}

\subsubsection{Cloning and expression of K. brevis $\mathrm{EH}$}

As the EH was to be expressed in E. coli, optimization of the codon usage is necessary to improve the heterologous expression. The EH sequence found in K. brevis EST library was sent to Genescript (Piscataway, NJ) for optimization and synthesis. The optimized EH DNA sequence was synthesized and cloned into pUC19 by Genescript. 
Table 6 shows the native and optimized sequence, the nucleoside without the stars are optimized for E. coli codon usage.

Table 6. Comparison of optimized (for E. coli) and native K. brevis EH sequence

\begin{tabular}{|c|c|c|}
\hline optimized & ATGCCGCTGACGGATCTGAAACCGTTCAAACTGACCGTTCCGGATCAGCAGCTGGATGAT & 60 \\
\hline \multirow[t]{2}{*}{ native } & ATGCCGTTGACTGATTTGAAACCCTTTAAGCTTACTGTGCCTGATCAGCAGCTGGATGAT & 60 \\
\hline & 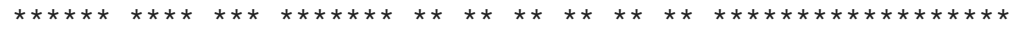 & \\
\hline optimized & CTGAAATATCGTATCTCTGCCACCCGCTGGCCGGATCAGCTGGATAGTCCGGCGAACGCC & 120 \\
\hline \multirow[t]{2}{*}{ native } & TTAAAGTATCGCATCTCTGCCACACGCTGGCCAGACCAGCTGGATTCACCTGCTAATGCA & 120 \\
\hline & 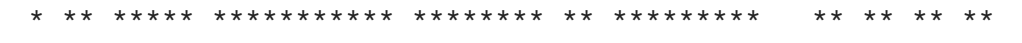 & \\
\hline optimized & AATTGGGAATATGGCACCGAAATTACGTACCTGAAAAGCCTGGCAGAATACTGGCGTACC & 180 \\
\hline \multirow[t]{2}{*}{ native } & AACTGGGAATATGGGACTGAAATCACTTACTTGAAAAGCTTGGCGGAATACTGGCGCACC & 180 \\
\hline & $* * \quad * * * * * * * * * * * \quad * * \quad * * * * * \quad * * \quad * * * \quad * * * * * * * * \quad * * * * \quad * * * * * * * * * * * \quad * * *$ & \\
\hline optimized & ACGTTTTCTTGGCGCAAACAGGAAGAACTGCTGAACGCAATGCCGCAGTTCACGGCGAAA & 240 \\
\hline \multirow[t]{2}{*}{ native } & ACGTTCAGCTGGCGTAAACAAGAAGAGCTTCTCAATGCAATGCCCCAGTTTACTGCAAAG & 240 \\
\hline & 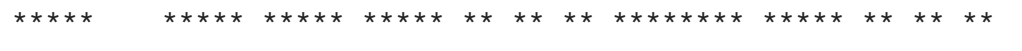 & \\
\hline optimized & CTGAATGGCGTGACCGTTCATTTTGTTCACCAGCGTTGCCTGAGCTCTCCGACCGCACCG & 300 \\
\hline \multirow[t]{2}{*}{ native } & CTGAACGGTGTGACAGTGCACTTTGTTCACCAGCGCTGCTTGAGCAGTCCGACAGCACCT & 300 \\
\hline & 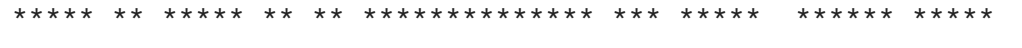 & \\
\hline optimized & GCACTGCTGATTTGTCATGGCTGGCCGGGTAGCATCTTTGAATTCCACAAAGTGCTGGGT & 360 \\
\hline \multirow[t]{2}{*}{ native } & GCTCTGCTGATTTGCCATGGCTGGCCAGGCTCTATCTTTGAGTTTCACAAGGTGCTGGGT & 360 \\
\hline & $* * \quad * * * * * * * * * * * \quad * * * * * * * * * * * \quad * * \quad * * * * * * * * \quad * * \quad * * * * * \quad * * * * * * * * *$ & \\
\hline optimized & CCGCTGGCCGAAAACTTTCATGTGGTTGCACCGAGTATTCCGGGCTATGGTTTTAGCGAA & 420 \\
\hline \multirow[t]{2}{*}{ native } & ССTTTGGCTGAGAATTTCCATGTCGTCGCCCCATCTATTCCTGGGTATGGCTTCTCAGAG & 420 \\
\hline & 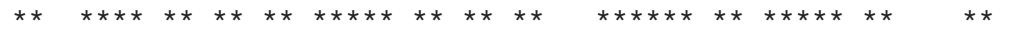 & \\
\hline optimized & GCGCCGCATAAACGTGGTTTCAATGCACCGGAAGCAGCACGTCTGTTTCACGCACTGATG & 480 \\
\hline \multirow[t]{2}{*}{ native } & GCTCCACACAAGCGTGGTTTCAACGCTCCGGAAGCAGCCCGTTTGTTTCATGCACTCATG & 480 \\
\hline & 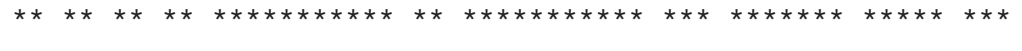 & \\
\hline optimized & CTGGAACTGGGTTATCAGGAATACGTTGCGCAGGGCGGTGATTGGGGCTCTGTGATTACG & 540 \\
\hline \multirow[t]{2}{*}{ native } & СTTGAGCTTGGATATCAAGAGTACGTCGCTCAAGGAGGTGATTGGGGGTCGGTGATCACG & 540 \\
\hline & 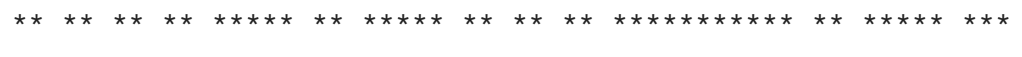 & \\
\hline optimized & CAGTGCATCGGTAAACTGTTTCCGAAACAGTGTAAAGCAATTCACATCAACATGCCGACC & 600 \\
\hline \multirow[t]{2}{*}{ native } & CAATGCATAGGCAAGCTGTTTCCAAAGCAGTGCAAAGCCATCCACATCAACATGCCAACG & 600 \\
\hline & 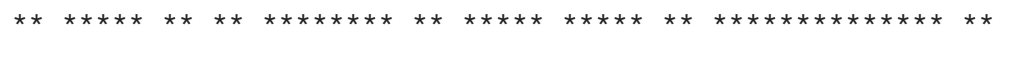 & \\
\hline optimized & GCACCGCGTCCGAAAGATTTCGATATGTCTAAACTGAACCCGGCAGAAGTGGAAGGTCTG & 660 \\
\hline \multirow[t]{2}{*}{ native } & GCACCACGTCCGAAGGACTTCGACATGTCCAAGCTGAATCCAGCAGAAGTAGAAGGCCTA & 660 \\
\hline & 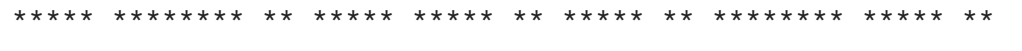 & \\
\hline optimized & CGTCGCACGATGGCATTTAATACCTATGGCACGGGTTACCAGAAAATCAGTGGTACCAAA & 720 \\
\hline
\end{tabular}




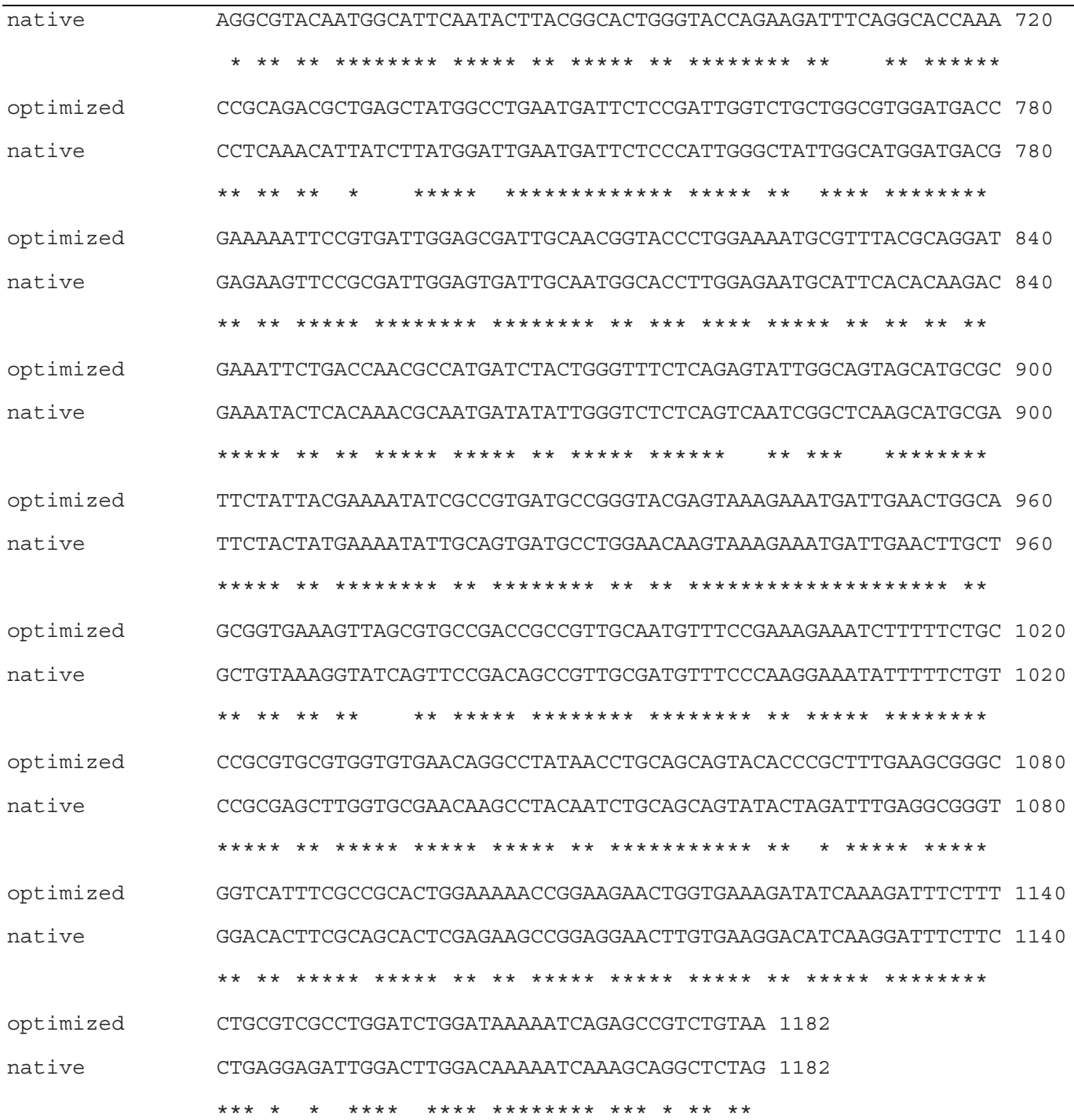

Specific primers (Forward: CACAATCATATGCCGCTGACGGA, Reverse: AATAAGCTTTAATGATGATGATGATGATGCAGACGGCTCTGATTTTTAT) were designed to amplify the codon optimized K. brevis EH. The primers incorporated HindIII (reverse primer) and NdeI (forward primer) restriction sites for directional cloning and 6 histidine codons (reverse primer). Because NdeI needs at least 6 extra nucleotides at both sides of cutting site, the amplified gene was first ligated into a TA vector, pCR2.1 to improve digestion efficiency. The recombinant $\mathrm{pCR} 2.1-\mathrm{KbEH}$ was then transformed into 
E. coli competent cells and extracted using a mini-prep kit (Qiagen). After double digestion with HindIII and NdeI, the KbEH gene and expression vector pET30a+ were ligated to construct the final recombinant plasmid (Figure 37).

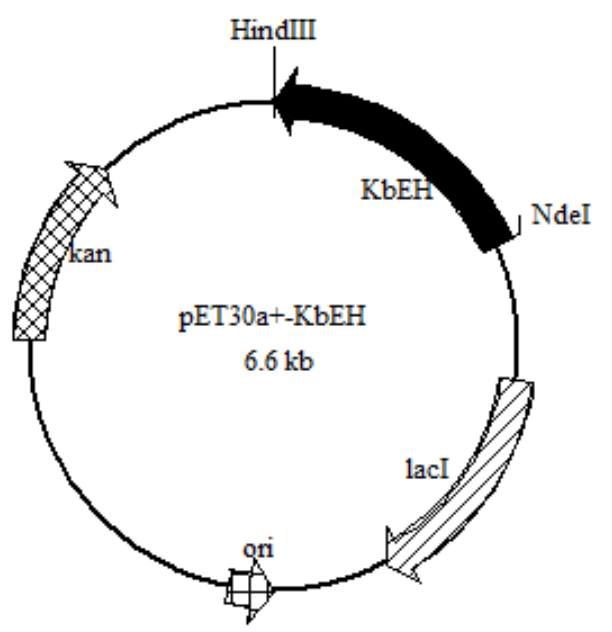

Figure 37. Recombinant pET-30a+-KbEH

The recombinant plasmid pET30a+ was transformed into E. coli strain BL21/DE3 for protein expression. After induction by IPTG, protein was then extracted and purified by nickel affinity chromatography. Molecular mass was confirmed to be $44 \mathrm{kD}$ by SDS polyacrylamide gel electrophoresis (PAGE) comparing with protein ladder (Figure 38). 


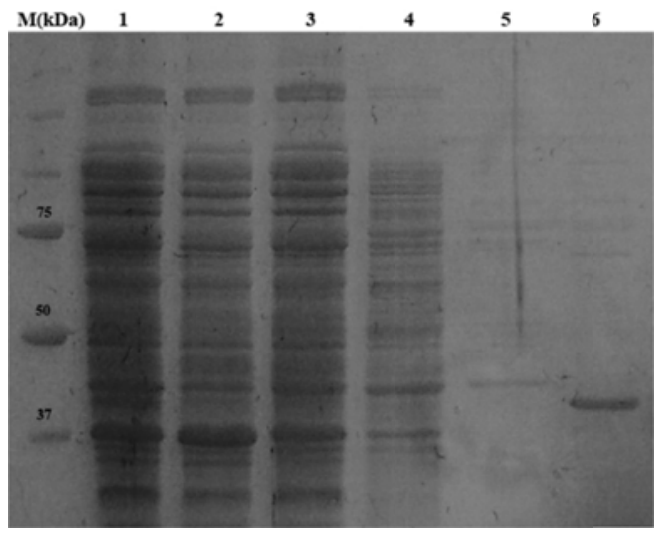

Figure 38. SDS PAGE of expressed EH after purification and dialysis. Lanes M: Precision Plus Protein Unstained Standards (Bio-Rad 161-0363) lane 1: lysate; lanes 2-3: column flowthrough; lanes 4-5: column washes by washing buffer; lane 6: eluted by elution buffer.

\subsubsection{Optimization of $\mathrm{pH}$ for $\mathrm{EH}$ assay}

In order to better study the characters of $\mathrm{EH}$, the assay conditions should be optimized. $\mathrm{pH}$ is one of the most essential factors for enzyme activity. K. brevis CFE dissolved in different $\mathrm{pH}$ phosphate buffer were incubated with fluorescent probe. The result (Figure 39) showed that when $\mathrm{pH}$ was 7.0, the $\mathrm{EH}$ had the best activity. All subsequent assays were performed in $\mathrm{pH} 7.0$ phosphate buffer.

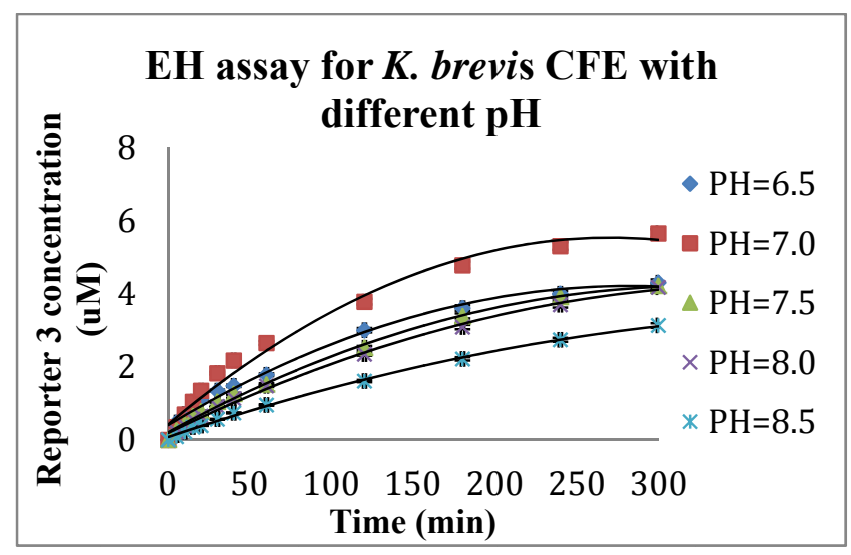

Figure 39. Optimization of $\mathrm{pH}$ for $\mathrm{EH}$ activity 


\subsubsection{EH vs Esterase activity}

The EH found in the Marine Genomics K. brevis EST library is an $\alpha, \beta$-fold EH, which belongs to $\alpha, \beta$-fold hydrolase superfamily. Esterases, the hydrolase enzymes that hydrolyze esters into an acid and an alcohol, also belong to this superfamily ${ }^{81}$. In the method we used to determine EH activity, if the enzyme is an esterase rather than EH, the fluorescent report will also be produced, as shown in Figure 27.

In order to confirm the enzyme obtained is $\mathrm{EH}$ rather than esterase, the precursor of the fluorescent probe without the epoxide group was used as the substrate in the assay. The expressed protein showed no activity with the alkene demonstrating that the enzyme was EH.

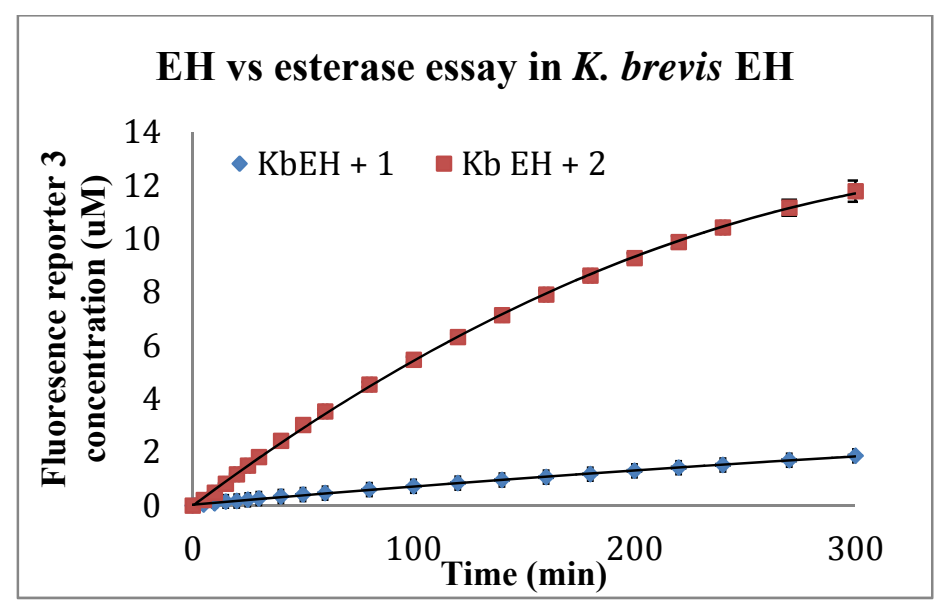

Figure 40. EH vs esterase activity in K. brevis EH

\subsubsection{Optimization of fluorescent substrate}

It was reasoned that a substrate containing aliphatic rather than aromatic substituents would be more representative of the native substrate if it were involved in 
brevetoxin biosynthesis. Thus a second probe $\mathbf{2} \mathbf{b}$ was prepared from trans-3-hexenoic acid according to the procedure described by Jones for the synthesis of $\mathbf{2}^{90}$.

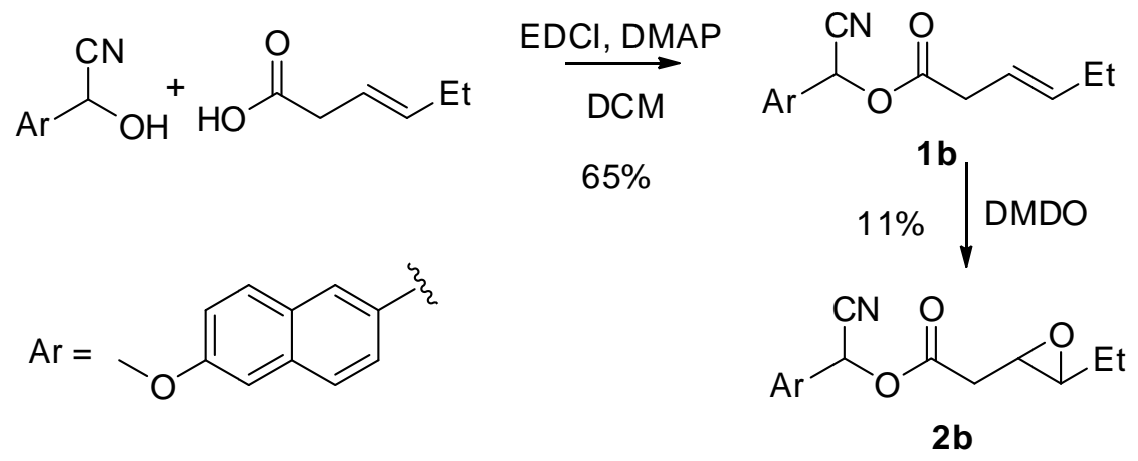

Figure 41. Preparation of an aliphatic substituted fluorescent probe

Activity was detected in K. brevis CFE using both probes, but probe $\mathbf{2 b}$ proved to be the better substrate as anticipated (Figure 42). The ratio of initial rates $\left(\mathrm{V}_{\mathrm{o}}\right)$ for substrates 2: 2b was 1:3.

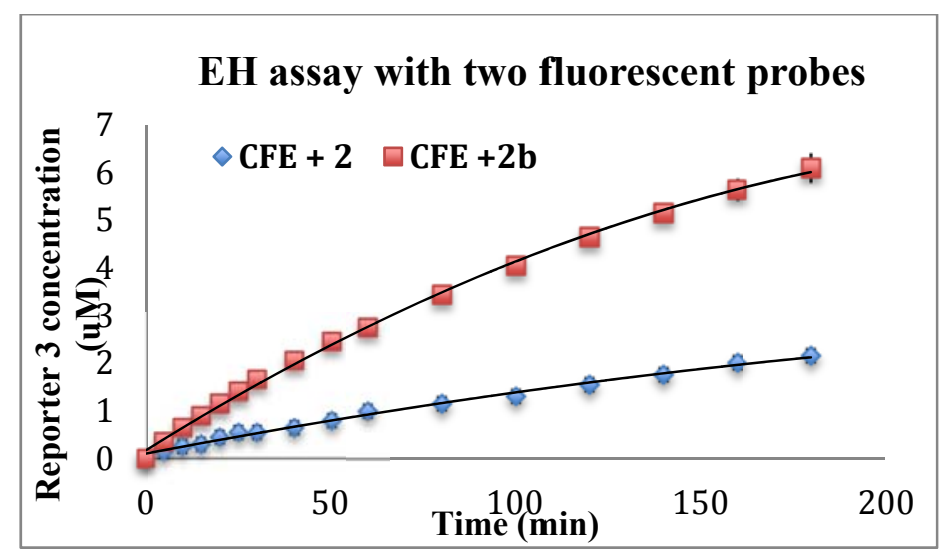

Figure 42. EH activity using two different substrates

\subsubsection{Characterization of K. brevis EH}

Substrate and enantioselectivity of the K. brevis EH was assessed by kinetic studies. Kinetic parameters of the enzyme using substrates $\mathbf{2}$ and $\mathbf{2} \mathbf{b}$ were performed 
using the sensitive fluorescent assay with different substrate concentration $(100 \mu \mathrm{M}$, $75 \mu \mathrm{M}, 50 \mu \mathrm{M}$ and $25 \mu \mathrm{M})$. Other substrates having no fluorescent reporter group were evaluated by GC-MS analysis of the reaction mixtures using 1-naphthol as an internal standard. A standard curve was obtained by using different substrate/internal standard ratio $(10: 1,8: 1,6: 1,4: 1,2: 1,1: 1,1: 2,1: 4,1: 6,1: 8,1: 10)$. Figure 43 shows the molar ratio vs GC-MS response ratio of styrene oxide and internal standard.

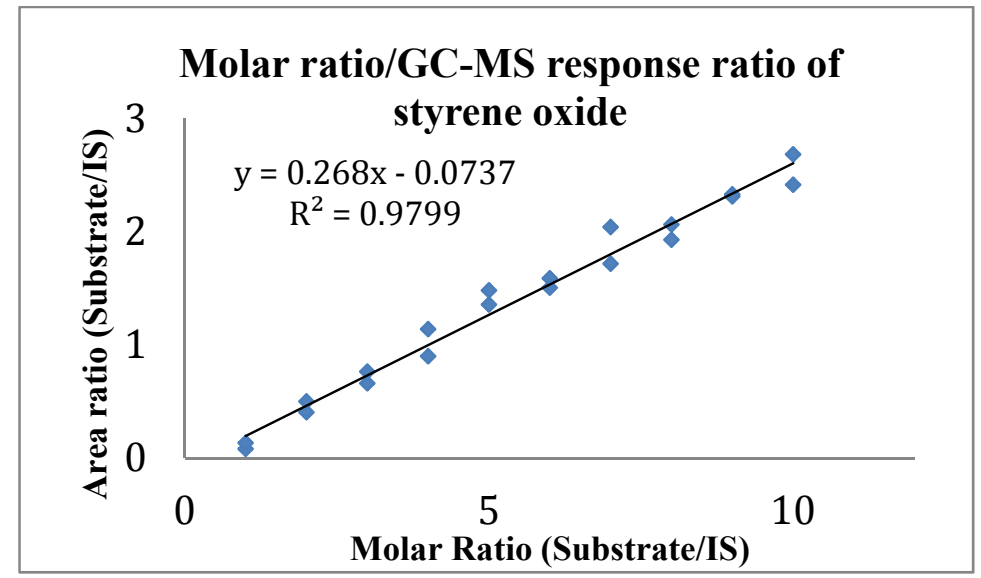

Figure 43. Molar ratio/GC-MS response ratio of styrene oxide

Enantiomers of styrene oxide and 1-butane oxide were used to evaluate the enantioselectivity of the enzyme. Figure 44 shows the substrates used in kinetic studies. 


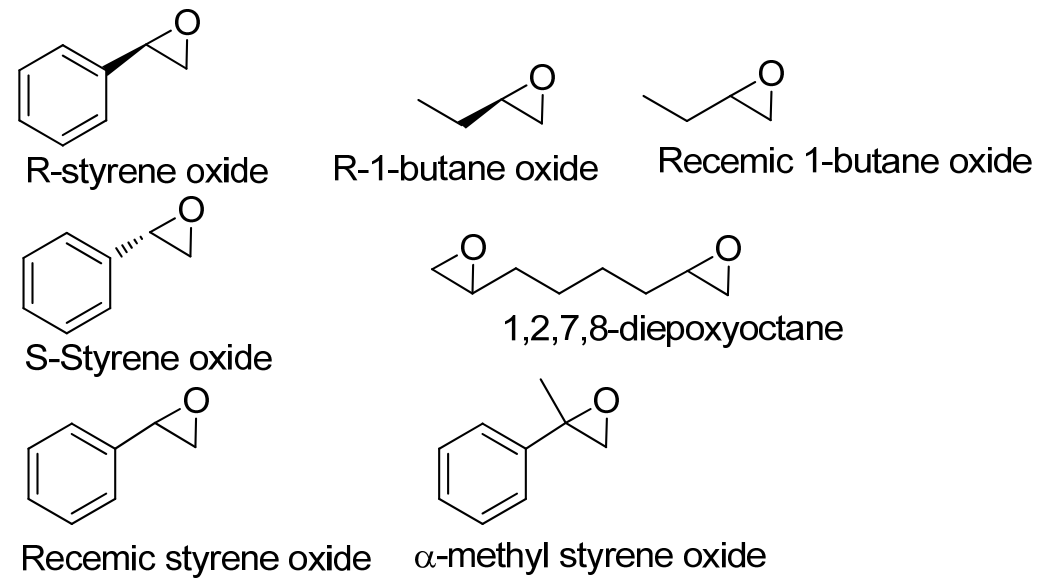

Figure 44. Epoxide substrates used in kinetic studies.

The data shown in Table 7 indicates that aliphatic substitutents are preferred over aromatic substituents by approximately 5:1 and the enzyme shows only a slight preference for $R$ over $S$ enantiomers.

Table 7. Kinetic parameters of the K. brevis EH with various substrates

\begin{tabular}{cccc}
\hline Substrate & $\mathrm{K}_{\mathrm{M}}(\mu \mathrm{M})$ & $\mathrm{k}_{\mathrm{cat}}\left(\mathrm{sec}^{-1}\right)$ & $\mathrm{k}_{\mathrm{cat}}\left(\mathrm{sec}^{-1}\right) / \mathrm{K}_{\mathrm{m}}(\mathrm{M})$ \\
\hline Probe $2(\mathrm{R}=\mathrm{Ph})$ & 13.6 & $7.81 \mathrm{E}-4$ & 57.4 \\
Probe $2 \mathrm{~b}(\mathrm{R}=\mathrm{Et})$ & 161 & $4.46 \mathrm{E}-3$ & 27.7 \\
$(R)$ styrene oxide & 6240 & $9.01 \mathrm{E}-1$ & 144 \\
(S) styrene oxide & 6430 & $8.32 \mathrm{E}-1$ & 129 \\
Racemic styrene oxide & 6570 & $8.58 \mathrm{E}-1$ & 131 \\
a-methylstyrene oxide & 5310 & $3.31 \mathrm{E}-1$ & 62.3 \\
$(R)$ 1-butane oxide & 25,800 & 6.15 & 238 \\
Racemic 1-butane oxide & 22,200 & 5.36 & 241 \\
1,2,7,8-diepoxyoctane & 4800 & 7.12 & 1480 \\
\hline
\end{tabular}

With the exception of the fluorescent probes $\mathbf{2}$ and $\mathbf{2 b}$, all the substrates above are terminal epoxides. Other substrates with substituentes on both ends of epoxide were synthesized from the corresponding alkene by epoxidation with dimethyldioxirane 
(DMDO) ${ }^{105}$ and tested, but the reaction rates were too slow to be determined using the GC-MS method. However, disubstituted epoxides proved to be competitive inhibitors of the K. brevis EH. Fluorescent probe $\mathbf{2 b}$ was used as substrate $(100 \mu \mathrm{M})$, along with different concentrations of these non-terminal epoxides as inhibitors. $\mathrm{IC}_{50}$ data was obtained for the aromatic inhibitors. No inhibition was observed when using cis-2,3epoxybutane and 2,3-dimethyl-2,3-epoxybutane as inhibitors. Data in table 8 showed cis$\beta$-methylstyrene oxide has the lowest $\mathrm{IC}_{50}$, which indicated it was the most preferred substrate among these substrates. This is consistent with the previous reports that microsomal EH prefer cis- over trans- substituted epoxides ${ }^{75}$.<smiles>C/C=C/c1ccccc1</smiles><smiles>CC1OC1c1ccccc1</smiles>

trans $\beta$-methylstyrene oxide

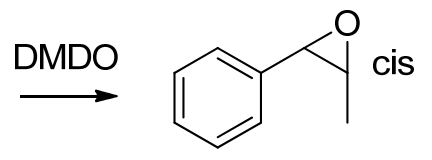
cis- $\beta$-methylstyrene oxide<smiles>CC(C)=Cc1ccccc1</smiles><smiles>C/C=C\c1ccccc1</smiles>

$$
\text { cis- }
$$<smiles>CC1(Cl)OC1c1ccccc1</smiles>

$\beta$-dimethylstyrene oxide

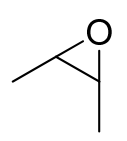

cis-2,3-epoxybutane

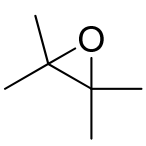

2,3-dimethyl-2,3-epoxybutane

Figure 45. Non-terminal epoxides

Table $8 . \mathrm{IC}_{50}$ for non-terminal epoxides using fluorescent probe $2 \mathrm{~b}$ as substrate

\begin{tabular}{lc}
\hline \multicolumn{1}{c}{ Substrate } & $\mathrm{IC}_{50}(\mathrm{mM})$ \\
\hline cis- $\beta$-methylstyrene oxide & 3.05 \\
trans- $\beta$-methylstyrene oxide & 14.28 \\
$\beta$-dimethylstyrene oxide & 6.99 \\
\hline
\end{tabular}


cis-2,3-epoxybutane

2,3-dimethyl-2,3-epoxybutane

\subsubsection{Assesment of EH catalysis of a cyclization reaction}

A noteworthy distinction between the monensin pathway and the proposed brevetoxin pathway is the site of nucleophilic attack on the epoxide substrate (Figure 45). In the case of non-ladder polyethers, the majority of epoxide ring opening reactions proceed via attack at the proximal carbon (exo-tet cyclization) while polyether ladder formation requires attack at the distal carbon (endo-tet cyclization). Both the empirical Baldwin's rules ${ }^{44}$ and molecular orbital calculations indicate that the endo-tet cyclization pathway is kinetically disfavored. The exception among the bacterial polyketides is lasalocid. In this polyether, the pyran ring arises from the endo-tet cyclization of an intermediate epoxide. This reaction is catalyzed by the EH Lsd19. Lsd19 is a bifunctional enzyme consisting of two domains (A and B). Each domain is responsible for the cyclization of one of the rings. Lsd19B catalyzes the endo-tet cyclization (Figure 14 in chapter 1).

The ability of the K. brevis EH to perform cyclization was also evaluated. As the natural substrate analog of K. brevis are highly challenging to synthesize, the substrate trans-4,5-epoxy-hexanol 7 was prepared as previously described ${ }^{105}$. This substrate may undergo endo-tet cyclization to produce pyran $\mathbf{8}$, or exo-tet cyclization to produce furan 9, or simple epoxide hydrolysis to produce the triol 10 . The substrate was incubated with the expressed EH in reaction buffer and the reaction was monitored by GC-MS. All three possible products were identified by GC-MS ${ }^{105}$, by comparison with authentic samples 
however, neither the percent conversion nor the product ratio differed from that of the buffer alone.

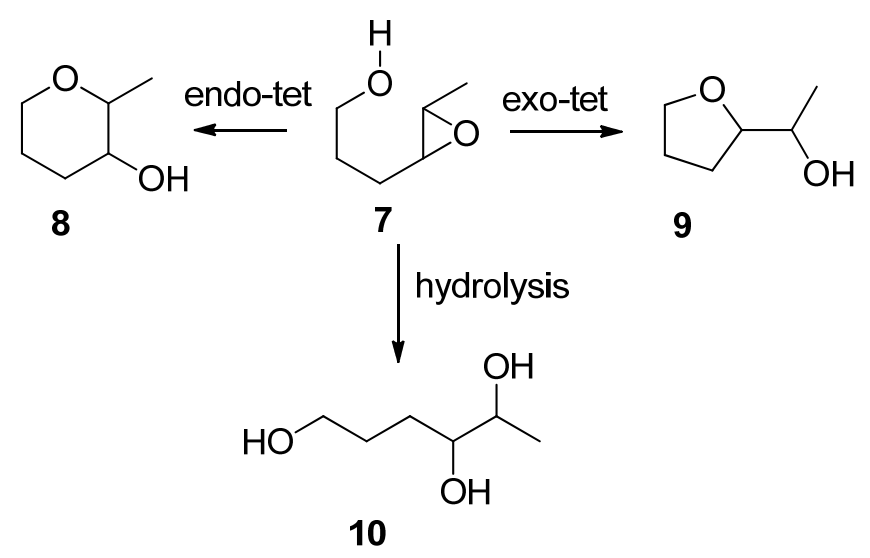

Figure 46. Alternate cyclization reactions or hydrolysis

3.2.7 EH activity/expression and toxin content over the life of a culture

Two cultures of $K$. brevis whose toxin content differs by ten-fold were evaluated over a period of three weeks for EH activity and EH mRNA levels. Both cultures are of the Wilson strain. However, toxin production of one culture suddenly dropped for reasons which are not yet understood. We are unaware of any studies which have uncovered any metabolic differences between these two cultures until now.

$\mathrm{EH}$ activity was assessed using the EH/esterase probe set $1 \mathrm{~b} / 2 \mathrm{~b}$ (ethyl probes). Esterase activity, determined using probe 1b, was subtracted from total activity. Cultures were diluted on day 0 to equal cell counts $(\sim 20,000$ per $\mathrm{mL})$ and monitored over a 21 day period. As shown in figure 47, 48, EH activity for the high toxin culture was consistently higher than that of the low toxin culture. On average, EH activity for the high toxin culture was $18 \%$ and $60 \%$ higher than the low-toxin culture when normalized to protein content or to cell counts, respectively. Over the three weeks that the cultures were 
monitored, both showed a slight drop in $\mathrm{EH}$ activity when normalized to protein content and an increase in activity when normalized to cell counts.
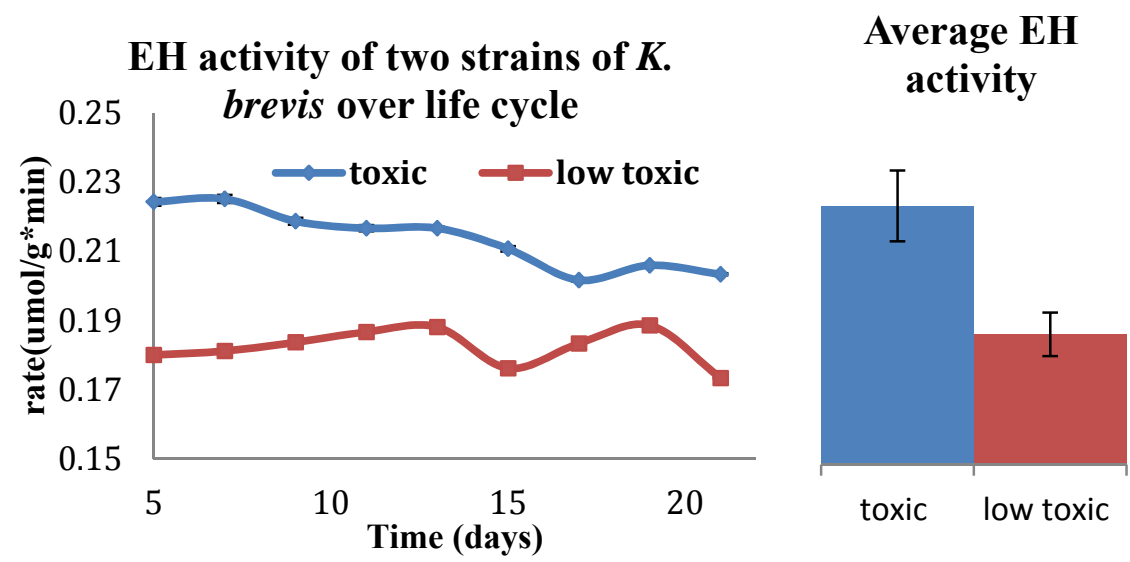

Figure 47. Left: EH activity of two strains of K. brevis over a 21 day period; right: average EH activity of two strains of $K$. brevis over 21 day period (normalized to protein concentration)

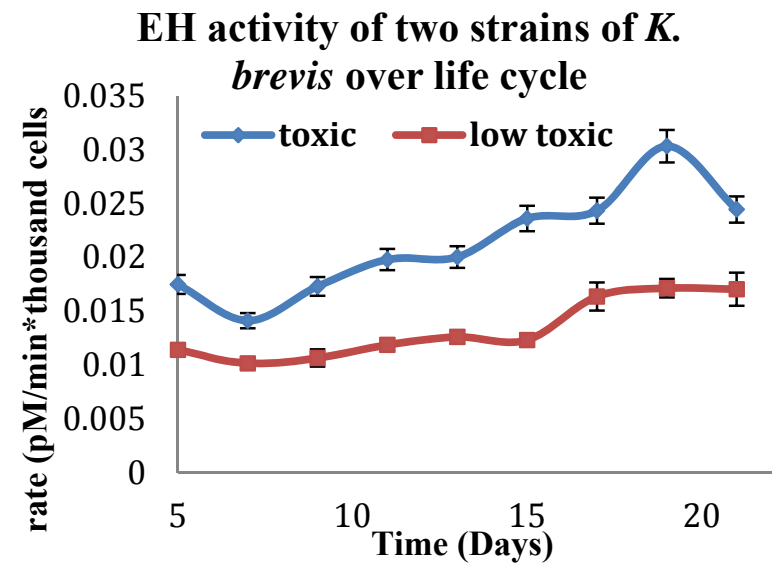

\section{Average EH activity}

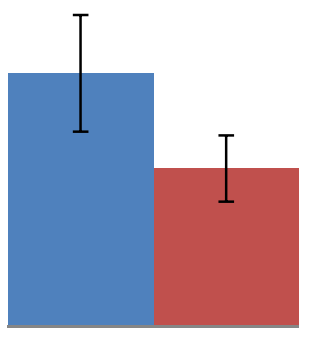

toxic low toxic

Figure 48. EH activity of two strains of $K$. brevis over a 21 day period; right: average EH activity of two strains of $K$. brevis over 21 day period (normalized to thousand cells)

Expression of the EH mRNA was also monitored over the same period by QPCR. Figure 49 shows the ratio of cycle thresholds $(\mathrm{Ct})$ for the EH mRNA normalized to RuBisCO mRNA. As higher $\mathrm{Ct}$ results from less mRNA, EH mRNA levels of the low 
toxin culture were either lower (Ct higher) or equal to that of the high toxin culture when normalized to RuBisCO. On average over the life of the culture, EH mRNA amount in two strains has a significant difference, even though gene expression in dinoflagellates is believed to occur principally at the translational level ${ }^{106}$.
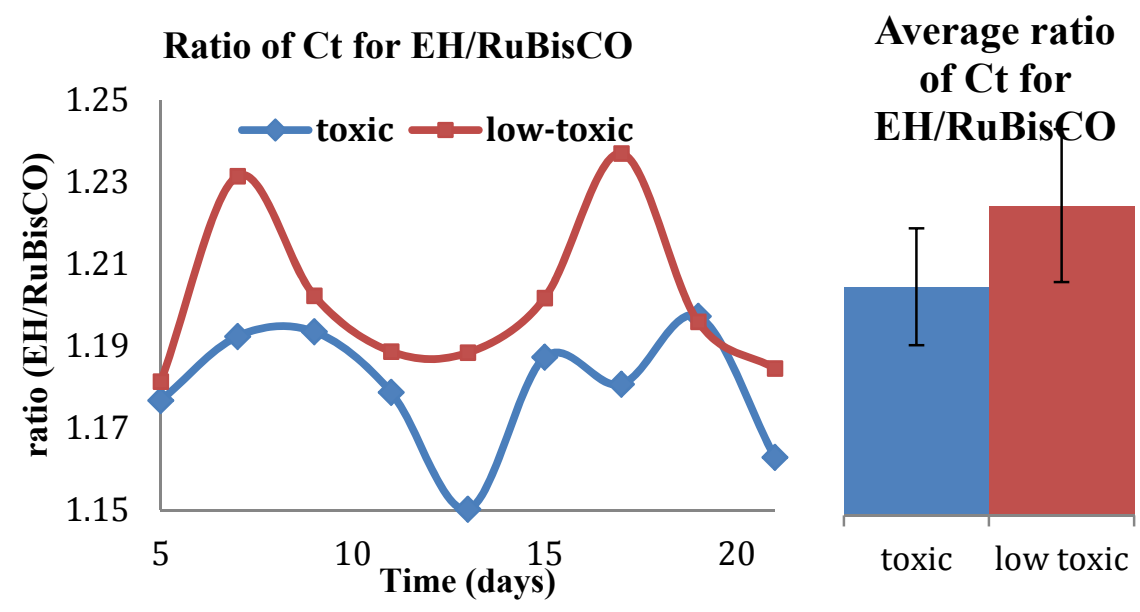

Figure 49. Left: Ratio of $\mathrm{C}_{\mathrm{t}}$ for $\mathrm{EH} / \mathrm{RuBisCO}$ for low and high toxin K. brevis; right: Average ratio of $\mathrm{Ct}$ for $\mathrm{EH} / \mathrm{RuBisCO}$

\subsection{CONCLUSIONS}

The EH identified from K. brevis EST library was cloned and expressed in E. coli. SDS-PAGE showed the EH was the anticipated size of $44 \mathrm{kD}$. The enzyme was confirmed to be an EH rather than esterase by comparing activity with two fluorescent probes $\mathbf{1}$ and $\mathbf{2}$. No activity was observed with the esterase probe $\mathbf{1}$.

As natural substrates of $K$. brevis $\mathrm{EH}$ would be very challenging to synthesize, other simple substrates were used to obtain indirect evidence of EH involvement of brevetoxin biosynthesis. The selectivity of the expressed $K$. brevis $\mathrm{EH}$ for aliphatic epoxides coupled with the consistently higher level of EH activity in the high toxin vs low toxin cultures of $K$. brevis is intriguing and may implicate the involvement of the $\mathrm{EH}$ 
in brevetoxin biosynthesis. However, the expressed EH did not appear to be capable of catalyzing the cyclization of epoxy alcohol 7 to either a furan or pyran. However, epoxy alcohol 7 may not sufficiently resemble the native substrate. Lsd19 was also not capable of catalyzing the cyclization of monoepoxy alcohol which was significantly smaller than pre-lasalocid.

The K. brevis EH showed a preference for terminal epoxides over non-terminal epoxides. Inhibition studies using fluorescent probes as substrate, and other epoxides as competitive inhibitors revealed preference for cis- over trans- substituted internal epoxides. Even with terminal epoxides, the $\mathrm{k}_{\mathrm{cat}}$ was lower than those observed for soluble EHs. All these are consistent with microsomal EH characters.

The $K$. brevis EH showed only slight enantioselectivity on $R$ over $S$ enatiomer with a ratio of 1.08 for $R / S$ styrene oxide and 1.15 for $R / S$ 1-butane oxide. It has further been suggested that an epoxidase could catalyze both the epoxidation and cyclization for PE ladder formation without the need for EH involvement. Therefore, further studies on epoxidase in K. brevis would possible reveal what is responsible for the enatioselectivity in ladder polyether compound biosynthesis.

\subsection{MATERIAL AND METHODS}

\subsubsection{Material}

Gene expression vector pET-30a+ and expression E. coli strain BL21/de3 were kindly provided by Dr. Leng (FIU). Restriction Enzymes NdeI and HindIII were purchased from New England Biolabs (Beverly, MA). High fidelity DNA polymerase $P f x 50$ kit and TOPO TA cloning kit were purchased from Invitrogen (Grand Island, NY). 
Primers were designed using the Primer-BLAST on NCBI and synthesized by Invitrogen (Grand Island, NY). QIAprep Spin Miniprep Kit, Qiaquick gel extraction kit and Ni-NTA agarose were purchased from Qiagen (Germantown, MD). Bacterial Protein Extraction reagent (B-PER) was purchased from Thermo Scientific. Unstained Protein Ladders were purchased from Bio-Rad. PCR reactions were performed on a Eppendorf Mastercycler Gradient thermal cycler. Optical density $\left(\mathrm{OD}_{600}\right)$ was measured with a micro-plate reader (Synergy $^{\mathrm{TM}} 2$ from Bioteck Instruments, Inc.) Protein expression induction reagent isopropyl- $\beta$-D-thiogalactoside (IPTG) was purchased from Sigma-Aldrich. LB agar and LB broth were purchased from Becton Dickinson (Franklin Lakes, NJ). The substrates of $\mathrm{EH}$, such as styrene oxide, 1-butane oxide or their corresponding precursor alkene, such as trans-methylstyrene, cis-methylstyrene were purchased from Sigma-Aldrich. iQ SYBR Green Supermix was purchased from Bio-Rad (Hercules, CA). Q-PCR reactions were performed using a DNA Engine from MJ Research (now Bio-Rad).

\subsubsection{Methods}

Amplification of EH gene

Pfx50 DNA polymerase, which offers 50 times better fidelity than Taq DNA polymerase, was used to amplify the target gene. The PCR reaction components were mixed according to the $p f x 50$ DNA polymerase manufacurer's instructions. The concentration of each component in PCR are as following: dNTP $(200 \mu \mathrm{M})$, reaction buffer (1x), primers $(0.05-1 \mu \mathrm{M}$ for both forward and reverse), template DNA $(<1,000$ ng) taq DNA polymerase (1.25 unit/50 $\mu \mathrm{L}$ PCR). The reactions were carried out by using the following steps: initial denaturation at $94{ }^{\circ} \mathrm{C}$ for 2 minutes followed by 35 cycles of 
$94{ }^{\circ} \mathrm{C}$ for 15 seconds (denaturation), $65{ }^{\circ} \mathrm{C}$ for 30 seconds (annealing), and $68{ }^{\circ} \mathrm{C}$ for 30 seconds (extension).

Ligation of PCR products and TA vector

The PCR products were treated with 2 units of Taq DNA polymerase for 30 minutes to add an "A" at both 5 and 3' ends. The PCR products were then purified by running an agarose gel and the band of the anticipated size was extracted from the gel using Qiagen Gel Extration kit. The ligation was performed using Invitrogen TOPO TA cloning kit by following the manufacture's instructions. The recombinant plasmid was transformed into Invitrogen's Mach1 TM competent E. coli cells provided with the cloning kit. After incubating and shaking in SOC medium at $37^{\circ} \mathrm{C}$ (250 rpm for 1 hour), $50 \mu \mathrm{L}$ transformed E. coli cells were spread on LB agar with ampicillin $(50 \mu \mathrm{g} / \mathrm{mL})$ and X-gal $(40 \mu \mathrm{g} / \mathrm{mL})$ and incubated at $37^{\circ} \mathrm{C}$ overnight. White colonies were picked and grown in LB broth $(5 \mathrm{~mL})$ with ampicillin $(50 \mu \mathrm{g} / \mathrm{mL})$. Plasmids were extracted using QIAprep Spin Miniprep Kit (Qiagen) according to the manufacturer's instructions.

Recombination of EH gene with pET-30a+

The pCR TOPO plasmid containing the EH gene insert and expression vector pET-30a + were digested by NdeI and HindIII at $37^{\circ} \mathrm{C}$ for 4 hours. The EH gene $(1.2 \mathrm{~kb})$ with cohesive ends was separated through agarose gel electrophoresis and extracted using the Gel Extration kit (Qiagen). Doubly enzyme-digested EH gene was ligated to the NdeI and HindIII restriction sites of the expression vector pET-30a+ using T4 DNA ligase (Invitrogen) according to the manufacturer's instructions. 
The newly constructed plasmid was transformed into the expression strain BL21(DE3) by electroporation. Transformed cells were spread on LB agar plates supplemented with kanamycin $(50 \mu \mathrm{g} / \mathrm{mL})$. These were then cultivated at $37{ }^{\circ} \mathrm{C}$ overnight. Twenty colonies were picked randomly and grown in LB broth with kanamycin $(50 \mu \mathrm{g} / \mathrm{mL})$. Plasmids were extracted using QIAprep Spin Miniprep Kit (Qiagen) according to the manufactuer's instructions. Clones of the E. coli BL21(DE3) containing recombinant plasmid $(6.6 \mathrm{~kb})$ were selected by comparing the size of plasmids through agarose gel electrophoresis. The recombinant plasmids were sent to Eurofins Genomics for sequencing using T7 primer and T7 terminator primer, to insure the fidelity of the insert sequence. Glycerol stock were prepared by adding 15\% sterilized glycerol and stored at $-80{ }^{\circ} \mathrm{C}$ until use.

\section{Protein Expression and purification}

The E. coli BL21/DE3 with recombinant pet30a+-KbEH was inoculated into LB broth with kanamycin $(50 \mu \mathrm{g} / \mathrm{mL})$ and shaken at $37{ }^{\circ} \mathrm{C}(250 \mathrm{rpm})$ overnight. The overnight culture $(5 \mathrm{~mL})$ was diluted into fresh LB broth $(500 \mathrm{~mL})$ with kanamycin $(50$ $\mu \mathrm{g} / \mathrm{mL})$, shaken at $37^{\circ} \mathrm{C}$ (250 rpm for $2 \sim 3$ hour). IPTG (1mM final concentration) was added when the $\mathrm{OD}_{600}$ reached to $0.6 \sim 0.8$. After shaking another $4 \sim 6$ hour, the culture was centrifuged (5000 x $g$ for $10 \mathrm{~min})$. Lysozyme $(2 \mu \mathrm{L}, 50 \mathrm{mg} / \mathrm{mL})$ and DNAse I (2 $\mu 1$, 2500 unit/mL) as well as Bacterial Protein Extraction reagent (B-PER, Thermo Scientific, $4 \mathrm{~mL} /$ gram of cells) were added to resuspend the pellets. After incubation at room temperature for $10 \mathrm{~min}$, the lysate was centrifuged $(15000 \mathrm{x} \mathrm{g}$ for $5 \mathrm{~min})$ to separate insoluble proteins. The supernatant was loaded on to a column of $1 \mathrm{~mL} \mathrm{Ni-NTA}$ agarose 
(Qiagen), which was pretreated with $10 \mathrm{~mL}$ phosphate buffer (20 mM phosphate, $0.5 \mathrm{M}$ $\mathrm{NaCl}, 5 \mathrm{mM}$ imidazole, $10 \%$ glycerol, $\mathrm{pH}$ 7.9). The column was washed by washing buffer (20 mM phosphate, $0.5 \mathrm{M} \mathrm{NaCl}, 20 \mathrm{mM}$ imidazole, 10\% glycerol, $\mathrm{pH}$ 7.9) until no more protein was eluted (as determined by $\mathrm{A}_{280}$ ) in the wash (typically $10 \mathrm{~mL}$ ). This was followed by elution buffer ( $20 \mathrm{mM}$ phosphate, $0.5 \mathrm{M} \mathrm{NaCl}, 250 \mathrm{mM}$ imidazole, $10 \%$ glycerol, $\mathrm{pH}$ 7.9) until no more protein was eluted also as determined by $\mathrm{A}_{280}$. The purified EH was dialyzed (MW cutoff $12-14 \mathrm{kD}$ ) in phosphate buffer (50 mM sodium phosphate, $\mathrm{pH}$ 7.0) at $0^{\circ}$ to $4^{\circ} \mathrm{C}$, overnight, flash frozen in liquid nitrogen and stored at $80^{\circ} \mathrm{C}$ until use.

\section{SDS-PAGE}

Protein samples were mixed at 4:1 volume ratio with $5 \mathrm{x}$ loading buffer $(10 \% \mathrm{w} / \mathrm{v}$ SDS, $10 \mathrm{mM} \beta$-mercapto-ethanol, 20\% v/v glycerol, $0.2 \mathrm{M}$ Tris-HCl, $\mathrm{pH} 6.8,0.05 \% \mathrm{w} / \mathrm{v}$ bromophenol blue), boiled for $5 \mathrm{~min}$. The mixed protein samples and loading buffer (10 $\mu$ l) were separated by SDS-PAGE with stacking gel $(1.25 \mathrm{~mL} 0.5 \mathrm{M}$ Tris- $\mathrm{HCl}, \mathrm{pH} 6.8$, $0.025 \mathrm{~mL} \mathrm{20 \% (w/v)} \mathrm{SDS,} 0.67 \mathrm{~mL}$ acrylamide/bis-acrylamide (30\%/0.8\% w/v), 0.025 $\mathrm{mL} \mathrm{10 \% (w/v)} \mathrm{ammonium} \mathrm{persulfate} \mathrm{(APS),} 0.005 \mathrm{~mL}$ TEMED, $3.075 \mathrm{~mL} \mathrm{H}_{2} \mathrm{O}$ ) and separating gel $(7.5 \mathrm{~mL} 1.5 \mathrm{M}$ Tris- $\mathrm{HCl}, \mathrm{pH} 8.8,0.15 \mathrm{~mL} \mathrm{20 \% (w/v)} \mathrm{SDS,} 15 \mathrm{~mL}$ acrylamide/bis-acrylamide $(30 \% / 0.8 \% \mathrm{w} / \mathrm{v}), 0.15 \mathrm{~mL} 10 \%(\mathrm{w} / \mathrm{v})$ ammonium persulfate (APS), $0.02 \mathrm{~mL}$ TEMED, $7.2 \mathrm{~mL} \mathrm{H}_{2} \mathrm{O}$ ).

Probe synthesis 
The fluorescent probe $\mathbf{2}$ was prepared as previously described ${ }^{90}$. A second probe $\mathbf{2 b}$ was prepared in a procedure identical to that of $\mathbf{2}$ except that (E)-4-phenylbut-3-enoic acid was replaced with (E)-pent-2-enoic acid. Both alkene and epoxide were purified by radial chromatography on a chromatotron (Harrison Research Corp.) using plates coated with silica gel 60 PF254 containing gypsum, using 5:1 hexane/ethyl acetate. Spectroscopic data for probe 2 were consistent with literature data ${ }^{90}$. ${ }^{1} \mathrm{H}-\mathrm{NMR}$ and ${ }^{13} \mathrm{C}$ NMR data were acquired on a Bruker Avance spectrophotometer (400 MHz for proton). ${ }^{1} \mathrm{H}$ NMR spectra were referenced internally to the residual proton resonance in $\mathrm{CDCl}_{3}(\delta$ $=7.26 \mathrm{ppm})$, or with tetramethylsilane $(\mathrm{TMS}, \delta=0.00 \mathrm{ppm})$ as the internal standard. Chemical shifts are reported as parts per million (ppm) in the $\delta$ scale downfield from TMS. ${ }^{13} \mathrm{C}$ NMR spectra were recorded with continuous proton decoupling. Chemical shifts are reported in ppm from TMS with the solvent as the internal reference $\left(\mathrm{CDCl}_{3}, \delta\right.$ $=77.0 \mathrm{ppm}$ ). Accurate mass spectra were acquired using a Bruker Daltonics - ultrOTOF$\mathrm{Q},+$ ESI-Q-q-TOF.

Alkene probe $1 \mathbf{b}\left(65 \%\right.$, colorless oil): ${ }^{1} \mathrm{H}-\mathrm{NMR}\left(\mathrm{CDCl}_{3}, 400 \mathrm{MHz}\right): \delta 7.94(\mathrm{~s}, 1 \mathrm{H}), 7.80$ (t, $2 \mathrm{H}, J=8.4 \mathrm{~Hz}), 7.53(\mathrm{~m}, 1 \mathrm{H}), 7.15-7.23(\mathrm{~m}, 2 \mathrm{H}), 6.57(\mathrm{~s}, 1 \mathrm{H}), 5.47-5.66(\mathrm{~m}, 2 \mathrm{H})$, 3.94 (s, 3H), 3.13 (m, 2H), 2.05 (m, 2H), 0.98 (t, 3H, $J=7.6 \mathrm{~Hz}) .{ }^{13} \mathrm{C}-\mathrm{NMR}\left(\mathrm{CDCl}_{3}, 100\right.$ MHz): $\delta 170.5,159.1,137.8,135.5,130.0,128.4,128.3,128.0,126.8,125.1,123.8$, 120.1, 119.1, 116.42, 105.9. HRMS (+ESI): calculated for $\mathrm{C}_{19} \mathrm{H}_{19} \mathrm{NO}_{3}[\mathrm{M}+\mathrm{Na}]^{+}$ 332.1257 , found 332.1250 . 
Epoxide probe $2 \mathbf{b}$ (11\%, yield yellow oil): ${ }^{1} \mathrm{H}-\mathrm{NMR}\left(\mathrm{CDCl}_{3}, 400 \mathrm{MHz}\right): \delta 8.26(\mathrm{~s}, 1 \mathrm{H})$, $7.80(\mathrm{t}, 2 \mathrm{H}, J=8.8 \mathrm{~Hz}), 7.52(\mathrm{~m}, 1 \mathrm{H}), 7.15-7.26(\mathrm{~m}, 2 \mathrm{H}), 6.60(\mathrm{~s}, 1 \mathrm{H}), 3.94(\mathrm{~s}, 3 \mathrm{H}), 3.08$ (m, 1H), $2.75(\mathrm{~m}, 1 \mathrm{H}), 2.66(\mathrm{~m}, 2 \mathrm{H}), 1.59(\mathrm{~m}, 2 \mathrm{H}), 0.97$ (t, 3H, $J=5.6 \mathrm{~Hz}) .{ }^{13} \mathrm{C}-\mathrm{NMR}$ $\left(\mathrm{CDCl}_{3}, 100 \mathrm{MHz}\right): \delta 168.8,159.0,135.4,129.9,128.2,128.0,127.8,126.3,125.0$, $120.0,116.0,105.8,63.4,59.5,55.4,52.9,37.3,24.7,9.6$. HRMS (+ESI): calculated for $\mathrm{C}_{19} \mathrm{H}_{19} \mathrm{NO}_{4}[\mathrm{M}+\mathrm{Na}]^{+}$348.1167, found 348.1206.

Synthesis of trans-4,5-epoxy-hexanol 7, 2-methyltetrahydro-2H-pyran-3-ol (8) and 1(tetrahydrofuran-2-yl)ethanol (9) were performed as previously described ${ }^{105}$. Trans-4hexen-1-ol $(500 \mu \mathrm{L}, 5.88 \mathrm{mmol})$ was mixed with $\mathrm{NaHCO}_{3}(1.775 \mathrm{~g})$, acetone $(5.6 \mathrm{~mL})$ and ethyl acetate $(20 \mathrm{ml})$. Oxone $(2.6 \mathrm{~g}, 17.1 \mathrm{mmol})$ was dissolved in water $(18 \mathrm{~mL})$ and added dropwise to the trans-4-hexen-1-ol solution over a period of $40 \mathrm{~min}$. The reaction was stirred for another hour. The organic solvents were evaporated in vacuo. The residue was extracted with ethyl acetate $(20 \mathrm{~mL})$. The organic layer was washed twice with an equal volume of brine, dried over anhydrous $\mathrm{Na}_{2} \mathrm{SO}_{4}$, filtered and the solvent evaporated in vacuo to yield trans-4,5-epoxy-hexanol 7 which was used in the next step without further purification. Spectroscopic data for 7 were consistent with literature data. Trans4,5-epoxy-hexanol 7 was treated with a solution boron trifluoride etherate in diethyl ether as described previously to produce a mixture of 8 and 9. Analysis by GC-MS showed two products with the same $\mathrm{m} / \mathrm{z}(116)$ in a ratio of 1:5 which were assigned as 8 and 9 respectively, based on previous reports ${ }^{105}$. 
Synthesis of cis- $\beta$-methylstyrene oxide, trans- $\beta$-methylstyrene oxide, $\beta$-dimethylstyrene oxide and $\alpha$-methylstyrene oxide were performed using the corresponding alkene precursors. The alkene $(500 \mu \mathrm{L})$ was mixed with $\mathrm{NaHCO}_{3}(1.775 \mathrm{~g})$, acetone $(5.6 \mathrm{~mL})$ and diethyl ether $(20 \mathrm{~mL})$. Oxone $(2.6 \mathrm{~g}, 17.1 \mathrm{mmol})$ was dissolved in water $(18 \mathrm{~mL})$ and added dropwise to the trans-4-hexen-1-ol solution over a period of $40 \mathrm{~min}$. The reaction was stirred for another 3 hours to overnight. The organic solvents were evaporated in vacuum at $30{ }^{\circ} \mathrm{C}$. The residue was extracted with ethyl ether $(20 \mathrm{~mL})$. The organic layer was washed twice with an equal volume of brine, dried over anhydrous $\mathrm{Na}_{2} \mathrm{SO}_{4}$, filtered and the solvent evaporated in vacuo to yield the epoxide. As some of the synthesized epoxides are low boiling, of extended exposure to vacuum often resulted lower yields. The structures of the epoxide products were confirmed by ${ }^{1} \mathrm{H}-\mathrm{NMR}\left(\mathrm{CDCl}_{3}, 400 \mathrm{MHz}\right)$, which were consistent with literature data.

\section{EH/esterase assay (fluorescent)}

Fluorescent probe $\mathbf{1} / \mathbf{1 b}, \mathbf{2} / \mathbf{2} \mathbf{b}(2 \mu \mathrm{L}, 10 \mathrm{mM}$, final concentration $100 \mu \mathrm{M})$ was added to K. brevis homogenate $(198 \mu \mathrm{L})$ or purified $\mathrm{EH}(198 \mu \mathrm{L})$ in duplicate. Fluorescence was monitored at $330 \mathrm{~nm}$ EX/ $465 \mathrm{~nm}$ EM (Synergy $^{\mathrm{TM}}$ 2, Bioteck Instrument, Inc.) every 5 minutes at $30^{\circ} \mathrm{C}$. The concentration of reporter $\mathbf{3}$ was calculated from a calibration curve prepared by measuring the fluorescence of 7-methoxy-2naphthaldehyde $(0,3.1,12,25,50 \mu \mathrm{M}$ in phosphate buffer (50 mM phosphate, $\mathrm{pH} 7.0)$. Fluorescence readings were normalized to protein concentration or cell number. 
EH assay (GC-MS)

Substrate (4 $\mathrm{mM}$ to $10 \mathrm{mM}$ final concentrations), internal standard, 1-naphthol (concentrations ranging from 0.4 to $4 \mathrm{mM}$; the concentration was optimized for each substrate to a relative response ratio of 1:5 5:1 for substrate/internal standard in the GC$\mathrm{MS}$ ), and purified $\mathrm{EH}(\sim 0.1 \mathrm{mg})$ was combined in phosphate buffer (50 mM phosphate, $\mathrm{pH}$ 7.0). Aliquots were removed every 5 minute and extracted using an equal volume of dichloromethane. Samples were evaporated to dryness and reconstituted in dichloromethane to $20 \mathrm{ppm}$. Samples were analyzed by GC-MS (Hewlett Packard 6890 with Alltech $30 \mathrm{~m}, \mathrm{DB} 5$, capillary column, $0.25 \mathrm{~mm}$ (ID) $0.25 \mu \mathrm{m}$ initial temperature 80 ${ }^{\circ} \mathrm{C}$ for 1 minute/increase to $300{ }^{\circ} \mathrm{C}$ at $10{ }^{\circ} \mathrm{C} /$ minute/hold for 7 minutes) and compared to standard curve of either the diol product or starting epoxide with the internal standard. Each reaction was performed in duplicate.

EH assay (cyclization reaction)

Trans-4,5-epoxy-hexanol 9 ( $1 \mu \mathrm{L} 0.4 \mathrm{M}$ stock solution in DMSO diluted to a final concentration of $4 \mathrm{mM})$ was incubated with protein $(100 \mu \mathrm{L} 0.1 \mathrm{mg} / \mathrm{mL}$ in dialysis buffer) or dialysis buffer $(100 \mu \mathrm{L})$ alone at $30^{\circ} \mathrm{C}$ for 1 to $3 \mathrm{~h}$. The reaction was extracted using an equal volume of dichloromethane. The organic extracts were evaporated to dryness and reconstituted in dichloromethane to $\sim 20 \mathrm{ppm}$ and analyzed by GC-MS as previously described. 
Determination of $\mathrm{K}_{\mathrm{M}}$ and $\mathrm{k}_{\mathrm{cat}}$

Specific enzyme activity was determined by the fluorescence assay (5a and 5b) or by GC-MS for non-fluorescent products. A constant enzyme concentration of the EH $(100 \mu \mathrm{L}, 0.1 \mathrm{mg} / \mathrm{mL}, \sim 1.926 \mu \mathrm{M})$ was incubated with a range of substrate concentrations. For fluorescent probes $(2,2 b)$, the final concentrations of substrate were $0,25,50,75$ and $100 \mu \mathrm{M}$. For other substrates, the final concentrations of substrate were $4,6,8$, and 10 $\mathrm{mM}$. The assays were performed as previous described. Lineweaver-Burk plots were obtained using initial velocities of substrate and their corresponding concentration, and Km, Vmax and $V m a x / K m$ were determined from the generated equation. These experiments were performed in duplicate.

\section{Inhibition assays}

$\mathrm{IC}_{50}$ values could be obtained by either using fixed substrate concentration with different concentration of inhibitors or several different substrate concentrations with a fixed inhibitor concentration. $\mathrm{IC}_{50}$ were determined using fluorescent substrate $\mathbf{2 b}$ $(100 \mathrm{uM}) . \mathrm{EH}(0.1 \mathrm{mg} / \mathrm{mL})$ was incubated with inhibitors for $2 \mathrm{~min}$ in phosphate buffer $(50 \mathrm{mM}, \mathrm{pH} 7.0)$ at $30^{\circ} \mathrm{C}$ prior to addition of the substrate. $\mathrm{EH}$ activity was measure as previously described by monitoring the fluorescence. Assays were performed by duplicate. By definition, $\mathrm{IC}_{50}$ value is concentration of inhibitor that reduces $\mathrm{EH}$ activity by $50 \%$. Six concentrations of inhibitors $(0,2,4,8,12,16 \mathrm{mM})$ were assayed to obtain an inhibition curve of inhibition/inhibitor concentration. 
RNA isolation

K. brevis culture $(100 \mathrm{~mL})$ was centrifuged $(450 \mathrm{x} \mathrm{g}$ for $5 \mathrm{~min})$ at $20^{\circ} \mathrm{C}$. The pellet was resuspended in water $(100 \mu \mathrm{L})$. Denaturing solution $(600 \mu \mathrm{L}, 5 \mathrm{M}$ guanidium thiocyanate, $50 \mathrm{mM}$ Tris $\mathrm{pH} 8,25 \mathrm{mM}$ sodium citrate, $0.5 \% \mathrm{w} / \mathrm{v}$ Sarkosyl, $2 \%$ PEG, 0.1 M DTT) was added. After standing at room temperature for 10 minutes, NaOAc $(60 \mu \mathrm{L}$, $3 \mathrm{M}, \mathrm{pH}$ 5.2) was added and the mixture was vortexed. An equal volume of phenol: chloroform: isoamyl alcohol (125:24:1, $\mathrm{pH} 4.3)$, was added and the mixture centrifuged at $\left(14,000 \mathrm{x} \mathrm{g}\right.$ for 15 minutes) at $4^{\circ} \mathrm{C}$. The top (aqueous) phase was transferred to a new tube followed by the addition of equal volume chloroform: isoamyl alcohol (24:1) and the mixture was vortexed. After centrifugation at $(14,000 \times g$ for 15 minutes $)$ at $4^{\circ} \mathrm{C}$, the top (aqueous) phase was transferred to new tube which contains equal volume of ice cold EtOH. RNA was allowed to precipitate at -20 degrees overnight. The mixture was centrifuged at $4^{\circ} \mathrm{C}$, for ( 30 minutes at $14,000 \times \mathrm{g}$ ) and the pellet was washed with cold $70 \% \mathrm{EtOH}(700 \mu \mathrm{l})$. After air-drying, the pellet was reconstituted in water $(50 \mu \mathrm{L})$. Total RNA concentration was quantitated using the Nanodrop 2000 (Thermo Scientific).

\section{RT-PCR}

Using the isolated RNA $(\sim 1 \mu \mathrm{g})$ as template and oligo dT as primer $(1 \mu \mathrm{L}, 50$ $\mathrm{mM}$ ), cDNA was synthesized using the AMV First Strand cDNA Synthesis kit (Life Technologies) according to the manufacturer's instructions. Reverse transcriptase reactions were diluted 1:5 in water. PCR reactions were carried out using the newly synthesized cDNA ( $1 \mu \mathrm{L}$ of the diluted reverse transcriptase reaction), PCR mix ( $25 \mu \mathrm{L}$, iQ SYBR Green Supermix, Bio-Rad), $1 \mu \mathrm{L}$ of each primer $(50 \mathrm{mM})$. EH primer set: 
forward; CAAGGTGCTGGGTCCTTTGG. Reverse; TTCCGGAGCGTTGAAACCAC. RuBisCO primers set: forward; GCAGCCTTTTATGCGGTATCG. Reverse; CACCAGCCATTCGCATCCATTT. PCR reactions were monitored using the DNA Engine Opticon (MJ Research) which can detect Sybr green (excitation: $497 \mathrm{~nm}$, emission: $520 \mathrm{~nm}$ ) fluorescence. Cycling conditions: $94{ }^{\circ} \mathrm{C}$ denaturation for $1 \mathrm{~min}$, annealing for $45 \mathrm{sec}$ at $60^{\circ} \mathrm{C}$, extension $72^{\circ} \mathrm{C}$ (RuBisCO primer set only, no extension time for EH primers), repeat 40 cycles. The efficiency of the PCR mix was determined by titrating the template cDNA concentrations by dilution of the RT reactions $(1: 5,1: 25$ and 1:125) in water. Efficiencies were calculated to be $\sim 90$ to $95 \%$. 


\section{FUTURE DIRECTION}

In the previous chapter, one EH identified from a K. brevis EST library was cloned and expressed. Through the enzymatic reactions with different substrates, and by EH activity monitoring over life time of the culture oftwo $K$. brevis strains, some evidence was obtained to support the proposed biosynthetic pathway of ladder polyether compounds. However, no direct evidence revealed the involvement of an EH in the biosynthesis of brevetoxins due to lack of natural-similar substrates. For the same reason, the potential of EH in semi-enzymatic synthesis to carry out kinetically disfavored cyclization was not developed. In this chapter, some thoughts about further study of the role of EH in biosynthesis of ladder polyethers will be discussed.

\subsection{SYNTHESIZE OF MORE APPROPRIATE ENZYME SUBSTRATES}

The study of Lsd19, the EH responsible for lasalocid cyclizations, revealed that the substrates' similarity to natural substrates significantly effected enzyme efficiency ${ }^{107}$. As mentioned in chapter 3, Lsd19 did show any activity towards the most simple monoepoxy alcohol. The cyclization ability of monensin EHs was also evaluated using several substrates. The substrates with different length of aliphatic chains (Figure 50) were tested. Under the same conditions, the conversion of epoxide to cyclization products

was $0 \%, 12 \%, 13 \%$, and $30 \%$ when using $\mathrm{C} 2, \mathrm{C} 6, \mathrm{C} 7$ and $\mathrm{C} 10$ analogs ${ }^{88}$. Apparently, the $\mathrm{C} 10$ analog was most similar to the proposed natural substrates of monensin $\mathrm{EH}$. 


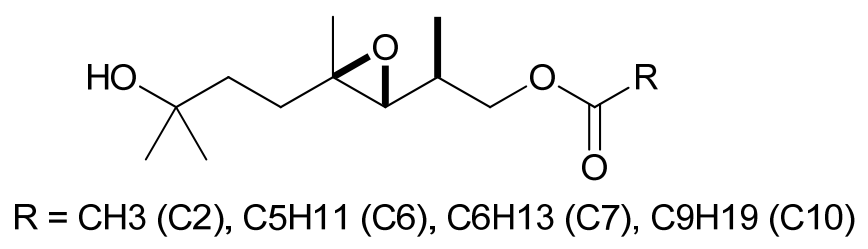

Figure 50. Substrates analog studied in monensin EHs

Therefore, in order to achieve successful cyclization reactions for K. brevis EH, it is essential to obtain a natural substrate analog. As the complicity of brevetoxins, even the smaller product brevenal, it is of great challenge to synthesize natural substrates of $K$. brevis EH. Fortunately, the structure elucidation of brevisamide ${ }^{108}$, suggested the $K$. brevis EH may also act on some less complex substrates.<smiles>CC(=O)NC[C@H]1O[C@H](CC/C=C(C)/C(C)=C/C=O)[C@@H](C)C[C@H]1O</smiles>

Figure 51. Structure of brevismide

Nerolidol is a potential precursor for synthesizing K. brevis EH substrates. Both cis and trans nerolidol could be purchased from Sigma-Aldrich. Figure 52 shows a scheme to synthesize the substrates of EH. The product of moneepoxide (Figure 52, left) is analog of brevisamide, whereas the product of bisepoxide (Figure 52, right) contains the first two rings of brevenal. 


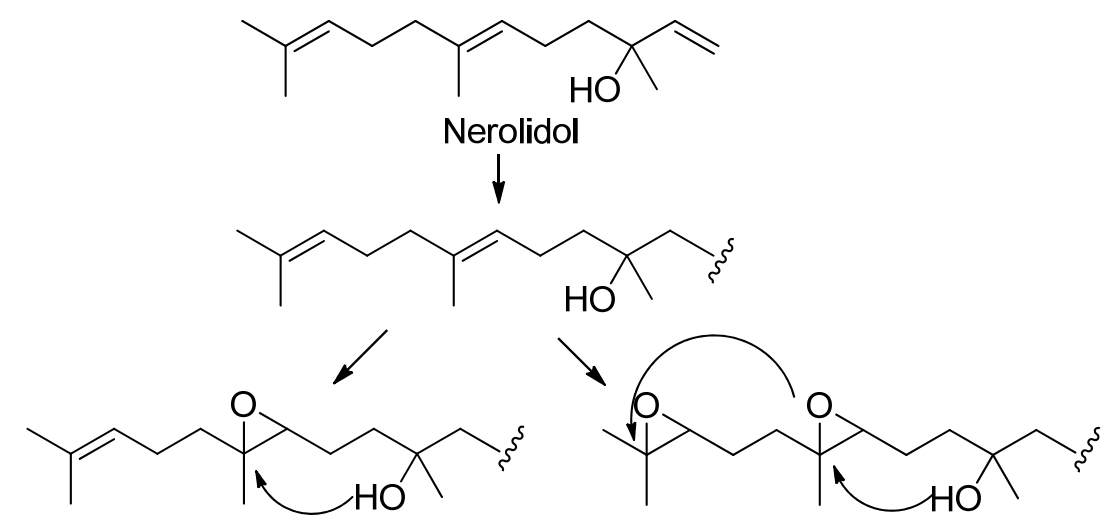

Figure 52. Scheme for syntheizing K. brevis EH substrates using nerolidol

\subsection{CHARACTERIZE THE OTHER $\alpha, \beta$-FOLD EH}

Three K. brevis reference transcriptome libraries containing 86,580 (Wilson strain), 93,668 (strain SP1) and 84,309 (strain SP3) predicted transcripts ${ }^{100}$ became available. As discussed in chapter, another $\alpha, \beta$-fold $\mathrm{EH}$ was identified from these three libraries. Further sequence analysis revealed that it was also microsomal EH. As previous reported, many organism had more than one EHs that were involved in the biosynthesis of polyethers, such as MonBI, MonBII in monensin biosynthesis and Lsd19A, Lsd19B in lasalocid biosynthesis. Suppose the hypothesis of biosynthesis of brevetoxins is true, it is not known that how many EHs are involved in it. Therefore, it is worthy to characterize the other EH found in K. brevis EST library.

\subsection{CONTINUE TO SEARCH FOR LIMONENE EH}

By comparing of mechanisms of $\alpha, \beta$-fold EH and LEH, the one-step direct hydrolysis performed by LEH is more likely involved in polyether cascade cyclization ${ }^{89 a}$. 
In fact, as to now, all EHs confirmed to be involved in the biosynthesis of polyethers are LEHs.

In previous chapter, different methods were discussed to search for LEH. However,no sequences similar to LEH were identified. After another three K. brevis EST libraries were published ${ }^{89 a}$, using the known LEHs, MonB1, MonB2, Lsd19A, Lsd19B, NanIA, NanIB, TmnB, NigB1 and NigB3, which were identified from polyether biosynthetic gene clusters as query, searches were made on the new libraries. However, still no LEH was found.

The fact that all the query sequences were from bacteria may be the reason for the failure to find LEH in the eukaryote $K$. brevis. However, no LEHs in eukaryotes were reported to be involved in the biosynthesis of polyether. BLASTp analysis of those known LEHs revealed that these enzymes belong to NTF2-like (Nuclear transport factor) superfamily, which includes members of the NTF2 family, $\Delta-5-3$-ketosteroid isomerases, scytalone dehydratases, and the beta subunit of ring hydroxylating dioxygenases. In the sequences, a SnoaL domain, which belongs to the family of small polyketide cyclases was detected. SnoaL was recognized as polyketide cyclase and was found in the biosynthesis of nogalamycin ${ }^{109}$ and was responsible for the cyclization of last ring (Figure 53). 


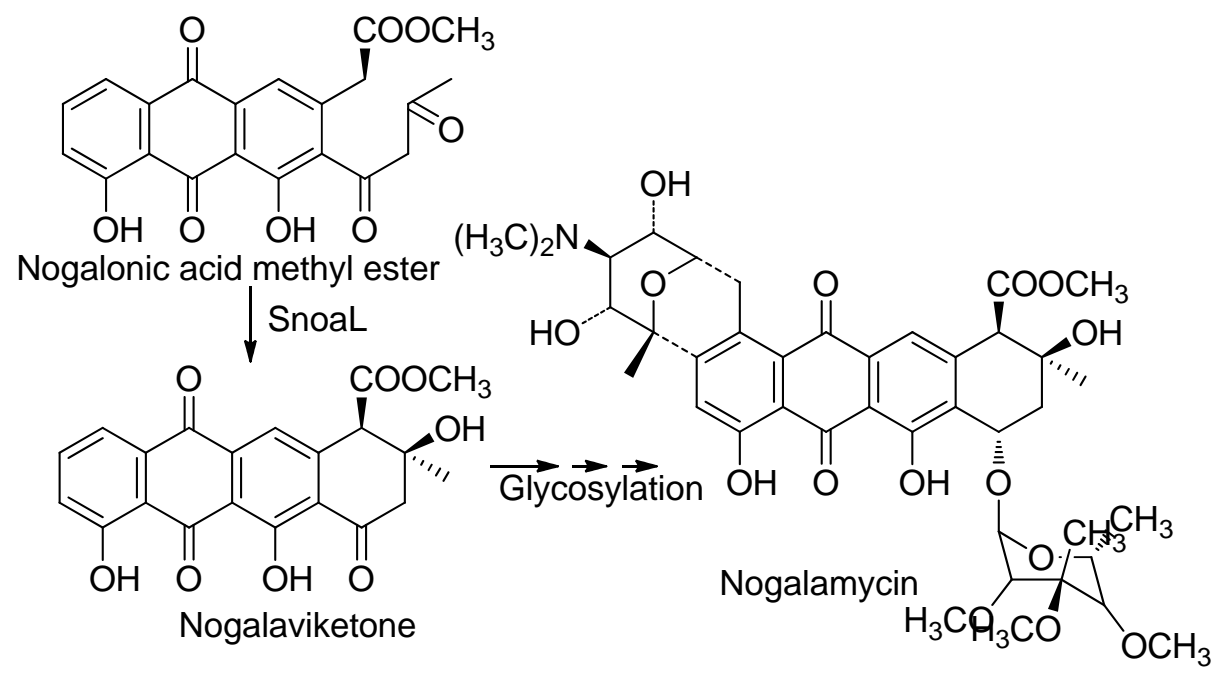

Figure 53. Biosynthesis of nagalamycin

The BLASTp results drive us using other polyketide cyclase from other organisms rather than bacteria as query to search for LEH. One hundred and seventythree polyketide cyclase from green plant were available in NCBI protein database. Of those one hundred and seventy-three, eight were from green algae. Using all polyketide cyclase sequences from green algae and another five sequences randomly chosen from green plants as query, searches on all available $K$. brevis EST libraries were made. Nothing was found from Marine Genomics K. brevis EST library, however, all three transcriptome libraries contained one sequence with an E-value at $1.0 \mathrm{e}-5$ with the polyketide cyclase (Accession: CEG01925.1) from Ostreococcus tauri. BLASTp analysis of this sequence against NCBI protein database revealed an NTF2-like domain, as other known LEH, and a HAD-like (haloacid dehalogenase) domain. 


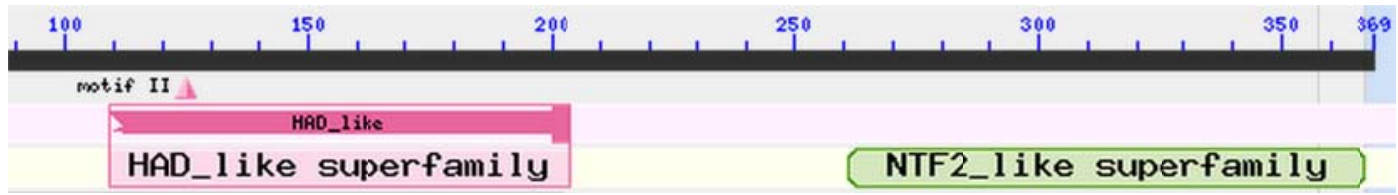

Figure 54. conserved domains of new found polyketide cyclase

More polyketide cyclases from other organism were then used as query to mine the K. brevis EST libraries. Another polyketide cyclase was identified when using the polyketide cyclase from Hassallia byssoidea, a cyanobacteria as query. In this sequence, there were two and half NTF2_like domains, which were of great interest as the structural complexity of brevetoxins is much higher than the polyethers identified from bacteria like monensin and lasalocid, more domains are required.

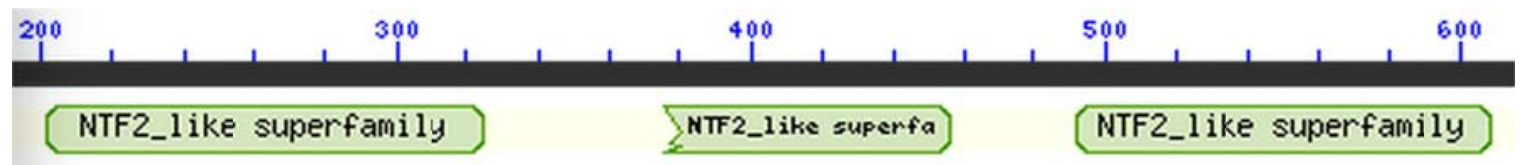

Figure 55. Conserved domains of second found polyketide cyclase

These two polyketide cyclases are worthy of further investigation. As no aromatic compounds were reported, what is the function of polyketide cyclase in K. brevis? In the first found polyketide cyclase, why there is an HAD-like protein cotranscripted with polyketide cyclase. Are the multiple NTF2-like domains found in second polyketide cyclase correlated with the repeated ether rings in brevetoxins? 


\section{REFERENCES}

1. (a) Silva, E. S.; Faust, M. A., Small cells in the life history of dinoflagellates (Dinophyceae): a review. Phycologia 1995, 34 (5), 396-408; (b) Lila Koumandou, V.; Nisbet, R. E. R.; Barbrook, A. C.; Howe, C. J., Dinoflagellate chloroplasts - where have all the genes gone? Trends in Genetics 2004, 20 (5), 261-267.

2. (a) Kamykowski, D.; Reed, R. E.; Kirkpatrick, G. J., Comparison of sinking velocity, swimming velocity, rotation and path characteristics among six marine dinoflagellate species. Marine Biology 1992, 113 (2), 319-328; (b) Kamykowski, D., Trajectories of autotrophic marine dinoflagellates. Journal of Phycology 1995, 31 (2), 200-208.

3. Guiry, M. D., How many species of algae are there? Journal of Phycology 2012, 48 (5), 1057-1063.

4. $\quad$ Tomas, C. R., Identifying marine phytoplankton. Academic press: 1997.

5. Taylor, F. J. R.; Hoppenrath, M.; Saldarriaga, J., Dinoflagellate diversity and distribution. In Protist Diversity and Geographical Distribution, Foissner, W.; Hawksworth, D., Eds. Springer Netherlands 2009, 8, 173-184.

6. Stoecker, D. K., Mixotrophy among Dinoflagellates. Journal of Eukaryotic Microbiology 1999, 46 (4), 397-401.

7. LaJeunesse, T., Diversity and community structure of symbiotic dinoflagellates from Caribbean coral reefs. Marine Biology 2002, 141 (2), 387-400.

8. Shimizu, Y., Microalgal metabolites. Current Opinion in Microbiology 2003, 6 (3), 236-243.

9. Hackett, J. D.; Anderson, D. M.; Erdner, D. L.; Bhattacharya, D., Dinoflagellates: a remarkable evolutionary experiment. American Journal of Botany 2004, 91 (10), 15231534.

10. Fensome, R. A.; Norris, G.; Sarjeant, W.; Taylor, F.; Wharton, D.; Williams, G., Aclassification of Living and Fossil Dinoflagellates. Micropaleontology Press, American Museum of Natural History: 1993.

11. Taylor, F. J. R., The biology of dinoflagellates. 1987.

12. Hastings, J. W., Chemistries and colors of bioluminescent reactions: a review. Gene 1996, 173 (1), 5-11. 
13. Haddock, S. H.; Moline, M. A.; Case, J. F., Bioluminescence in the sea. Marine Science 2010, 2.

14. Spector, D. L., Dinoflagellate nuclei. Dinoflagellates 1984, 107-147.

15. Turner, J. T.; Roncalli, V.; Ciminiello, P.; Dell'Aversano, C.; Fattorusso, E.; Tartaglione, L.; Carotenuto, Y.; Romano, G.; Esposito, F.; Miralto, A., Biogeographic effects of the Gulf of Mexico red tide dinoflagellate Karenia brevis on Mediterranean copepods. Harmful Algae 2012, 16, 63-73.

16. Guiry, M. D.; Guiry, G., AlgaeBase. AlgaeBase 2008.

17. Haywood, A. J.; Steidinger, K. A.; Truby, E. W.; Bergquist, P. R.; Bergquist, P. L.; Adamson, J.; Mackenzie, L., Comparative morphology and molecular phylogenetic analysis of three new species of the genus Karenia (dinophyceae) from New Zealand. Journal of Phycology 2004, 40 (1), 165-179.

18. Ross, C.; Ritson-Williams, R.; Pierce, R.; Bullington, J. B.; Henry, M.; Paul, V. J., Effects of the Florida red tide dinoflagellate, Karenia brevis, on oxidative stress and metamorphosis of larvae of the coral Porites astreoides. Harmful Algae 2010, 9 (2), 173 179.

19. Van Dolah, F. M.; Lidie, K. B.; Monroe, E. A.; Bhattacharya, D.; Campbell, L.; Doucette, G. J.; Kamykowski, D., The Florida red tide dinoflagellate Karenia brevis: new insights into cellular and molecular processes underlying bloom dynamics. Harmful Algae 2009, 8 (4), 562-572.

20. Moestrup, Ø., Toxic Phytoplankton Blooms in the Sea. Proceedings of the Fifth International Conference on Toxic Marine Phytoplankton, Newport, Rhode Island, 28 Oct-1 Nov 1991. Phycologia 1994, 33 (5), 396-396.

21. Kamykowski, D.; Milligan, E.; Reed, R., Relationships between geotaxis/phototaxis and diel vertical migration in autotrophic dinoflagellates. Journal of Plankton Research 1998, 20 (9), 1781-1796.

22. Vargo, G. A.; Heil, C. A.; Ault, D. N.; Neely, M. B.; Murasko, S.; Havens, J.; Lester, K. M.; Dixon, L. K.; Merkt, R.; Walsh, J., Four Karenia brevis blooms: a comparative analysis. Harmful Algae 2002, 14-16.

23. Stumpf, R.; Culver, M.; Tester, P.; Tomlinson, M.; Kirkpatrick, G.; Pederson, B.; Truby, E.; Ransibrahmanakul, V.; Soracco, M., Monitoring Karenia brevis blooms in the Gulf of Mexico using satellite ocean color imagery and other data. Harmful Algae 2003, $2(2), 147-160$. 
24. Vargo, G.; Carder, K.; Gregg, W.; Shanley, E.; Heil, C.; Steidinger, K.; Haddad, K., The potential contribution of primary production by red tides to the west Florida shelf ecosystem. Limnology and Oceanography 1987, 32 (3), 762-767.

25. Tester, P. A.; Steidinger, K. A., Gymnodinium breve red tide blooms: initiation, transport, and consequences of surface circulation. Limnology and Oceanography 1997, 42 (5part2), 1039-1051.

26. Magaña, H. A.; Contreras, C.; Villareal, T. A., A historical assessment of Karenia brevis in the western Gulf of Mexico. Harmful Algae 2003, 2 (3), 163-171.

27. Millie, D. F.; Schofield, O. M.; Kirkpatrick, G. J.; Johnsen, G.; Tester, P. A.; Vinyard, B. T., Detection of harmful algal blooms using photopigments and absorption signatures: A case study of the Florida red tide dinoflagellate, Gymnodinium breve. Limnology and Oceanography 1997, 42 (5part2), 1240-1251.

28. Gray, M.; Wawrik, B.; Paul, J.; Casper, E., Molecular detection and quantitation of the red tide dinoflagellate Karenia brevis in the marine environment. Applied and environmental microbiology 2003, 69 (9), 5726-5730.

29. Spear, A. H.; Daly, K.; Huffman, D.; Garcia-Rubio, L., Progress in developing a new detection method for the harmful algal bloom species, Karenia brevis, through multiwavelength spectroscopy. Harmful Algae 2009, 8 (2), 189-195.

30. Watkins, S. M.; Reich, A.; Fleming, L. E.; Hammond, R., Neurotoxic shellfish poisoning. Marine Drugs 2008, 6 (3), 431-455.

31. Dechraoui, M.-Y. B.; Wang, Z.; Ramsdell, J. S., Intrinsic potency of synthetically prepared brevetoxin cysteine metabolites BTX-B2 and desoxyBTX-B2. Toxicon 2007, 50 (6), 825-834.

32. Wang, D.-Z., Neurotoxins from marine dinoflagellates: A brief review. Marine Drugs 2008, 6 (2), 349-371.

33. Tong, R.; McDonald, F. E., Mimicking biosynthesis: Total synthesis of the triterpene natural product abudinol B from a squalene like precursor. Angewandte Chemie 2008, 120 (23), 4449-4451.

34. Heffron, T. P.; Jamison, T. F., SiMe3-based homologation-epoxidationcyclization strategy for ladder thp synthesis. Organic letters 2003, 5 (13), 2339-2342.

35. Vilotijevic, I.; Jamison, T. F., Epoxide opening cascades in the synthesis of polycyclic polyether natural products. Angewandte Chemie International Edition 2009, 48 (29), 5250-5281. 
36. Lin, Y.-Y.; Risk, M.; Ray, S. M.; Van Engen, D.; Clardy, J.; Golik, J.; James, J. C.; Nakanishi, K., Isolation and structure of brevetoxin B from the" red tide" dinoflagellate Ptychodiscus brevis (Gymnodinium breve). Journal of the American Chemical Society 1981, 103 (22), 6773-6775.

37. Fenical, W.; Jensen, P.; Kauffman, C.; Mayhead, S.; Faulkner, D.; Sincich, C.; Rao, M.; Kantorowski, E.; West, L.; Strangman, W., New anticancer drugs from cultured and collected marine organisms. Pharmaceutical biology 2003, 41 (s1), 6-14.

38. Abraham, W. M.; Bourdelais, A. J.; Sabater, J. R.; Ahmed, A.; Lee, T. A.; Serebriakov, I.; Baden, D. G., Airway responses to aerosolized brevetoxins in an animal model of asthma. American journal of respiratory and critical care medicine 2005, 171 (1), 26-34.

39. Nicolaou, K.; Rutjes, F.; Theodorakis, E.; Tiebes, J.; Sato, M.; Untersteller, E., Total synthesis of brevetoxin B. 2. Completion. Journal of the American Chemical Society 1995, 117 (3), 1173-1174.

40. $\quad$ Nicolaou, K.; Yang, Z.; Shi, G.-q.; Gunzner, J. L.; Agrios, K. A.; Gärtner, P., Total synthesis of brevetoxin A. Nature 1998, 392 (6673), 264-269.

41. (a) Takamura, H.; Kikuchi, S.; Nakamura, Y.; Yamagami, Y.; Kishi, T.; Kadota, I.; Yamamoto, Y., Total synthesis of brevenal. Organic letters 2009, 11 (12), 2531-2534; (b) Fuwa, H.; Ebine, M.; Sasaki, M., Total synthesis of the proposed structure of brevenal. Journal of the American Chemical Society 2006, 128 (30), 9648-9650.

42. (a) Nicolaou, K.; Wallace, P. A.; Shi, S.; Ouellette, M. A.; Bunnage, M. E.; Gunzner, J. L.; Agrios, K. A.; Shi, G. q.; Gärtner, P.; Yang, Z., Total synthesis of brevetoxin A: Part 2: Second generation strategy and construction of EFGH model system. Chemistry-a European Journal 1999, 5 (2), 618-627; (b) Matsuo, G.; Kawamura, K.; Hori, N.; Matsukura, H.; Nakata, T., Total synthesis of brevetoxin-B. Journal of the American Chemical Society 2004, 126 (44), 14374-14376; (c) Kadota, I.; Takamura, H.; Nishii, H.; Yamamoto, Y., Total synthesis of brevetoxin B. Journal of the American Chemical Society 2005, 127 (25), 9246-9250; (d) Crimmins, M. T.; Zuccarello, J. L.; McDougall, P. J.; Ellis, J. M., Enantioselective total synthesis of brevetoxin A: Convergent coupling strategy and completion. Chemistry-a European Journal 2009, 15 (36), 9235-9244; (e) Crimmins, M. T.; Ellis, J. M.; Emmitte, K. A.; Haile, P. A.; McDougall, P. J.; Parrish, J. D.; Zuccarello, J. L., Enantioselective total synthesis of Brevetoxin A: Unified strategy for the B, E, G, and J subunits. Chemistry-a European Journal 2009, 15 (36), 9223-9234.

43. Mori, Y.; Yaegashi, K.; Furukawa, H., A new strategy for the reiterative synthesis of trans-fused tetrahydropyrans via alkylation of oxiranyl anion and 6-endo cyclization. Journal of the American Chemical Society 1996, 118 (34), 8158-8159. 
44. Baldwin, J. E., Rules for ring closure. J. Chem. Soc., Chem. Commun. 1976, (18), 734-736.

45. Still, W. C.; Hauck, P.; Kempf, D., Stereochemical studies of lasalocid epimers. Ion-driven epimerizations. Tetrahedron letters 1987, 28 (25), 2817-2820.

46. Agtarap, A.; Chamberlin, J. W.; Pinkerton, M.; Steinrauf, L. K., Structure of monensic acid, a new biologically active compound. Journal of the American Chemical Society 1967, 89 (22), 5737-5739.

47. Pressman, B.-C.; Harris, E.; Jagger, W.; Johnson, J., Antibiotic-mediated transport of alkali ions across lipid barriers. Proceedings of the National Academy of Sciences of the United States of America 1967, 58 (5), 1949.

48. Russell, J. B.; Houlihan, A. J., Ionophore resistance of ruminal bacteria and its potential impact on human health. FEMS Microbiology Reviews 2003, 27 (1), 65-74.

49. Rein, K. S.; Borrone, J., Polyketides from dinoflagellates: origins, pharmacology and biosynthesis. Comparative Biochemistry and Physiology Part B: Biochemistry and Molecular Biology 1999, 124 (2), 117-131.

50. Shen, B., Polyketide biosynthesis beyond the type I, II and III polyketide synthase paradigms. Current Opinion in Chemical Biology 2003, 7 (2), 285-295.

51. (a) Nakanishi, K., The chemistry of brevetoxins: a review. Toxicon 1985, 23 (3), 473-479; (b) Lee, M. S.; Qin, G.; Nakanishi, K.; Zagorski, M. G., Biosynthetic studies of brevetoxins, potent neurotoxins produced by the dinoflagellate Gymnodinium breve. Journal of the American Chemical Society 1989, 111 (16), 6234-6241.

52. Yamazaki, M.; Izumikawa, M.; Tachibana, K.; Satake, M.; Itoh, Y.; Hashimoto, M., Origins of oxygen atoms in a marine ladder-frame polyether: evidence of monooxygenation by ${ }^{18} \mathrm{O}-$ labeling and using tandem mass spectrometry. The Journal of organic chemistry 2012, 77 (11), 4902-4906.

53. Cane, D. E.; Liang, T.-C.; Hasler, H., Polyether biosynthesis. Origin of the oxygen atoms of monensin A. Journal of the American Chemical Society 1981, 103 (19), 5962-5965.

54. Cane, D. E.; Liang, T. C.; Hasler, H., Polyether biosynthesis. 2. Origin of the oxygen atoms of monensin A. Journal of the American Chemical Society 1982, 104 (25), 7274-7281.

55. Cane, D. E.; Celmer, W. D.; Westley, J. W., Unified stereochemical model of polyether antibiotic structure and biogenesis. Journal of the American Chemical Society 1983, 105 (11), 3594-3600. 
56. Koert, U., Oxidative Polycyclisierung contra „Polyepoxidkaskade”: neue Wege in der Polyether(bio)synthese? Angewandte Chemie 1995, 107 (3), 326-328.

57. Townsend, C. A.; Basak, A., Experiments and speculations on the role of oxidative cyclization chemistry in natural product biosynthesis. Tetrahedron 1991, 47 (14-15), 2591-2602.

58. McDonald, F. E.; Towne, T. B., syn-Oxidative Polycyclization of Hydroxy Polyenes: A new approach to polyether synthesis. Journal of the American Chemical Society 1994, 116 (17), 7921-7922.

59. Leadlay, P.; Staunton, J.; Oliynyk, M.; Bisang, C.; Cortes, J.; Frost, E.; HughesThomas, Z.; Jones, M.; Kendrew, S.; Lester, J., Engineering of complex polyketide biosynthesis-insights from sequencing of the monensin biosynthetic gene cluster. Journal of Industrial Microbiology and Biotechnology 2001, 27 (6), 360-367.

60. Oliynyk, M.; Stark, C. B. W.; Bhatt, A.; Jones, M. A.; Hughes-Thomas, Z. A.; Wilkinson, C.; Oliynyk, Z.; Demydchuk, Y.; Staunton, J.; Leadlay, P. F., Analysis of the biosynthetic gene cluster for the polyether antibiotic monensin in Streptomyces cinnamonensis and evidence for the role of $\mathrm{monB}$ and $\mathrm{monC}$ genes in oxidative cyclization. Molecular Microbiology 2003, 49 (5), 1179-1190.

61. Bhatt, A.; Stark, C. B. W.; Harvey, B. M.; Gallimore, A. R.; Demydchuk, Y. A.; Spencer, J. B.; Staunton, J.; Leadlay, P. F., Accumulation of an E,E,E-Triene by the monensin-producing polyketide synthase when oxidative cyclization is blocked. Angewandte Chemie 2005, 117 (43), 7237-7240.

62. Gallimore, A. R.; Stark, C. B.; Bhatt, A.; Harvey, B. M.; Demydchuk, Y.; Bolanos-Garcia, V.; Fowler, D. J.; Staunton, J.; Leadlay, P. F.; Spencer, J. B., Evidence for the role of the monB genes in polyether ring formation during monensin biosynthesis. Chemistry \& biology 2006, 13 (4), 453-460.

63. Shichijo, Y.; Migita, A.; Oguri, H.; Watanabe, M.; Tokiwano, T.; Watanabe, K.; Oikawa, H., Epoxide hydrolase Lsd19 for polyether formation in the biosynthesis of Lasalocid A: Direct experimental evidence on polyene-polyepoxide hypothesis in polyether biosynthesis. Journal of the American Chemical Society 2008, 130 (37), 1223012231.

64. Migita, A.; Shichijo, Y.; Oguri, H.; Watanabe, M.; Tokiwano, T.; Oikawa, H., Stereo-controlled synthesis of prelasalocid, a key precursor proposed in the biosynthesis of polyether antibiotic lasalocid A. Tetrahedron letters 2008, 49 (6), 1021-1025.

65. Smith, L.; Hong, H.; Spencer, J. B.; Leadlay, P. F., Analysis of specific mutants in the lasalocid gene cluster: Evidence for enzymatic catalysis of a disfavoured polyether ring closure. ChemBioChem 2008, 9 (18), 2967-2975. 
66. (a) Lee, M. S.; Repeta, D. J.; Nakanishi, K.; Zagorski, M. G., Biosynthetic origins and assignments of carbon 13 NMR peaks of brevetoxin B. Journal of the American Chemical Society 1986, 108 (24), 7855-7856; (b) Chou, H. N.; Shimizu, Y., Biosynthesis of brevetoxins. Evidence for the mixed origin of the backbone carbon chain and possible involvement of dicarboxylic acids. Journal of the American Chemical Society 1987, 109 (7), 2184-2185.

67. (a) Murata, M.; Izumikawa, M.; Tachibana, K.; Fujita, T.; Naoki, H., Labeling pattern of okadaic acid from ${ }^{18} \mathrm{O}_{2}$ and $\left[{ }^{18} \mathrm{O}_{2}\right]$ acetate elucidated by collision-induced dissociation tandem mass spectrometry. Journal of the American Chemical Society 1998, 120 (1), 147-151; (b) Izumikawa, M.; Murata, M.; Tachibana, K.; Fujita, T.; Naoki, H., 18O-Labelling pattern of okadaic acid from $\mathrm{H}_{2}{ }^{18} \mathrm{O}$ in dinoflagellate Prorocentrum lima elucidated by tandem mass spectrometry. European Journal of Biochemistry 2000, 267 (16), 5179-5183.

68. (a) Giner, J.-L.; Li, X.; Mullins, J. J., Mechanistic studies of the biomimetic epoxy ester-orthoester and orthoester-cyclic ether rearrangements. The Journal of organic chemistry 2003, 68 (26), 10079-10086; (b) Giner, J.-L., Tetrahydropyran formation by rearrangement of an epoxy ester: A model for the biosynthesis of marine polyether toxins. The Journal of organic chemistry 2005, 70 (2), 721-724.

69. Morisseau, C.; Hammock, B. D., Epoxide hydrolases: mechanisms, inhibitor designs, and biological roles. Annu. Rev. Pharmacol. Toxicol. 2005, 45, 311-333.

70. Parker, R.-E.; Isaacs, N., Mechanisms of epoxide reactions. Chemical reviews 1959, 59 (4), 737-799.

71. Oesch, F., Mammalian epoxide hydrases: inducible enzymes catalysing the inactivation of carcinogenic and cytotoxic metabolites derived from aromatic and olefinic compounds. Xenobiotica 1973, 3 (5), 305-340.

72. van der Werf, M. J.; Swarts, H. J.; de Bont, J. A., Rhodococcus erythropolis DCL14 contains a novel degradation pathway for limonene. Applied and environmental microbiology 1999, 65 (5), 2092-2102.

73. Archelas, A.; Furstoss, R., Synthetic applications of epoxide hydrolases. Current Opinion in Chemical Biology 2001, 5 (2), 112-119.

74. (a) Kiyosue, T.; Beetham, J. K.; Pinot, F.; Hammock, B. D.; Yamaguchi Shinozaki, K.; Shinozaki, K., Characterization of an Arabidopsis cDNA for a soluble epoxide hydrolase gene that is inducible by auxin and water stress. The Plant Journal 1994, 6 (2), 259-269; (b) Guo, A.; Durner, J.; Klessig, D. F., Characterization of a tobacco epoxide hydrolase gene induced during the resistance response to TMV. The Plant Journal 1998, 15 (5), 647-656; (c) Kato, T.; Yamaguchi, Y.; Uyehara, T.; Yokoyama, T.; Namai, T.; Yamanaka, S., Defense mechanism of the rice plant against 
rice blast disease. Naturwissenschaften 1983, 70 (4), 200-201; (d) Blee, E.; Schuber, F., Biosynthesis of cutin monomers: involvement of a lipoxygenase/peroxygenase pathway. The Plant Journal 1993, 4 (1), 113-123.

75. Wixtrom, R. N.; Hammock, B. D., Membrane-bound and soluble-fraction epoxide hydrolases: methodological aspects. Biochemical pharmacology and toxicology 1985, 1, $1-93$.

76. (a) Smith, C. A.; Harrison, D. J., Association between polymorphism in gene for microsomal epoxide hydrolase and susceptibility to emphysema. The Lancet 1997, 350 (9078), 630-633; (b) Baxter, S.; Choong, D.; Campbell, I., Microsomal epoxide hydrolase polymorphism and susceptibility to ovarian cancer. Cancer letters 2002, 177 (1), 75-81; (c) To-Figueras, J.; Gené, M.; Gómez-Catalán, J.; Piqué, E.; Borrego, N.; Caballero, M.; Cruellas, F.; Raya, A.; Dicenta, M.; Corbella, J., Microsomal epoxide hydrolase and glutathione S-transferase polymorphisms in relation to laryngeal carcinoma risk. Cancer letters 2002, 187 (1), 95-101.

77. (a) Moghaddam, M. F.; Grant, D. F.; Cheek, J. M.; Greene, J. F.; Williamson, K. C.; Hammock, B. D., Bioactivation of leukotoxins to their toxic diols by epoxide hydrolase. Nature medicine 1997, 3 (5), 562-566; (b) Yu, Z.; Xu, F.; Huse, L. M.; Morisseau, C.; Draper, A. J.; Newman, J. W.; Parker, C.; Graham, L.; Engler, M. M.; Hammock, B. D., Soluble epoxide hydrolase regulates hydrolysis of vasoactive epoxyeicosatrienoic acids. Circulation research 2000, 87 (11), 992-998; (c) Campbell, W. B., New role for epoxyeicosatrienoic acids as anti-inflammatory mediators. Trends in pharmacological sciences 2000, 21 (4), 125-127; (d) Davis, B. B.; Thompson, D. A.; Howard, L. L.; Morisseau, C.; Hammock, B. D.; Weiss, R. H., Inhibitors of soluble epoxide hydrolase attenuate vascular smooth muscle cell proliferation. Proceedings of the National Academy of Sciences 2002, 99 (4), 2222-2227.

78. Rudberg, P. C.; Tholander, F.; Andberg, M.; Thunnissen, M. M.; Haeggström, J. Z., Leukotriene $\mathrm{A}_{4}$ hydrolase identification of a common carboxylate recognition site for the epoxide hydrolase and aminopeptidase substrates. Journal of Biological Chemistry 2004, 279 (26), 27376-27382.

79. van der Werf, M. J.; Overkamp, K. M.; de Bont, J. A., Limonene-1, 2-epoxide hydrolase from Rhodococcus erythropolis DCL14 belongs to a novel class of epoxide hydrolases. Journal of bacteriology 1998, 180 (19), 5052-5057.

80. Carr, P. D.; Ollis, D. L., $\alpha / \beta$ Hydrolase fold: an update. Protein and peptide letters 2009, 16 (10), 1137-1148.

81. Nardini, M.; Dijkstra, B. W., $\alpha / \beta$ Hydrolase fold enzymes: the family keeps growing. Current Opinion in Structural Biology 1999, 9 (6), 732-737. 
82. Holmquist, M., Alpha beta-hydrolase fold enzymes structures, functions and mechanisms. Current Protein and Peptide Science 2000, 1 (2), 209-235.

83. Yamada, T.; Morisseau, C.; Maxwell, J. E.; Argiriadi, M. A.; Christianson, D. W.; Hammock, B. D., Biochemical evidence for the involvement of tyrosine in epoxide activation during the catalytic cycle of epoxide hydrolase. Journal of Biological Chemistry 2000, 275 (30), 23082-23088.

84. Arand, M.; Hallberg, B. M.; Zou, J.; Bergfors, T.; Oesch, F.; van der Werf, M. J.; de Bont, J. A.; Jones, T. A.; Mowbray, S. L., Structure of Rhodococcus erythropolis limonene 1, 2 epoxide hydrolase reveals a novel active site. The EMBO journal 2003, 22 (11), 2583-2592.

85. Sun, Y.; Zhou, X.; Dong, H.; Tu, G.; Wang, M.; Wang, B.; Deng, Z., A complete gene cluster from Streptomyces nanchangensis NS3226 encoding biosynthesis of the polyether ionophore nanchangmycin. Chemistry \& biology 2003, 10 (5), 431-441.

86. Demydchuk, Y.; Sun, Y.; Hong, H.; Staunton, J.; Spencer, J. B.; Leadlay, P. F., Analysis of the tetronomycin gene cluster: Insights into the biosynthesis of a polyether tetronate antibiotic. ChemBioChem 2008, 9 (7), 1136-1145.

87. Harvey, B. M.; Mironenko, T.; Sun, Y.; Hong, H.; Deng, Z.; Leadlay, P. F.; Weissman, K. J.; Haydock, S. F., Insights into polyether biosynthesis from analysis of the nigericin biosynthetic gene cluster in Streptomyces sp. DSM4137. Chemistry \& biology 2007, 14 (6), 703-714.

88. Sato, K.; Minami, A.; Ose, T.; Oguri, H.; Oikawa, H., Remarkable synergistic effect between MonBI and MonBII on epoxide opening reaction in ionophore polyether monensin biosynthesis. Tetrahedron letters 2011, 52 (41), 5277-5280.

89. (a) Minami, A.; Migita, A.; Inada, D.; Hotta, K.; Watanabe, K.; Oguri, H.; Oikawa, H., Enzymatic epoxide-opening cascades catalyzed by a pair of epoxide hydrolases in the ionophore polyether biosynthesis. Organic letters 2011, 13 (7), 16381641; (b) Tosin, M.; Smith, L.; Leadlay, P. F., Insights into lasalocid A ring formation by chemical chain termination in vivo. Angewandte Chemie International Edition 2011, 50 (50), 11930-11933.

90. Jones, P. D.; Wolf, N. M.; Morisseau, C.; Whetstone, P.; Hock, B.; Hammock, B. D., Fluorescent substrates for soluble epoxide hydrolase and application to inhibition studies. Analytical biochemistry 2005, 343 (1), 66-75.

91. Kim, I.-H.; Morisseau, C.; Watanabe, T.; Hammock, B. D., Design, synthesis, and biological activity of 1, 3-disubstituted ureas as potent inhibitors of the soluble epoxide hydrolase of increased water solubility. Journal of medicinal chemistry 2004, 47 (8), $2110-2122$. 
92. Massarelli, I.; Cioffi, R.; Batelli, G.; De Palma, M.; Costa, A.; Grillo, S.; Leone, A., Functional screening of plant stress-related cDNAs by random over-expression in Escherichia coli. Plant Science (Amsterdam, Netherlands) 2006, 170 (4), 880-888.

93. Lidie, K. B.; Ryan, J. C.; Barbier, M.; Van Dolah, F. M., Gene expression in Florida red tide dinoflagellate Karenia brevis: analysis of an expressed sequence tag library and development of DNA microarray. Marine Biotechnology 2005, 7 (5), 481493.

94. (a) Goldberg, I.; Walker, J. R.; Bloch, K., Inhibition of lipid synthesis in Escherichia coli cells by the antibiotic cerulenin. Antimicrobial Agents and Chemotherapy 1973, 3 (5), 549-554; (b) Kodali, S.; Galgoci, A.; Young, K.; Painter, R.; Silver, L. L.; Herath, K. B.; Singh, S. B.; Cully, D.; Barrett, J. F.; Schmatz, D.; Wang, J., Determination of selectivity and efficacy of fatty acid synthesis inhibitors. Journal of Biological Chemistry 2005, 280 (2), 1669-1677.

95. Blanc, G.; Agarkova, I.; Grimwood, J.; Kuo, A.; Brueggeman, A.; Dunigan, D. D.; Gurnon, J.; Ladunga, I.; Lindquist, E.; Lucas, S., The genome of the polar eukaryotic microalga Coccomyxa subellipsoidea reveals traits of cold adaptation. Genome Biol 2012, 13 (5), R39.

96. Zou, J.; Hallberg, B. M.; Bergfors, T.; Oesch, F.; Arand, M.; Mowbray, S. L.; Jones, T. A., Structure of Aspergillus niger epoxide hydrolase at $1.8 \AA$ resolution: implications for the structure and function of the mammalian microsomal class of epoxide hydrolases. Structure 2000, 8 (2), 111-122.

97. Arand, M.; Hemmer, H.; Durk, H.; Baratti, J.; Archelas, A.; Furstoss, R.; Oesch, F., Cloning and molecular characterization of a soluble epoxide hydrolase from Aspergillus niger that is related to mammalian microsomal epoxide hydrolase. Biochem. $J$ 1999, 344, 273-280.

98. Altschul, S. F.; Gish, W.; Miller, W.; Myers, E. W.; Lipman, D. J., Basic local alignment search tool. Journal of molecular biology 1990, 215 (3), 403-410.

99. Rose, T. M.; Henikoff, J. G.; Henikoff, S., CODEHOP (COnsensus-DEgenerate hybrid oligonucleotide primer) PCR primer design. Nucleic Acids Research 2003, 31 (13), 3763-3766.

100. Ryan, D. E.; Pepper, A. E.; Campbell, L., De novo assembly and characterization of the transcriptome of the toxic dinoflagellate Karenia brevis. BMC genomics 2014, 15 (1), 888 .

101. (a) Thunnissen, M. M.; Nordlund, P.; Haeggström, J. Z., Crystal structure of human leukotriene $\mathrm{A}_{4}$ hydrolase, a bifunctional enzyme in inflammation. Nature 
Structural \& Molecular Biology 2001, 8 (2), 131-135; (b) Orning, L.; Gierse, J.; Fitzpatrick, F., The bifunctional enzyme leukotriene- $\mathrm{A}_{4}$ hydrolase is an arginine aminopeptidase of high efficiency and specificity. Journal of Biological Chemistry 1994, 269 (15), 11269-11273.

102. Arand, M.; Muller, F.; Mecky, A.; Hinz, W.; Urban, P.; Pompon, D.; Kellner, R.; Oesch, F., Catalytic triad of microsomal epoxide hydrolase: replacement of Glu404 with Asp leads to a strongly increased turnover rate. Biochem. J 1999, 337, 37-43.

103. Arnold, K.; Bordoli, L.; Kopp, J.; Schwede, T., The SWISS-MODEL workspace: a web-based environment for protein structure homology modelling. Bioinformatics 2006, 22 (2), 195-201.

104. Gates, J. A.; Wilson, W. B., The toxicity of Gonyaulax monilata Howell to Mugil cephalus. Limnology and Oceanography 1960, 5 (2), 171-174.

105. Coxon, J.; MP, H.; Swallow, W., Study of hydroxyl participation in acyclic epoxide systems-acid-catalyzed rearrangements of trans-3, 4-epoxypentan-1-ols, and cis3, 4-epoxypentan-1-ols, 4, 5-epoxyhexan-1-ols, and 5, 6-epoxyheptan-1-ols. Australian Journal of Chemistry 1973, 26 (11), 2521-2526.

106. Greenbaum, D.; Colangelo, C.; Williams, K.; Gerstein, M., Comparing protein abundance and mRNA expression levels on a genomic scale. Genome Biol 2003, 4 (9), 117.

107. Matsuura, Y.; Shichijo, Y.; Minami, A.; Migita, A.; Oguri, H.; Watanabe, M.; Tokiwano, T.; Watanabe, K.; Oikawa, H., Intriguing substrate tolerance of epoxide hydrolase Lsd19 involved in biosynthesis of the ionophore antibiotic lasalocid A. Organic letters 2010, 12 (10), 2226-2229.

108. (a) Van Wagoner, R. M.; Satake, M.; Bourdelais, A. J.; Baden, D. G.; Wright, J. L., Absolute configuration of brevisamide and brevisin: confirmation of a universal biosynthetic process for Karenia brevis polyethers. Journal of natural products 2010, 73 (6), 1177-1179; (b) Satake, M.; Bourdelais, A. J.; Van Wagoner, R. M.; Baden, D. G.; Wright, J. L., Brevisamide: an unprecedented monocyclic ether alkaloid from the dinoflagellate Karenia brevis that provides a potential model for ladder-frame initiation. Organic letters 2008, 10 (16), 3465-3468.

109. Torkkell, S.; Kunnari, T.; Palmu, K.; Hakala, J.; Mäntsälä, P.; Ylihonko, K., Identification of a cyclase gene dictating the C-9 stereochemistry of anthracyclines from Streptomyces nogalater. Antimicrobial Agents and Chemotherapy 2000, 44 (2), 396-399. 
VITA

\section{PENGFEI SUN}

\section{EDUCATION}

Born, Shandong, China

2009

B.S., Biology

Shandong University, Weihai, Shandong, China

2012

Doctoral Candidate

Florida International University

Miami, Florida 